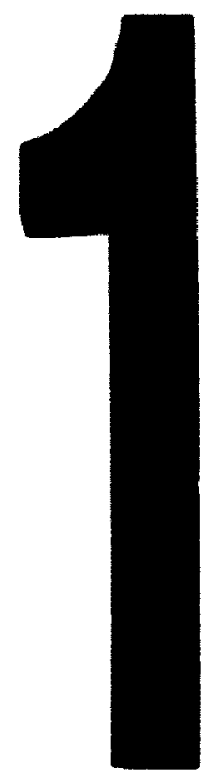

PM-1 $3^{1 / 2}$ ' $\times 4^{\prime \prime}$ PHOTOGRAPHIC MICROCOPY TARGET NBS to10a AMSI/ISO "2 EOUNALENT

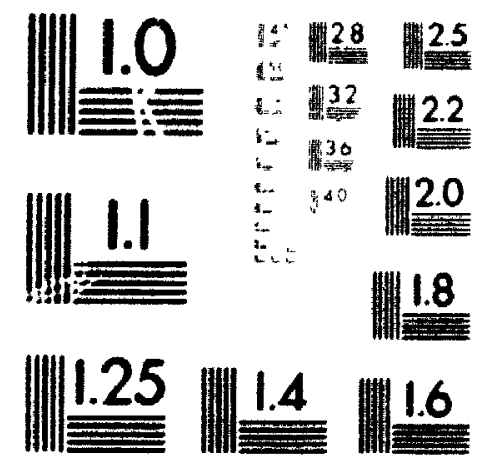


The quality of this microforr. is heavily dependent upon the quality of the original thesis submitted for microfilming. Every effort has been made to ensure the highest quality of reproduction possible.

If pages are missing, contact the university which granted the degree.

Some pages may have indistinct print especially if the original pages were typed with a poor typewriter ribbon or if the university sent us an inferior photocopy.

Reproduction in full or in part of this microform is governed by the Canadian Copyright Act, R.S.C. 1970, c. C-30, and subsequent amendinents.
La qualité cie cette microforme dépend grandement de la qualité de la thèse soumise au microfilmage. Nous avons tout fait pour assurer une qualité supérieure de reproduction.

S'il manque des pages, veuillez communiquer avec l'université qui a conféré le grade.

La qualité d'impression de certaines pages peut laisser à désirer, surtout si les pages originales ont été dactylographiées à l'aide d'un ruban usé ou si l'université nous a fait parvenir une photocopie de qualité inférieure.

La reproduction, même partielle, de cette microforme est soumise à lá Loi canadienne sur le droit d'auteur, SRC 1970, c. C-30, et ses ameridements subséquents. 


\title{
High-Speed Multiprocessor Simulation of VBR Video Coding and Transmission through an ATM Network
}

\author{
by \\ Nabeel M. Ghuzlaan, B. Sc.
Jordan University of Science and Technology
}

A thesis submitted to the

Faculty of Graduate Studies and Research

in partial fultillment of the requirements

for the degree of

Master of Engineering

\author{
Gtawa-Carleton Institute for Electrical Engineering \\ Faculty of Engineering \\ Department of Systems and Computer Engineering \\ Carleton University \\ Otlawa, Ontario, Canada
}

March 19, 1993

(6) 1993 Nahed M. Ghuzlaan 
National Library

of Canada

Acquisitions and

Bibliographic Services Branch

395 Wellington Street

Otawa. Onlario

KIA ONA

\section{Bibliothéque nationale}

du Canada

Direction des acquisitions et

des services bibliographiques

395, rue Wellington

Onlawa (Ontario)
The author has granted an irrevocable non-exclusive licence allowing the National Library of Canada to reproduce, loan, distribute or sell copies of his/her thesis by any means and in any form or format, making this thesis available to interested persons.
L'auteur a accordé une licence irrévocable et non exclusive permettant à la Bibliothèque nationale du Canada de reproduire, prêter, distribuer ou vendre des copies de sa thèse de quelque manière et sous quelque forme que ce soit pour mettre des exemplaires de cette thèse à la disposition des personnes intéressées.

L'auteur conserve la propriété du droit d'auteur qui protège sa thèse. Ni la thèse ni des extraits substantiels de celle-ci ne doivent être imprimés ou autrement reproduits sans son autorisation.

ISBN $\quad 0-315-84117-6$ 
Neme Naterl M. Eluzlaan

Dissertition Abstracts Internutional is arranged $\mathrm{E}$, brood, general subject categories Please select the one subject which mast nearly describes the content of your dissertation Enter the corresponding four-digit code in the spaces provided

\section{Subject Colegories}

\section{THI MUMANITIES AND SOCIAL SCIENCFS}

\begin{tabular}{|c|c|}
\hline 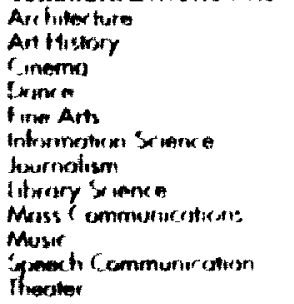 & $\begin{array}{l}0172 \\
0317 \\
0400 \\
0378 \\
0357 \\
0723 \\
0301 \\
0540 \\
0708 \\
0413 \\
0459 \\
0465\end{array}$ \\
\hline 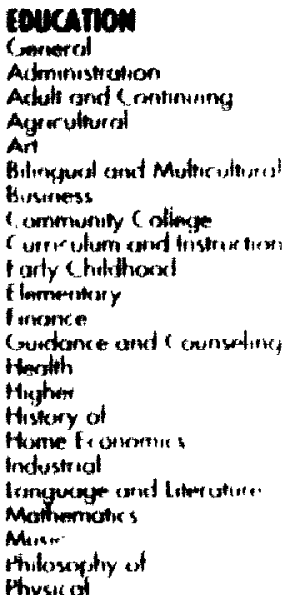 & $\begin{array}{l}0 \\
0 \\
0 \\
0 \\
0 \\
0 \\
0 \\
0 \\
0 \\
0 \\
0 \\
0 \\
0 \\
0 \\
0\end{array}$ \\
\hline
\end{tabular}

\begin{tabular}{|c|}
\hline 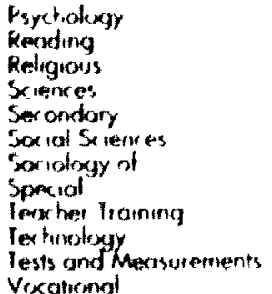 \\
\hline
\end{tabular}

\section{UNGUAG, UTERATURE ANO Uncustics}

Ianquage

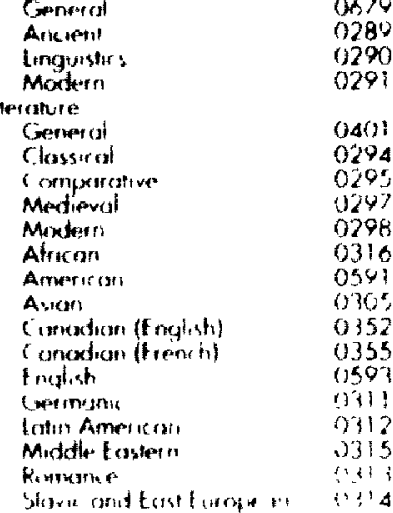

thysicat
314

0,16

273

0282

1275

) 72

0324

717

(1)

1) 43

378

) 21

379

5522

(1) 51
PHilosorit, Retucton awo

\section{THEOLOEY}

Philosophy

Reiligion

Biblical studies

Clergy

Clergy

Phslosophy of

Theology

\section{soan sandes}

American Studies

Anthropology

Archoeology

Cultural

Business Adminustiation

General

Arcounting

Bonking

Manogement

Markeling

Eranodian Studies

Fconomics

Ceneral

Agricultuial

Finonce

History

Lobor

friklistio

reorgtaphy

cortgritology

itistory

ind
0422

0318

032

0318

0320

0322

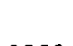

0323

0324

0326
0327

0310

0272

0272

0454

0338

0385

0501

0503

0505

0508

0509
0510

0510

0358

0360

035

0578

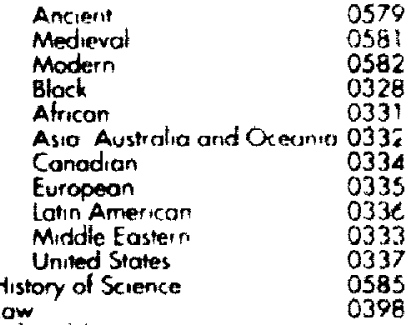

law

General

International law and

Relotions

Public Administrotion

Recreotion

Social Work

Soxiotogy

General 0626

Criminology and Penoiogy 0627

Eemography 0038

individual ond family

Studies

Industrial and lrator

Relations

0628

Public and Social Weltare

Social Siructure and

Development

Theory and Methods

Iransportation

Urban and Regional Planni",

Women s Studies

0629

0630

0700

0344

0709

0453

\section{THi SCIFNCES AND ENGINEARINC}

\section{morosicu sazmas}

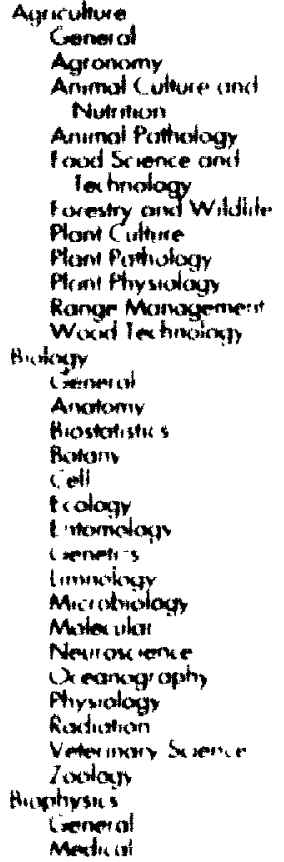

\section{Hati screncs}

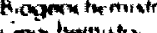

coudesy

ceoluxy

(xeoplysurs:

Mydronogy

Paleobotany

Paleocecotogr

Palnonislixjy

Poteor sology

Polynology

Physic al teograptis

Physical chermegrapt.

MEATH AMD ERVIRONMEMTAL SCENCES

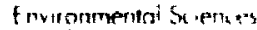

Hersith Sx tences

Gerver al

Andiologr

chementheringy

Deatistis

thospifol Ma'b azernents

thospun Develogmerst

limmon' Develof

Medir ine and Surgers

Mental theolith

Nutsang

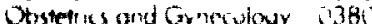

Droupational tiecith

theropy

iphotholnoliog

Pothologn

Phor toweology

Pharmoxy

Physind theiger

Piblis Healtit

$120 \%$

Rustrumayo

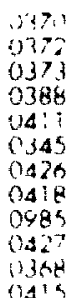

(I) 15

$\cos 8$

2500

0300

1002

0350

o?

$0+58$

398 ?

0504

$034^{7}$

ose

0354

0354

1381
0571

0571

$05>2$

0382

$05 \div 3$

$05>5$
Speech Pott.wase. $\quad 0460$

Poricology

tome Economirs

PUYSICAL SCIEnCES

Pure Sciences

Chem stry

General

Agrecultural

Anglyisal

Bichemis

turleor

Orgoris

Dharmoxenticel

Physical

Polyme

Fadiotion

Aattiematics

Physics

Comeral

Astronomy and

Astrophysics

Amospheric $5 c$ ence

Alomic

Electronics and Electring

High Energ.

Flund and Plasmo

Molerulor

Nuclear

Optics

Rodrotion

Solind

Applied Sciences

Applied Mechanics

Compules Srience
3383
0386

$n 485$

0749

0486

0487

0738

0490

0491

0494

0495

0754
0405

0605

0986

0606

0608

0748

0607

0798

0759

0609

0610

0752

0756

0756
0611
0483

0346

0984

Engineering

Aerospace

Agricultural

Automotive

B:omedical

Chemical

Civil

Electronics and Electrical

Heat and Thermadynamics

Hydroulic

Industrial

Morine

Moterigls Scrence

Mechanica

Metallurgy

Muring

Packaging

Petroleum

Santory and Municuper

System Scrence

Geotechnology

Operations Research

Plastics Technology 
The undersigned recommend to the Faculty of Graduate Studics and Research acceptance of the thesis

"High-Speed Multiprocessor Simulation of VBR Video Coding and Transmission through an A IM Network"

Submilled by

Nabeel M. Ghuzlaan, B. Sc.

in partial fultillmen! of the requirements

for the degre: of Master of Enginecring.

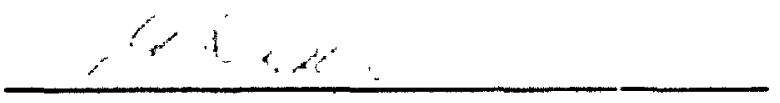

Thesis Supervisor

Thesis Co-supervisor

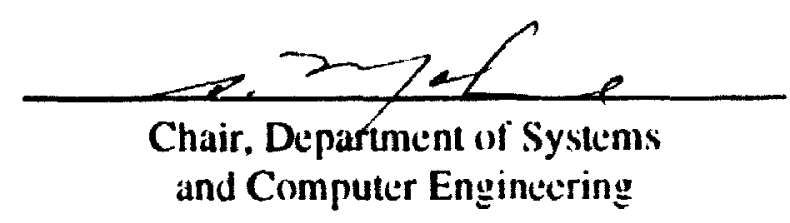

Carleton University

March 19. 1993 


\section{Abstract}

Evaluation of the real-time hehaviour of video coding algorithms and their rohustness agains ATM channel impairments normally requires cornputationally demanding and time-consuming simulations. The visual effect of channel impairments is even more difficult to simulate. This thesis investigaies the impact of using multiprocessing architectures for these tasks. Parallel and pipelined architectures are configured using a representative multiprocessing system. A representative image coding algorithm is used to study the general hehaviour of coding algorithms in multiprocessing environments. Data hlocking and distribution techniques and interpiocessor data transfer methods are examined and optimal methods are proposed depending on the nature of the underlying coding algorithm used. Spatial blocking data distribution methods are found to be more suitable for interframe coding in simple implementations; temporal blocking methods, for intralrame coding and more complicated implementations. Pipelined architectures are forund to be hetter for high-kevel image processing operations. Star architectures are found to he optimal for less complicated processing operations and large implementations. An example system architecture design is presented based on the results of the experiments conducted. Using such architectures raises the possibility of economical, real-time simulation. 


\section{Acknowledgements}

I am deeply indehted to my thesis supereisors Dr. A. R. Kalye and Dr. R. A. Couturath fint their patience, help, guidance and encouragement throughout this program. Thanks w Dr. D. C. Coll. Mr. T. Pearce. Mr. F. Idris and Mr. M. Tharf tor their time and help. Dr. S. A. Mahmoud's advice and encouragement was indispensahle. Help from the department staff. Darlene, Dina and Vivienne is highly appreciated. The video conding algorithm was suggested by Mr. R. Thomas. The Telecommunications Rexearch Institute of ( )ntarm provided financial support for this research project. Special thanks to Dr. A. U. H. Sheikh. Dr. N. Georganas, Dr. A. Abu-el-Haija and Dr. M. Irshid. withutt whose help I would not have had the opportunity to be in this program. Thanks to my mother. family. Sami luneibi and other friends for their help and encouragement. Most special thanks are due wo Gind for His continuous care. 
To Sami Iqneibi 


\section{Table of Contents}

Acceptance Sheet ii

Abstract iii

Acknowledgements iv

List of Tables $x$

List of Figures $\quad x i$

Acronyms and Glossary $\quad$ xii

1 Introduction 1

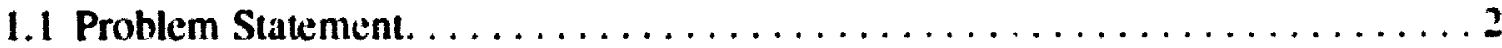

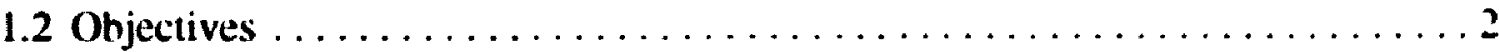

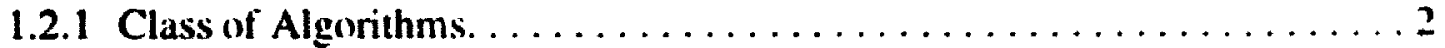

1.2.2 Class of Architectures . . . . . . . . . . . . . . . . . . . . . . .

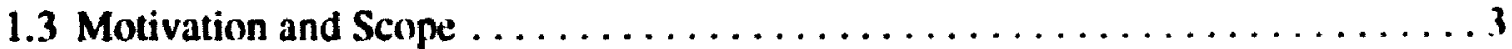

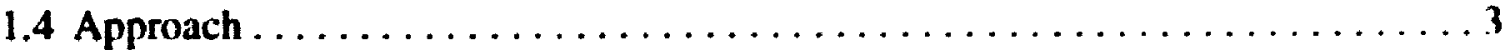

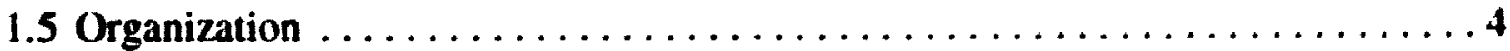

2 Background 5

2.1 Multiprocessor Architectures $\ldots \ldots \ldots \ldots \ldots \ldots \ldots \ldots \ldots \ldots$

2.1.1 Computer Classifications . . . . . . . . . . . . . . . . . . . .

2.1.2 Mesh Architectures . . . . . . . . . . . . . . . . . . .

2.1.3 Pyramid Architectures..........................

2.1.4 Hypercuie Architectures........................ 7

2.1.5 Shared-Memory Architectures ...................... 8

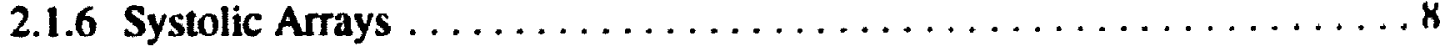

2.1.7 Hybrid Architectures. . . . . . . . . . . . . . . . . .

2.2 Asynchronous Transfer Mode $\ldots \ldots \ldots \ldots \ldots \ldots \ldots \ldots \ldots \ldots$

2.2.1 Priority Mechanisms............................. (1)

2.2.2 Packet Video in the ATM Environment .................. 10

2.3 Video Compression Algorithms $\ldots \ldots \ldots \ldots \ldots \ldots \ldots \ldots \ldots \ldots \ldots$

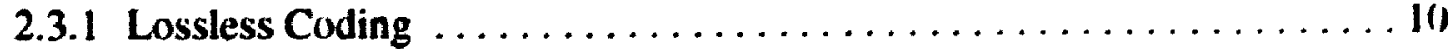

2.3.1.1 Huffman Coding $\ldots \ldots \ldots \ldots \ldots \ldots \ldots \ldots \ldots \ldots \ldots \ldots$

2.3.1.2 Lempel-Ziv Coding ....................... 


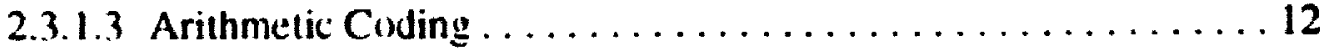

2.3.1.4 Run-Length Coding. ........................ 13

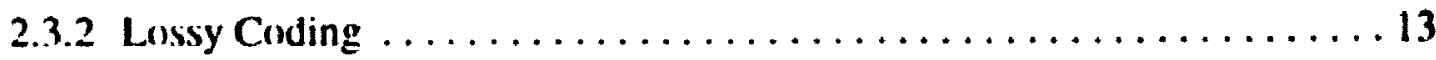

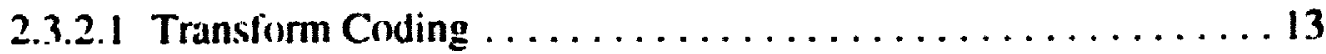

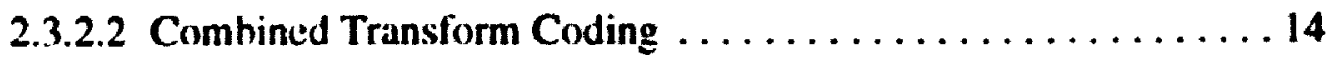

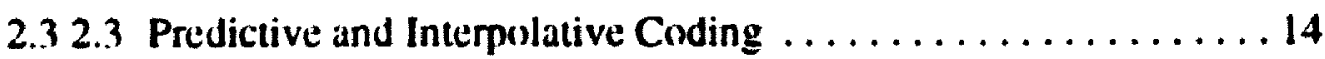

2.3.2.4 Subhand Coding.......................... 15

2.3.2.5 Vector Quantization...................... 15

2.3.2.6 Second-Generation Compression Schemes............ I5

2.3.2.7 JPEG and MPEG Standards. . . . . . . . . . . . . . 16

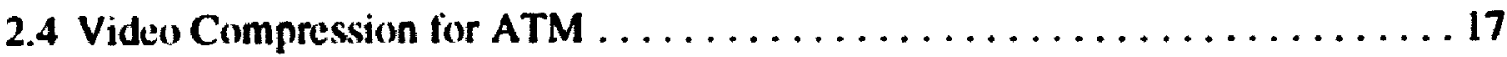

3 Experimental System 18

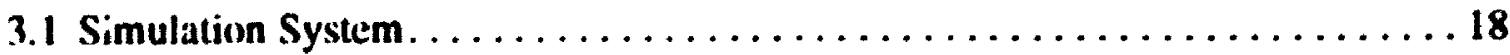

3.1.1 Compression Algorithm $\ldots \ldots \ldots \ldots \ldots \ldots \ldots \ldots \ldots \ldots \ldots \ldots$

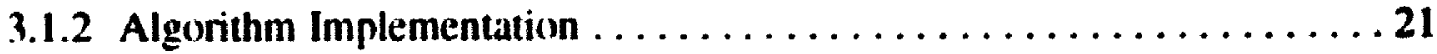

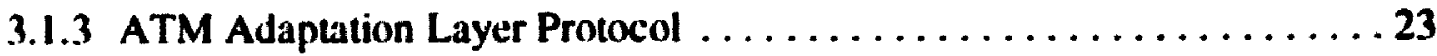

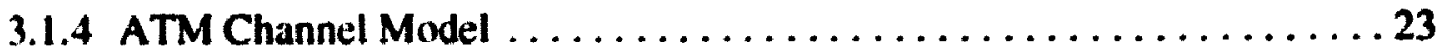

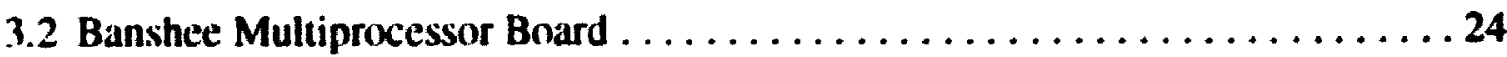

3.2.1 The C30 Processor .............................. 24

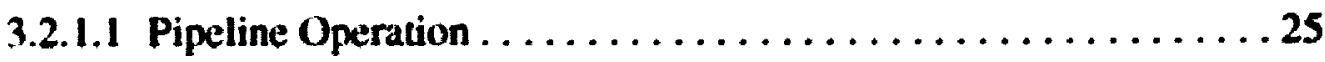

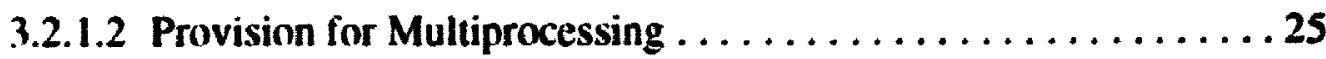

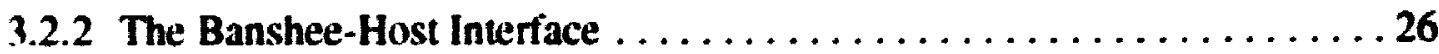

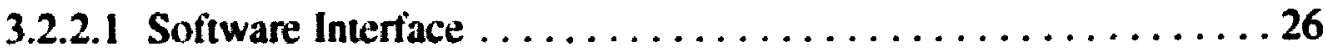

3.2.2.2 Hardware Interface. . . . . . . . . . . . . . . . . . . 26

3.2.2.3 The Banshee-Host Communication ............... 26

3.2.3 The Banshee Multiprocessor Interface ..................27

3.2.3.1 Interprocessor Communication $\ldots \ldots \ldots \ldots \ldots \ldots \ldots \ldots \ldots 28$

4 Single Processor Performance 29

4.1 Personal Computer Performance . ....................... 30

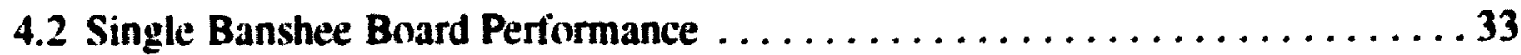

5 Multiprocessor Performance $\quad 37$

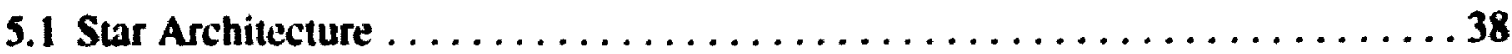


5.1.1 Spatial Data Blocking .............................. 34

5.1 .2 Temporal Data Blocking. ........................

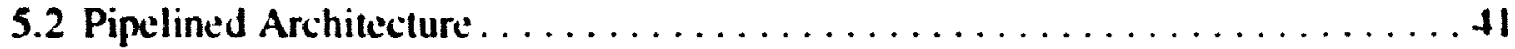

5.2.1 Program-Driven Communication $\ldots \ldots \ldots \ldots \ldots \ldots \ldots \ldots \ldots+3$

5.2.2 Program-Driven DMA Communication ..................4

5.2.3 Interrupt-Driven DMA Communication .................. 45

5.2.4 Buffered Interrupt-Driven Communication ................ th

5.2.5 Delayed, Butfered. Interrupt-Driven Communication .......... 47

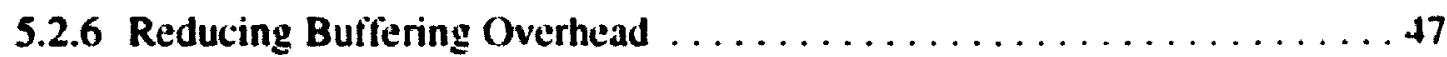

5.3 Hybrid Architecture. ........................

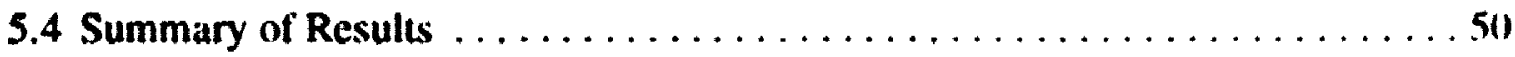

6 Extension of the Architecture 53

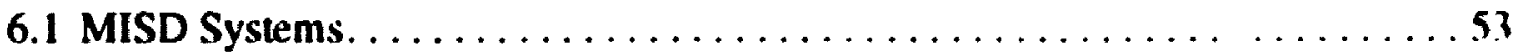

6.1.1 Functional Segmentation. . . . . . . . . . . . . . . . . . . 54

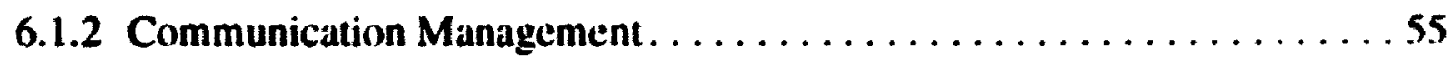

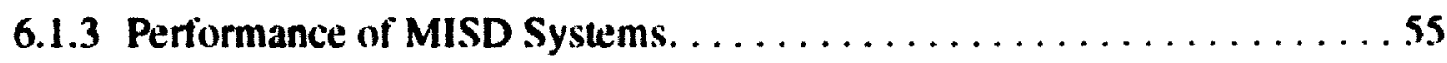

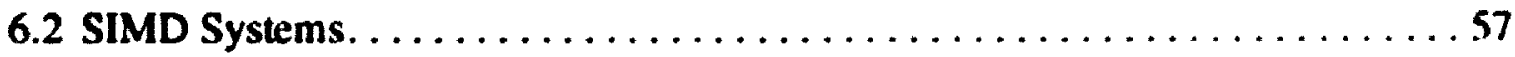

6.2.1 Data Segmentation ............................. 57

6.2.2 Synchronization and Communication . . . . . . . . . . . . . 59

6.2.3 Performance of SIMD Systems. . . . . . . . . . . . . . . .

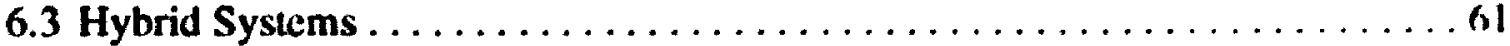

6.3.1 Hybrid System Design $\ldots \ldots \ldots \ldots \ldots \ldots \ldots \ldots \ldots \ldots \ldots \ldots . \ldots \ldots 2$

6.3.2 Performance of Hybrid Architectures.................. 6.3

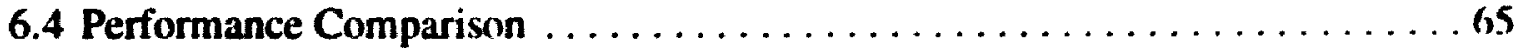

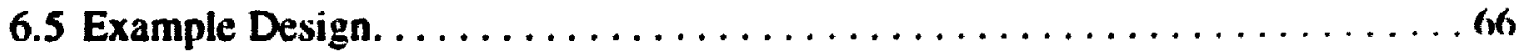

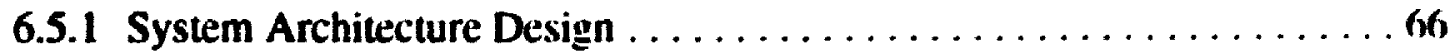

6.5.1.1 Data Acquisition System Specilications .............67

6.5.1.2 Data Dispensation System Specifications .............. 68

6.5.1.3 Host System Specifications . . . . . . . . . . . . .

6.6 Interframe Predictive and Interpolative Coding . . . . . . . . . . . 69

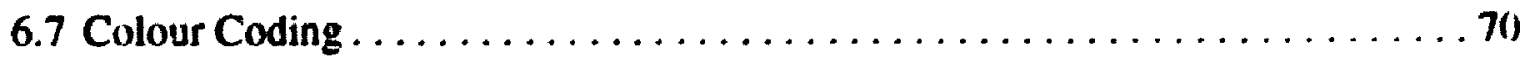

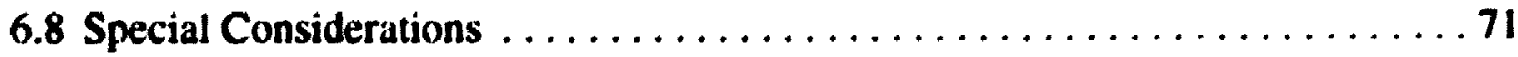




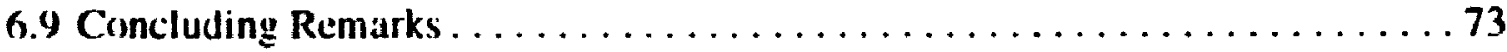

7 Conclusions $\quad 75$

7.1 Results and Contrihution . . . . . . . . . . . . . . . . 75

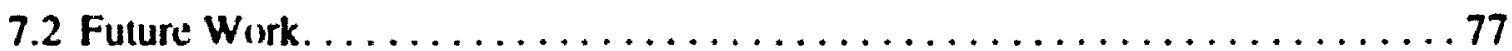

$\begin{array}{ll}\text { A Visual Illustration of the Algorithm } & 78\end{array}$

A.I Frequency Band Division $\ldots \ldots \ldots \ldots \ldots \ldots \ldots \ldots \ldots \ldots \ldots$

A.1.1 Low Frequency Band Component $\ldots \ldots \ldots \ldots \ldots \ldots \ldots \ldots$

A.1.2 Medium Frequency Band Component . . . . . . . . . . . . . 79

A.1.3 High Frequency Band Component $\ldots \ldots \ldots \ldots \ldots \ldots \ldots \ldots$. $\ldots \ldots \ldots$

A.2 Data Transmission Cell Loss Effects. . . . . . . . . . . . . . 81

A.2.1 High-Priority Cell Loss Errors $\ldots \ldots \ldots \ldots \ldots \ldots \ldots \ldots \ldots \ldots \ldots$

A.2.2 Low-Priority Cell Loss Errors. . . . . . . . . . . . . . . . 82

$\begin{array}{ll}\text { Bibliography } & 83\end{array}$ 


\section{List of Tables}

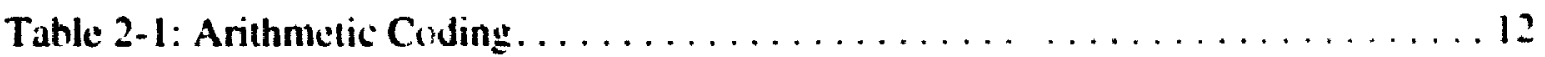

Tahle 4-1: Coding Algorithm Perlormance on Dillerent Systcms . . . . . . . . . . 24

Table 4-2: Fersonal Computer Time Const of Suhtasks. . . . . . . . . . . 32

Table 4-3: Banshee System Time Cost of C Program Suhtasks. . . . . . . . . . . 4

Table 4-4: Banshee System Time Cost of Assembly-Language Program Subtasks . . . I6

Table 5-1: Comparison of CPU and DMA Transfer Schemes . . . . . . . . . . . .4

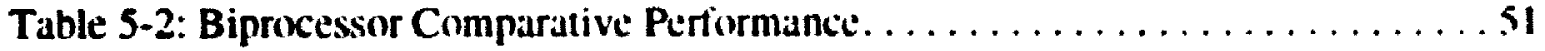




\section{List of Figures}

Figure 2-1: Mesh Architecture $\ldots \ldots \ldots \ldots \ldots \ldots \ldots \ldots \ldots \ldots \ldots \ldots \ldots \ldots \ldots \ldots \ldots$

rigure 2-2: Systolic Architecture $\ldots \ldots \ldots \ldots \ldots \ldots \ldots \ldots \ldots \ldots \ldots$

Figure 3-1: Illustration of Terminology $\ldots \ldots \ldots \ldots \ldots \ldots \ldots \ldots \ldots \ldots \ldots$

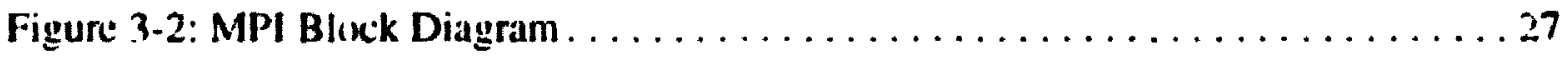

Figure 4-1: Comparative Performance Bar Graph ................. 30

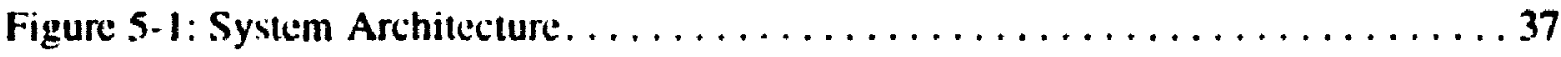

Figure 5-2: Star Configuration ............................. 39

Figure 5-3: Spacial Blick Distribution Scheme $\ldots \ldots \ldots \ldots \ldots \ldots \ldots \ldots \ldots 40$

Figure 5-4: Temporal Block Distribution Scheme $\ldots \ldots \ldots \ldots \ldots \ldots \ldots \ldots \ldots$ II

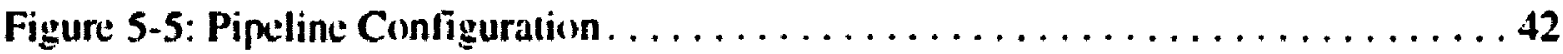

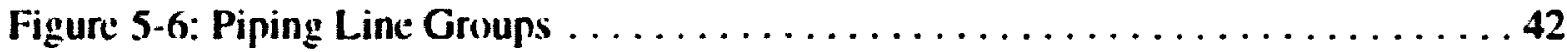

Figure 5-7: Data Paths in Hybrid Architectures .................. 49

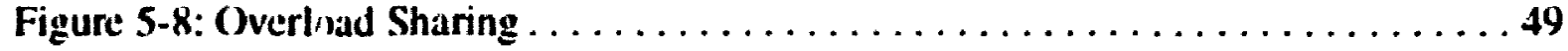

Figure 5-9: Biprocessor Comparative Bar Graph................ 51

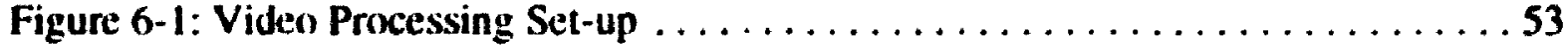

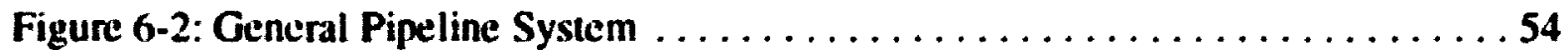

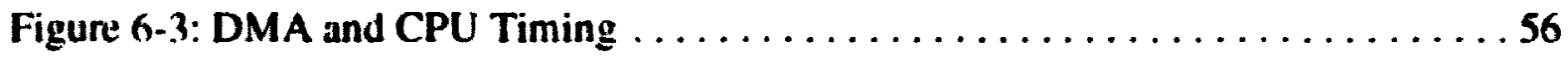

Figure 6-4: Temporal Distribution $\ldots \ldots \ldots \ldots \ldots \ldots \ldots \ldots \ldots \ldots \ldots \ldots \ldots \ldots$

Figure 6-5: Spatial Distribution $\ldots \ldots \ldots \ldots \ldots \ldots \ldots \ldots \ldots \ldots \ldots \ldots \ldots \ldots$

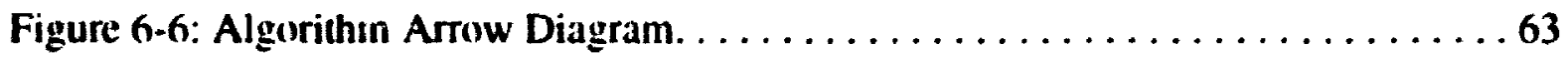

Figure 6-7: Example of Hybrid Systems $\ldots \ldots \ldots \ldots \ldots \ldots \ldots \ldots \ldots \ldots \ldots$

Figure 6-8: Pipelined and Star Performance..................... 65

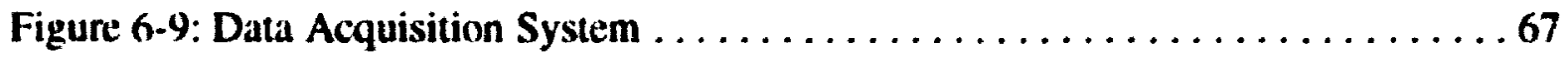

Figure 6-10: Data Dispensation System $\ldots \ldots \ldots \ldots \ldots \ldots \ldots \ldots \ldots \ldots \ldots \ldots \ldots \ldots \ldots \ldots$

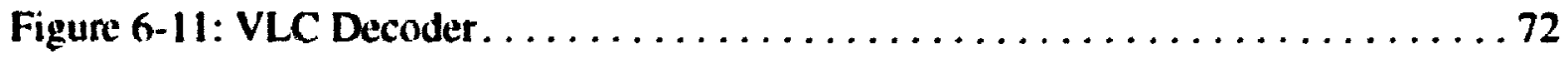

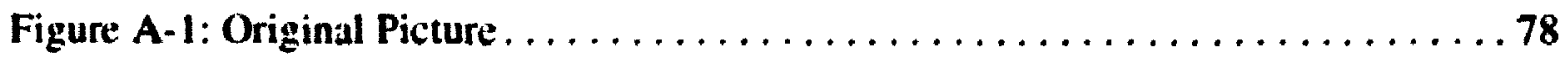

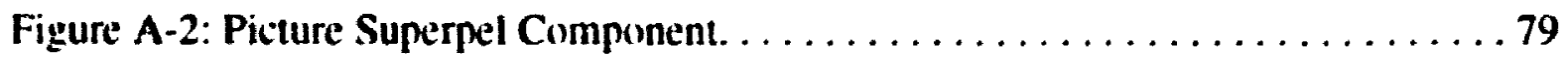

Figure A-3: Picture Triad Component $\ldots \ldots \ldots \ldots \ldots \ldots \ldots \ldots \ldots \ldots \ldots \ldots \ldots \ldots \ldots \ldots$

Figure A-4: Picture High-Priority Component $\ldots \ldots \ldots \ldots \ldots \ldots \ldots \ldots \ldots$

Figure A-5: Picture Differential Pel Component $\ldots \ldots \ldots \ldots \ldots \ldots \ldots \ldots \ldots$.

Figure A-6: Picture with Cell Loss Errors $\ldots \ldots \ldots \ldots \ldots \ldots \ldots \ldots \ldots \ldots$ 


\section{Acronyms and Glossary}

\section{AAL}

ATM adaptation layer

AC

alternating current (here refers (o) a variable whose average is aero)

ATM

Asynchronous Transfier Mode

barrel shifter

a data shifter where combinatorial logic is used to shift the hits to achicve single cycle operation regardless of the number of shifts per uperation

\section{BISDN}

Broadband Integraked Services Digital Network

CAM

content-addressable memory

CBR

constant hit rate

CPM

critical-path method

CPU

central processing unit

DC

direct current (here refers to the average of any signal)

DCT

discrete cosine transform

DMA

direct memory access

DOS

disk operating system

DPCM

differential pulse code modulation

DSP

digital-signal processing/processor 


\section{FPROM}

erasable programmahle read-only memory

\section{FFMR}

irce-irame-memory register

Harvard architecture

architecture having separate data and program memory spaces

\section{HDTV}

high-delinition television

\section{high-level vision}

the image processing task that involves object recognition and interpretation

vo

input/output

intermediate-level vision

the image processing task that involves segmenting images into objects and describing them

\section{Kbyte}

kilohyle (1024 8-bit byles)

\section{Kword}

kiloword ( 1024 16-hiv/32-bit words)

low-level vision

the image processing task that involves image acquiring, enhancing and noise suppression

\section{MA}

memory access

\section{Mbyte}

megabyte $(1,048,576$ hytes $)$

\section{MFLOPS}

mega floating-point operations per second

\section{MIMD}

multiple-instruction stream, multiple-data stream

\section{MIPS}

million instructions per second 


\section{MIISD}

multiple-instruction stream, single-dala stream

MS

Microsoi: Corporation

PC

personal computer

PE

processing element

pel

picture element, also pixel

PERT

project evaluation and review technique

\section{PLA}

programmable logic array

\section{PU}

processing unit

\section{RAM}

random-access memory

resource leveling

lowering maximum resource requirements hy shifting a noncritical activity hetween its maximum allowable limits

\section{RISC}

reduced-instruction-set computer. This architecture has simple and fast hasic instructions.

\section{RLC}

run-length code

\section{ROM}

read-only memory

\section{round robin}

arranging elements in a circular queue and servicing them in that order SBC

subband coding 
SDU]

strvice data unit

SSCI

synchronous serial communications interface

SIMD

single-instruction stream, multiple-data stream

SISD

single-instruction stream, single-data stream

SRAM

static random-aceess menory

TV

kelevision

VBR

variahle bit rate

VLC

variable-length code

VQ

vector quantization 


\section{1 \\ Introduction}

The Broadband Integrated Services Digital Network (BISDN) is gradually replacing the current wideband networks ${ }^{\prime 1.21}$. One network will carry multimedia traftic of various characteristics including data, voice, audio, graphics, video and image lor telepheny. television, conferencing, computing and other services ${ }^{13.41}$.

Asynchronous Transter Mode (ATM) will he used for switching those services ${ }^{\mid \$ !}$. It combines elements of circuit and packet switching ${ }^{|6|}$ and conserves handwidth hy allocating it on a statistical basis ${ }^{16.71}$. This mode of bandwidth allocation will cause the bandwidth allocated to fall shon of the required peak bandwidth of hursty sources $s^{(7)}$ and may cause network nodes to be swamped with data and to drop cells $s^{|t|}$. For real-time services, excessively delayed cells are also considered los $\left.\right|^{|8|}$ and retransmission cannot be considered.

Variable bit-rate (VBR) video transmission, which is more handwidth-efficient than constant bit-rate video transmission' ${ }^{|9|}$, will suffer from the cell loss prohlem ${ }^{|S|}$. What can be done, in this regard, is to devise video coding and decoding schemes that are more robust against the cell loss problem ${ }^{[10 !}$. Simulating those coding schemes in the presence of ATM cell losses is necessary to evaluate, subjectively, the etfect of errors on the reconstructed image because there is no objective means of doing so.

Since a uniprocessor system is slow to perform the simulation efficiently, this thesis investigates the possibility of designing a multiprocessor system to achieve real-time simulation of the coding schemes classified in Section 1.2.1. 


\subsection{Problem Statement}

VBR video frames undergo source coding, channel coding, channel impairments, ( hannel decoding and sturce decoding hetore the final frames can be viewed. The ameunt of processing involved, especially in the compression and decompression of video images, makes it impossible for general purpose computer systems to be able to simulate the complete process in real time, especially for research purposes.

At the time this thesis commenced, a large. state-of-the-art computer system was being ustd for video-to-video simulation of a coding scheme alone without channel errors, resulting in a 24-hour processing time for 2 seconds of video transmission. However, this methex provided the required flexibility for development of new algorithms. VLSI implementations of some video algorithms are available, but they cannot be used to investigate the efficiency and robustness of new algorithms. Furthermore. demand on picture quality and resolution is always increasing.

\subsection{Objectives}

An objective of this thesis is to examine the feasibility and efficiency of using multiprocessor architectures to study the performance of video coding algorithms in ATM networks. A further objective is to evaluate various processor interconnection topologies and algorithm partitioning schemes in improving video processing.

The purpose is to speed up simulation while maintaining flexibility in the system for modifying the algorithm and changing simulation parameters. The possibility of achieving real-time performance is examined. It is desirable that the system be inexpensive and require minimum technical knowledge to be used and expanded as a research tool for viden coding algorithms.

\subsubsection{Class of Algorithms}

The class of algorithms examined lends itself well to spatial data blocking. It can process hlocks of the same image frame with minimum access requirement to remote picture elements in other blocks (in other processors). Most video coding algorithms fit in this class (Section 2.3). but the class excludes interframe coding algorithms. The gencralization of the results $w$ interframe and colour coding schemes is addressed at the end of the thesis (Sections 6.6-6.7). 


\subsubsection{Class of Architectures}

The multiprocessor systems considered in this study include hoards that can share a highspeed memory communication channel with a suitahle host in a hosvslave contiguration. These systems are programmed and controlled through the host. which provides them with power supply and inputoutput (I/O) services and controls their operation.

The processing power of a hoard is furnished hy an on-hoard high-portiormatic processor which has local memory and V(O) peripherals on-chep or on-hourd. Mamy sush boards exist, based upon processors like Motorola DSP56(K) and DSP)(6)(1). Intel is(N). Texas Instruments TMS32(C)30 and TMS320C40) ramilies, and they can he interconnecled within themselves (e.g. in a ring) in addition to their connection with the host. This class of architectures provides cost-effective, high-performance processing power: it is llexihle and its use does not require much technical knowledge (see Figure 5-1 for a 2-hoard system example).

\subsection{Motivation and Scope}

This thesis aims to analyze the impact of using a multiprocessor system as the test hed of a VBR video coding and transmission algorithm on the processing time required to carry out the end-to-end frame transformation. Analysis of improvement of the processing time of the algorithm may lead to the design of a multiprocessor system that could carry out the end-to-end video processing in real time so that the resultant video images can be viewed as if they were on a television (TV) system without storage requirements.

This project is motivated by the emergence of the BISDN network. Eflicient video compression, channel-coding and error-correction methods should the developed thetore the BISDN is in operation. These VBR video processing algorithms should increase speed and conserve bandwidth while preserving picture quality.

\subsection{Approach}

A simple, typical image-compression algorithm was used to carry out the source coding and decoding of the raw digital video bits. The images that were used to carry out the experiments were in 256-grey scale, every pixel being represented by one hyte (octet).

First the frames were subjected to a simple subhand decomposition scheme which transformed the image into three streams differing in resslution. The highest-resolution lowest-priority stream was compressed through run-length coding and then further 
compressed using Hutiman coding. The first two streams were merged into one stream and the resulting (wo streams were subjected to ATM channel impairments. Cell loss rates differed for each stream to reflect the use of cell-loss priority in the ATM network. Finally, the two streams that were received at the end of the ATM channel were used to reconstruct the destination picture. The high-priority stream was used to reconstruct the more important features of the image and then the low-priority stream was Huffman-decoded, run-length-decoded and superimposed on the low-resolution image to achieve the final image.

The ahove process was initially distributed between two processors, each carrying half of each image to he processed. The improvement achieved over the unipiocessor case was then projected for more processors to estimate the required number of processors to carry out the simulation in real time.

\subsection{Organization}

The next chapter will provide some background necessary for this study and will examine what has been done in related areas. A review of multiprocessor architectures. ATM and digital video compression is presented and a brief literature survey follows.

The third chapter addresses the problem to be solved. It provides more detailed information ahout the specific compression and channel models used in the simulation and presents the hardware and software system used in the experiments.

The fourth chapter presents the performance of conventional single processor systems for comparison: performances of a 386-based personal computer (PC) and a single processing hoard are compared.

The fifth chapter analyzes the performance of multiprocessor boards. The video processing load is distributed between two processors, and improvements on performance are analyzed.

The sixth chapter extends the performance of the multiprocessor system to cases where more processors are used to arrive at the design of the real-time simulation system. Alternative designs are suggested.

The thesis concludes with a summary of results and suggestions for future research work. 


\section{2 \\ Background}

This chapter reviews multiprocessor architectures. ATM, and video compression algorithms. The chapter concludes with a section on research done on video coding for the ATM environment.

\subsection{Multiprocessor Architectures}

Due to the demand on processing power. central processing unit (CPU) designs incorporate instruction decode overlap. multiple cunctional units, pipelining' ${ }^{\prime \prime \prime}$ and Harvard architectures ${ }^{(12)}$ to speed up processing. but this provides limited improvements. There are several ways to gather and connect processors together to perfiorm tasks fasiter and more efficiently. The optimal architecture of a multiprocessor system depends on the type of task tackled. This section gives a general review of multiprocessor archilectures.

The multiprocessor architectures discussed below can be huilt casily using transputers. which are high-performance microprocessors, designed to facilitate interprocess and interprocessor communication ${ }^{[13]}$. Processes are the fundamental transputer sofftware building blocks, and they can be directly implemented in hardware ${ }^{1 / 1}$, with the hardware management being expressed in the context of the Occam language ${ }^{13 !}$.

\subsubsection{Computer Classifications}

The multiprocessor system architectures are classified according to their logical and functional structure at the program levels. Different classifications were proposed by Flynn, Shore, Skillicorn, Hwang-Briggs, Erlangen. Giloi and others ${ }^{\mid 12.151}$. (Ine of the earliest and most cited schemes is Flynn's. It consists of four taxa: 
SISD: single-instruction stream, single-data stream, which is the traditional von Neumann computer.

SIMD: single-instruction stream, multiple-data steam. where the same processing is made for each processors's local data as in parallel vector or array processors.

MISD: multiple-instruction stream, single-data stream, which refers to a pipeline computer. The Hwang-Briggs modification to Flynn's classification eliminates this texon.

MIMD: multiple-instruction stream, multiple-data stream. where each processor runs its own instructions on its local dati.

Each taxon of the above spans a wide number of computers such that comparison cannot be made hetween them. However, it helps explain the architectures reviewed below.

\subsubsection{Mesh Architectures}

Mesh-connected processors were one of the first architectures used for image processingl|16|, because images map naturally onto this architecture. A typical machine consists of a large number of processors. each of which is usually connected to its four nearest neightuurs, as shown in Figure 2-1. However, other connecting schemes may be used.

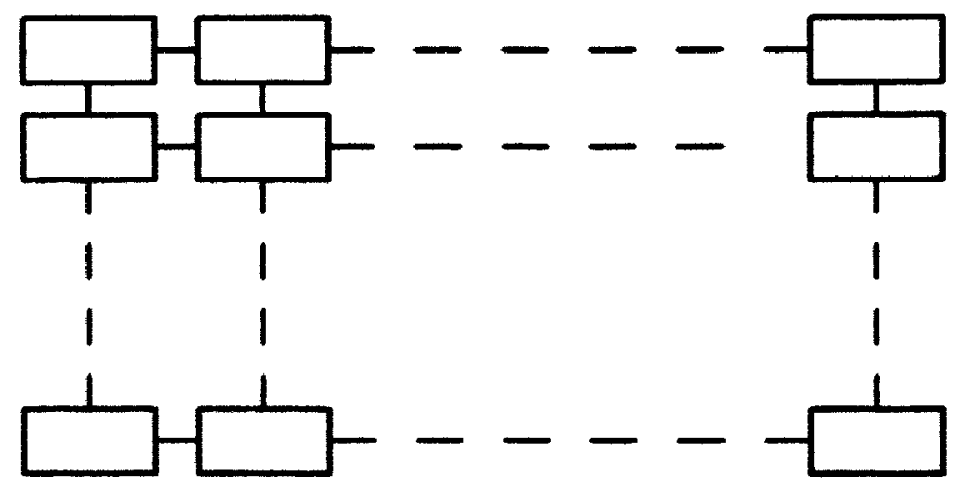

Figure 2-1: Mesh Architecture

Most mesh-connected machines are SIMD machines. Each processing element (PE) has its own memory and can he masked selectively using mask registers. Each PE responds in the SISD mode to controller instruction broadcast. The connections can be wrapped around in the Taurus model where top row PEs are connected to bottom row ones and the 
first and last columns are connected together in a grid"l?. Another variation is connecting the PEs of each row in a hus. Those enhancements do not change the hasic characteristics of the model. Mesh algorithms can use simple scanning techniques and linish in thetr optimal time ||$x \mid$.

The advantage of this architecture is that images can map anto it sasily. especially when the image size corresponds to the processor array sia when calculations need to the made on individual pels or depend on a close neightourhoud of pels. Duc w the connection architecture, this architecture is ineficient for tasks where calculations demend on distant groups of pels because communication hetween distant PEs is expensive and incticient. Because this is a SIMD architecture, tasks that require more complicated processing cannot be carried on this system, especially that the PEs are simple. If the task dowes nut map exactly to the size of the mesh. processing power will the wasted. A major drawhack is the inefficiency of collecting and evaluating the results rapidly dice 10 communication bottlenecks.

\subsubsection{Pyramid Architectures}

If the mesh is extended in the third dimension to facilitate communication hetween distant cells, a pyramid architecture will result. In this architecture, each level is four times the size of the level above ${ }^{[16]}$. Therefore, a parent PE has tour children 10 which it is connected in addition to its four neighbours and its parent if it is not at the top of the pyramid.

This hierarchical structure simplities communication hetween distant cells, but it is more complex to build than a mesh because it involves many communication links and it requires about twice the number of PEs to process the same image resolution. All the PEs operate in the SIMD mode, running the same program. System utilization can he increased by driving each layer by a separate controller in a multiple SIMD mode. Elficient pyramid algorithms need to reduce information in two dimensions simultaneously and this, in general, requires considerable effort ${ }^{[18]}$.

The computation pipeline is bottom-up causing the slowiest proxessors in the hottom level to slow down the whole system and limit the utilization at all levels. It also requires thousands of processors to solve a problem of reasonable siza. Adapting the algorithms (1) process problems of difterent sizes on the same number of processors is not al ways clear.

\subsubsection{Hypercube Architectures}

A hypercube is topologically an $n$-dimensional cube consisting of $2^{n}$ PEs where every PE 
is connected to the $n$ PEs differing in only one bit position from its binary representation ${ }^{|16|}$. Therefore, the longest distance hetween any two PEs is $n$ links.

This architecture can execute SIMD and MIMD programs. In the SIMD configuration, it is suitable for low-kevel and intermediate-level image processing. However, low-level and intermediate-level processing cannot occur simultaneously. In the MIMD configuration, it is suituble for intermediate-level and high-level processing. Its advantage is the efficient long-distance communication between processors. In large machines, however, communication is inefficient due to the slow communication bandwidths. A major disadvantage of the hypercube is the need to use the underlying topology for the algorithms to efliciently utilize the machine. A hypercuhe machine also lacks the global contrul.

\subsubsection{Shared-Memory Architectures}

Normally, shared-memory multiprocessor systems are MIMD machines ${ }^{16 !}$. In addition to a large global memory, each processor has a small local memory. The processors gain access to the global memory through an interconnection network, which is usually bushased or multistage. Due to bus access botlenecks, bus-based systems cannot be large.

A more scalable class of shared-memory systems uses a multistage interconnection network lor processor-processor or processor-memory interconnections. This contiguration provides case of programming and a uniform view of the system. This makes this architecture hest suited for high-level processing. However, bottlenecks and hot spots (cciur due to using global memory for communication and interaction between processors and tasks. It also makes the overhead of synchronization very high. Due io the fact that accessing global memory is very slow compared to computation speed, this architecture is efticient for large-grain parallelism tasks exhibiting regular memory access patterns with little interaction. As the number of processors increase, the synchronization overhead grows and dominates the processing time, causing the return of using a larger-sized system wo hecome negative heyond a certain size. This also limits the scalability of this class of shared-memory multiprocessors.

\section{1.6 Systolic Amays}

When the algorithm can be implemented using very simple operations with a regular flow 


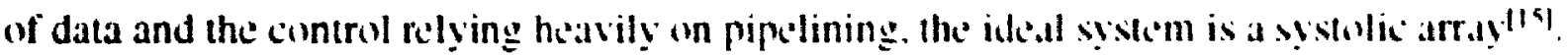

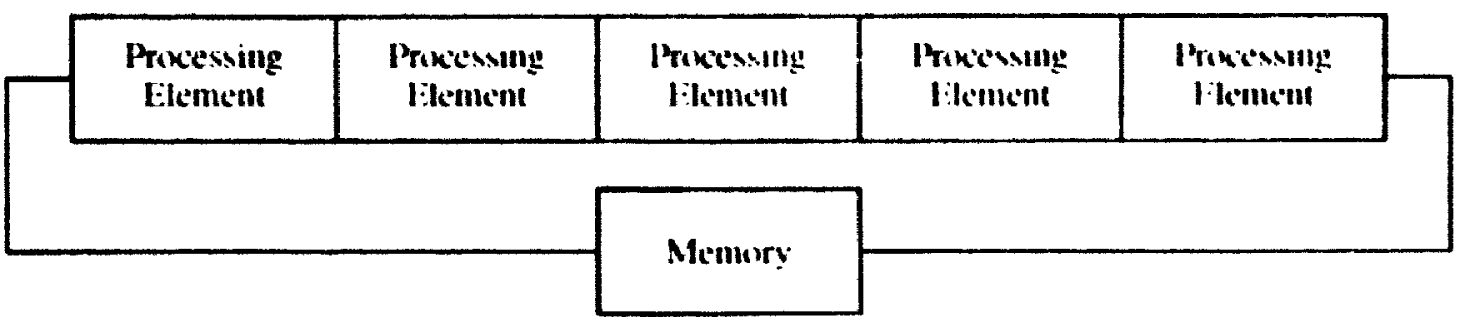

Figure 2-2: Systulic Architecture

A systolic array consists of connected processorsilnt. (In tach makhinc cycle. taich processor takes data from its input ports, pertiorms the computation and passes the results and data through its output ports. The $I /()$ only accurs at houndary cells ${ }^{121}$. The systiolic array is a pipeline of a series of processing elements operating in parallel when the pipe is filled so they might be considered MISD ${ }^{[14]}$. The primary advantage af programmable systolic arrays is high pertormance for low cosil|h. 1"|. They are hest suiled for image processing. Systolic arrays can be conligured in a parallel and pipeline mode (MIMD) (1) increase the processing efficiencyl20!. The results cannot be evaluated unlll all dalla has passed through the array; therefore. it cannot adapt quickly (1) the characteristics of the image.

\subsubsection{Hybrid Architectures}

More flexible and partitionable system architectures were designed for more complicalted image processing tasks as in computer vision where all three levels of processing need (o be done simultaneously ${ }^{[16]}$. Such architectures are capahle of running SIMI and MIMI) programs at the same time. System configuration is under soliware control.

\subsection{Asynchronous Transfer Mode}

ATM has a flexible bandwidth allocation scheme which will he the transport technique for the broadband integrated services digital network, BISDN ${ }^{17}$. ATM is cell-based with a cell size of 53 bytes, 5 of which are the cell header and the rest is the information payload. ATM was chosen because of its capahility of supporting multirate services. Its statistical multiplexing allows for the integration of services with a wide variety of characleristics. Assigning the peak rate bandwidth to calls of bursty or variahle bit-ratc nature decreastes the network utilization considerably. ( In the other hand, assigning bandwidth less than the 
peak rate makes cell loss inevituhle. Cell loss prohahilities larger than $10^{-4}$ are not acceptable for most services. Therefore, handwidth allecation must be decided carefully.

\subsubsection{Priority Mechanisms}

The quality of service required by services varies widely. It depends mainly on the cell Iranster delay and the cell loss prohahility $\left.\right|^{|+|}$. The main factor in cell delay is the queueing delay which varies statistically depending mainly on the link's load. Cell loss caused mainly hy huffer overflow depends on the network load and the size of the buffers.

There is one priority control hit in an ATM header although more priority levels may be needed for different classes of services $1+.7 .21 .22 .23$.

\subsubsection{Packet Video in the ATM Environment}

ATM provides a tlexible environment for VBR video ${ }^{2}$.2+1. The variability of video bit rate is expected to reduce deiay, keep video quality constant. improve transmission efficiency ${ }^{|2|}$ and enahle users to control picture quality. However. this requires solutions to cell loss, high-speed multiplexing and appropriate protocols on support VBR video transmission.

\subsection{Video Compression Algorithms}

Digital image data is compressed to save channel bandwidth. Compression removes different portions of the spatial and temporal redundancy exhibited in digital video. Layered viden coding schemes arrange picture information in a pyramid according to their imponancel"l. Bit-plane separation schemes assign the top of the pyramid to the most signiticant hit plane. Frequency-domain separation schemes, like subband coding. separate the image information into frequency hands; they are suitable for low loss rates hecause of the non-linear feature of frequency hands. Some schemes combine both methous to degrade gracefuily in low and high loss rates. Some compression methods are completely reversible without losing any of the original data and hence are called -lossless" coding lechniques. ()thers remove insignificant details of the orignal image and hence are called 'lossy' coding techniques. Following is a brief review of some video compression methods.

\subsubsection{Lossless Coding}

Lossless coding preserves all the intormation of the coded data. These coding schemes 
have low compression ratios and are usually used to colle high priority intormation or motion vectors after lossy codingly.

\subsubsection{Huffman Coding}

This scheme uses variable-length condes. When an alphahet of 11 symbols is conled, the intuitive idea is 10 assign short conde words to the most probahle symbulsticl. Fir an alphabet of $n$ symbols associated with an information source, Hutiman colling algurithm guarantees a uniquely decodahle code with the minimum average number of hils per symbol, $R$, with

$$
H \leq R \leq H+1, \text { where } H=\sum_{i=1}^{n} p_{i} \log _{2} y_{i} \text {. }
$$

$p_{i}$ is the prohability of symbol $S_{i}, \sum_{i=1}^{n} p_{i}=1 . H$ is the entropto of the intormation source.

The average code length varies depending on the symbisl prohability distribution. Huffman coding is highly efficient in situations where the probahility distribution of adjacent pels is not uniform. A Hufiman code can he generated systematically and easily with a computer program. The ideal decoding scheme is a code treeter) since this conde abides by the prefix condition'. Partitioning the incoming data rate among multiprocessors cannot guarantee fair partilianing of the coding processing load heciduse of the entropy variation.

\subsubsection{Lempel-Ziv Coding}

This scheme applies variable-rate coding to a "standard scan" of a picturel2!! An information lossless encoder of finite order is used to encode the largest number of jistinct strings that constitute the input data streami ${ }^{|2 x|}$. Intially, the code table is empty. Strings that are not in the code table are added when forst encountered in the input stream, increasing the size of the code tahle as encoding proceeds. Each new string to be added is a codeword that already exists in the table plus a symbol, such that the new string dexts not yet exist in the table. This new table entry is the next input string. In doing so, the algorithm adapts to the input stream; however. the compression ration is low hefore

1 No codeword is a prefix of another 
sulficient adaptation has occurred. After the restricted code table is full, the algorithm stops (1) adapt $["$ " ")]. The algorithm is optimal for infinite input streams (with an infinite code tahle size). A modified version of this coding scheme is used in compressing computer data files.'

\subsubsection{Arithmetic Coding}

This coding technicue represents information at least as compact as the Huffman method $^{|x| l}$. Arithmetic coding dispenses with the restriction of having to assign an integral number of hits to each symbol. The scheme works by assigning subintervals to symbols. $A$ symbol's suhinterval is equal in length to its prohahility. A message is represented by a reat number in the total interval in the form

$$
\text { Message }_{0}=I S_{0}+p_{0}\left(I S_{1}+p_{1}\left(I S_{2}+\ldots\right)\right) \text {. }
$$

where IS $S_{i}$ is the interval start of symbol $S_{i}, p_{i}$ is the probability of symbol $S_{i}$, the index $i$ denotes the symbols' order in the message, not the code table (see below for illustration).

In decoding, the first symbol is the one in whose subinterval the real number lies. Then the tirst symbol subinterval is scaled up to one to decode the next symbol in thi same fashion:

$$
\text { Message }_{1}=\frac{\text { Message }_{0}-1 S_{0}}{p_{0}},
$$

where Message, denotes the original message and Message, denotes the original message after decoding the first symbol. This procedure is repeated until the entire message is decoded

Tahk 2-1: Arithmetic Coding

\begin{tabular}{|c|c|c|}
\hline Symbol & Probability & Subinterval \\
\hline \hline$a$ & 0.2 & {$[0,0.2)$} \\
\hline$b$ & 0.1 & {$[0.2,0.3)$} \\
\hline$c$ & 0.4 & {$[0.3,0.7)$} \\
\hline$d$ & 0.3 & {$[0.7,1)$} \\
\hline
\end{tabular}

1. The popular compress program used on UNIX machines uses a Welch modified version of Lempel-Ziv algorithm. hence the file name extenskn 1.TW. 
Consider the symbol probahility distribution in Tahle 2-1. The messiage "hald" an he represented by any number in the interval [0.214, 0.22(1). Suppose the real number 0.215 was transmitted. Becauxe it lies in the suhinterval $\mid 11.2,(1.3)$, the symbol " $h$ " is recognised.

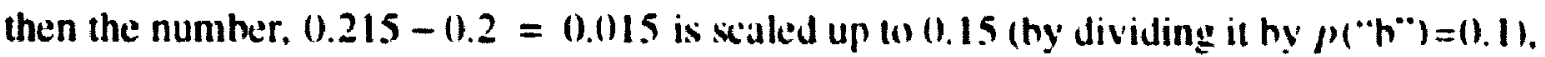
which lies in the " $a$ " subinterval. Then the number, 0.15. is scaled up (1) 0.75 (hy dividing it by $p(" a ")=0.2$ ) which lies in the " $\mathrm{d}$ " subinterval. In this fashion. the scheme can remove" the sharp houndaries hetween codes to achieve higher compression than Ilutiman and Lempel-Ziv methods. Usually, it is easier to implement and faster than the Ilutiman scheme. This scheme is heing standardized in the Joint Binary Image (iroup (JIBI(i) standard $[3]$.

\subsubsection{Run-Length Coding}

This simple method exploits pel-to-pel correlation ${ }^{[3]}$. Considerable reatction oxcurs when, instead of transmitting a long run of the same symbol, only the run length and the: symbol are transmitted. With increased high-frequency content regions, runs are very short and it may require more hits to transmit the run parameters than to transmit the original pels. Bit plane images can be run-length-coded. This scheme ean he extended to a second dimension by area coding, where a 2-dimensional region consists of the same pel value, but this does not occur often. This scheme can be easily programmed and is computationally inexpensive, especially in the decode stage.

\subsubsection{Lossy Coding}

Lossy coding methods are not completely reversible; distortion and loss of fidelity may result in the coded image. The distortion and lack of minor details caused hy this class of coding are intended to be transparent, or very closely so, to the practical destination of the image data.

\subsubsection{Transform Coding}

Transforms are used to decorrelate image datal?. The aim is to compact the image energy into a minimum number of statistically independent coefficients concentrated to a minimum region. The uptimal transform for this is the computationally expensive Karhunen-Loeve transform (KLT). This transform is often approximated hy fast sinusoidal unitary transforms such as Discrete Fourier transform (DFT), Discrete Cosine 
transform (DC $\Gamma$ ), Discrete Sine transform (DST), etc. DCT is generally considered to be the cloxest approximation to KLT. Duc to their computational efficiency, nonsinusoidal orthogonal unitary transforms are used for video compression; examples are WalshHamard and llaar transforms. Series expansion models are also used, such as singular value decomposition. which is superior in compression performance but prohibitively expensive to he used in real-time applications.

Intertrame coding schemes can reduce the data rate considerably. Conditionalreplenishment coding is such a predictive scheme, which transmits the difference between the actual and predicted frames. Motion compensation can be used in predictive coding schemes. A number of eoding schemes is hased upon intertrame motion compensation and intralirame transfiorm coding.

\subsubsection{Combined Transform Coding}

Dividing images into blocks and transformirig them independently in transform coding leaves the correlation hetween different blocks high. Besides affecting compression performance, this creates a "blocking effect" across the block boundaries, especially at low hit rates "I. This blocking effect is the main limitation of transform-hased low bit-rate cording. Various methods were used to reduce this effect. Smoothing the block edges may cause the loss of high-frequency information. Other methods have various disadvantages: therefore, a combined transtorm scheme was suggested.

The combined transform coding scheme divides the image into two image planes: the upper image plane (UIP), which contains the most important information, and the lower image plane (LIP). The UIP. the motion vectors and direct-current (DC) coefficients of the LIP are losslessly coded and are assigned the highest priority. The transform coefficients of the LIP form a pyramid in the frequency plane. Cells are dropped staring from the bottom of the pyramid in case of congestion so that performance degrades gracefully as the loss rate increases.

\subsubsection{Predictive and Interpolative Coding}

Dut to the high correlation hetween pels in a local region, a pel might be predicted from knowledge of past pels or interpolatively inferred from past and future pels ${ }^{\mid 33\}}$. Transmission of a starting value or periodical transmission of actual pel values, to avoid large errors. might he required. A compromise is made hetween the accuracy of the 
predictor and its complexity. This compromise solution is to use a lintar predecur and transmit a starting value and prediction emor estimation.

Interpolative coding may. for example, transmit every wher line of the image and use interpolation w estimate the missing lines. Computationally complex inferpolative systems can reconstruct a band-limited signal exactly. hut due to their complexity. simpler methods have been considered.

\subsubsection{Subband Coding}

This scheme separates the video signal into subbands of different frequencies. Each subband is then encoded separately. This allows for higher compression hecause interframe motion can be estimated more efficiently for subbands than for full hands. Furthermore, it can be combined with other coding techniques. SBC/DPCM (suhhand coding/differential pulse code modulation), SBC/DCT, SBC/VQ (vector quantization) and other combinations have heen developed. VBR SBC schenes have the rohustness and compression performance appropriate for packet videol?!

\subsubsection{Vector Quantization}

Vector quantization schemes can remove interpel correlation, statistical dependence and some of the geometric redundancyl3!. Huge processing is involved in establishing and searching code books that are uxed by the scheme. This makes it not ready yet lo he used for real-time VBR transmission.

\subsubsection{Seconci-Generation Compression Schemes}

Second-generation compression schemes employ geometric and global redundancy in natural scenes. Such schemes use computer vision, image segmentation and the understanding and characteristics of the human visual system. mostly operating on images with simple geometric patterns.

The fractal scheme ${ }^{(3+)}$ breaks digital images into segments using color separation, edge detection and other techniques. Using the collage theorem, segments are looked :p in a library of codes used to reproduce corresponding fractals. The appropriate codes replace the original segments, achieving compression ratios in the order of $10,(1)(1)$ or more, hut the ratio is much lower for natural images. Images can he reproduced (1) any desired accuracy. However, this scheme is computationally very expensive!. IFSIS ${ }^{13+1}$, a special hardware 
device, achieved a decoding performance of several frames per second. This scheme is still not suitable forr real-time applications.

\subsubsection{JPEG and MPEG Standards}

The JPEG standard was developed by the Joint Photographic Experts Group. The MPEG standard was developed by the Moving Pictures Experts Group-an ISO committee ${ }^{\mid 35]}$. JPEG is a gencral-purnose standard designed for continuous-tone, still-image applications $s^{|4|} \mid$ as in videotex and still-image telephony. MPEG is a generic standard designed for video signals at ahout $1.5 \mathrm{Mb} / \mathrm{s}$, audio signals at 64.128 and $192 \mathrm{~kb} / \mathrm{s}$ and synchronizing and multiplexing multiple compressed video and audio streams. Draft dicuments ${ }^{(7)}$ show that the MPEG I VBR peak bit rate is 1.5 Mbps and the MPEG2 VBR peak hit rate will be 10 Mhps, both with a Type 2 AAL. Broadband video recommendations are to be approved in 1994. MPEG2 is expected in 1994 for digical VTR. digital disc and cable TV. MPEG 3 is expected to be approved in a few years. Its peak hit rate will be 40 Mhps and will be used for HDTV systems.

MPEG I codes frames in three types: intra-coded (I) frames. predictive-coded (P) frames and hidirectionally predictive-coded (B) frames ${ }^{|38|}$. 1-frames are encoded individually with intratrame coding methods. P-frames are coded using motion compensated prediction irom past I or P-frames. B-frames are coded using motion compensated prediction from past and/or future I or P-frames. A group of frames begins with an I-frame and ends with the P-frame just before the next I-frame and a sequence of frames is a series of those groups of frames. This scheme is capable of forward and hackward. normal and fast play and skip. pause, and high-resolution still. Blocks a:e pigzag-scanned. DCT-transfiormed and the coetficients variable-length-coded (VLCcoded). For colour video. luminance (Y), red chroma (CR) and blue chroma (CB) matrices are constructed. Motion information is based on 16-by-16 blocks and is compressed via VLC $w$ he transformed along with spatial information. Many other unapproved proposed algorithms are being developed by different companies.

JPEG can also be used for video. achieving compression ratios in the vicinity of 25:1 with gond picture quality. MPEG 1 achieves 2.5 times the compression ratio achieved by JPEG 'S: however, it is much more complicated. JPE.G is symmetrical so it can be encoded

1. Irrixessing a complex colour image on Masscomp $5(x)$ (a workstation based upon 268020 processors)

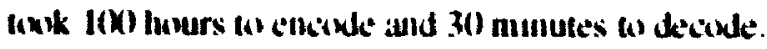


and decoded on the same system, hut MPEGI is asymmetrical and another system is required to carry out the inverse half of the eycle. Therefore, it is suited (a) asymmetrical applications where end user products need only decompress data which have heen alrealy compressed by the source. A single-chip, high-pertormance processor has he'n huilt which could carry out MPEG 1 decompression in real time ${ }^{\text {3.5! }}$.

\subsection{Video Compression for ATM}

Video transmission will he a major service of ATM $^{\mid 29]}$ since there is a high demand firr video conferencing and telephony. TV and high-detinition television (HDTV). (ctc. "'il) The cell-loss characteristics of ATM(10) may degrade video quality considerahlyl". especially since video services are much more sensitive to cell loss than voice telephony|'t). The need to compress HDTV by a ratio over four ${ }^{+1) !}$, and encode it in VBR. probahly using interframe compression, will make cell loss a serious drawhack|ly|. Much rescarch has been done to investigate cell loss protection and recovery for video transmission in the ATM environment ${ }^{[3]}$. Many rescarch papers address VBR video conding tor packet switching networks and ATM.

Verbiest et al..$^{|9|}$ discussed the impact of ATM on video coding. Ghanhari ${ }^{|\mathrm{k}|}$ dixcusses general aspects of video packetizing. Lee et al. ${ }^{|10|}$ analyzed video packet loss in ATM networks. Morrison ${ }^{|+|\}}$describes a hardware implementation of a variable hit-rate extended standard fixed-rate video coder tor ATM. Zhang et al. ${ }^{[3]}$ surveyed methods (1) compensatt for cell loss in VBR video transmission and elaborated on different layered source conding schemes. Verbiest and Pinnoo ${ }^{[5]}$ presented a DPCM-based VBR video codec for ATM with cell loss. Takase et al. ${ }^{|+0|}$ discussed coding and functional requirements of VBR HD'TV in ATM networks. Kishino et al. ${ }^{|2|}$ presented a two-priority layered VBR viden coding scheme to compensate for cell loss. Darragh and Baker ${ }^{[2]}$ presented a lixced-distortion subband image coding scheme for packet-switched networks. Kinoshita and Nakahashilty described a two-layer DCT-based codec for HDTV, using hlock interleaving and data transposition with cell loss detection. 


\section{3 \\ Experimental System}

In this thesis, a representative scheme of VBR video coding and transmission is used to evaluate the possibility of applying multiprocessor simulation to the general class of VBR coding algorithms. The following sections explain the software representing the VBR coding and transmission scheme and the hardware system used to carry out the required simulation processing.

\subsection{Simulation System}

The simulated system includes the coding algorithm, a basic part of the ATM adaptation layer, and a simplified model of the ATM channel followed by decoding. The compression algorithm used in the experiments exemplifies behaviour exhibited by various coding algorithms in having a certain pattern of data dependencies and irregularities in subtask and frame coding processing demand. Single frames are used in the initial set of experiments, and the results are expanded later to more general video processing schemes. The source and destination of image data is the memory of the host system.

\subsubsection{Compression Algorithm}

The video compression algorithm used in the simulation is a layered video coding scheme which separates the feature plane into three layers. The three layers in descending order of feature importance are the superpel, triad and pel layers. In this section, width is the image width in pels, $M$ and $N$ are the height and width of a superpel in pels, respectively. Image 
width is divisible by superpel width. $N$. Figure $3-1$ illustraltes this nomenclature.

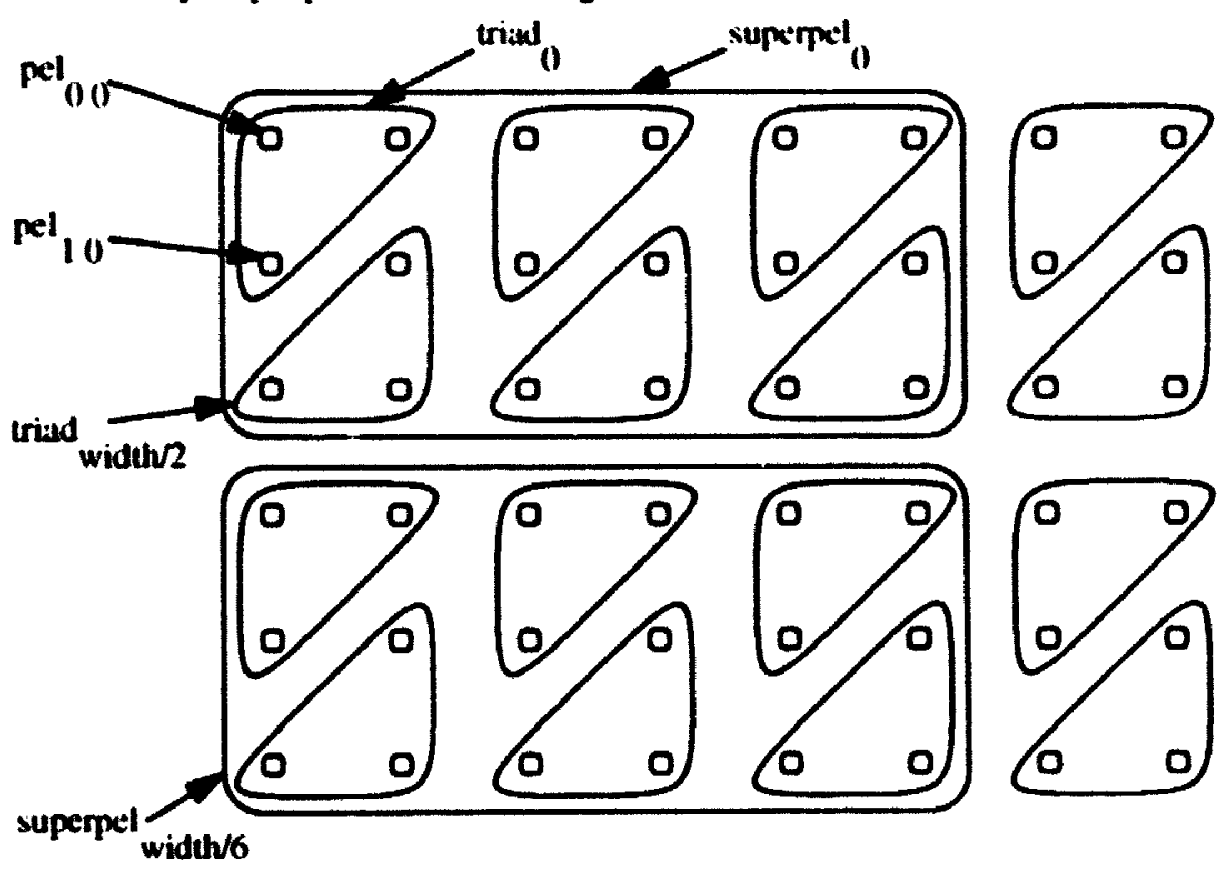

Figure 3-1: Illustration of Terminulangy

For an image matrix, a superpel (here. the average of 18 pels) is calculated as follows:

$$
\text { superpel }_{k}=\frac{1}{M N} \sum_{j=N \bmod \left(k, \frac{\text { width }}{N}\right)}^{N \bmod \left(k, \frac{\text { width }}{N}\right)+N-1} \sum_{i=M \operatorname{Mdiv}\left(k \cdot \frac{\text { width }}{N}\right)}^{N(k)+M-1}
$$

where $\operatorname{div}(a, b)$ denotes the quotient of the integer division of $a$ hy $b$, and mod $a, b)$ denotes the remainder of dividing $a$ by $b ; a, b$ are integers. The above expression simply means that the horizontal index of the pel at the top left corner of the superpel is incremented by $\boldsymbol{N}$ with every new superpel. It is reset and the vertical index of that pel is incremented by $M$ when the superpel index is divisible hy the number of superpels per line.

In the algorithm implemented in this work. $M=3, N=6$. The above expression evaluates for superpel width/6 $_{\text {as: }}$ 


$$
\begin{gathered}
\left.\frac{1}{3 \times 6} \sum_{j=6 \bmod \left(\frac{\text { width }}{6}, \frac{\text { width }}{6}\right)}^{6} \sum_{i=3 \operatorname{div}\left(\frac{\text { width }}{6}, \frac{\text { width }}{6}\right)+6-1}, \frac{\text { width }}{6}\right) \\
=\frac{1}{18} \sum_{j=0}^{5} \sum_{i=3}^{5} \text { pel }_{i j} .
\end{gathered}
$$

A triad in the upper row of a line group (where mod(div( $\left.l, \frac{\text { width }}{2}\right), 2$ ) $=0$ ) is calculated hy:

$$
\text { triad, }=\frac{1}{3}\left(\text { pel }, j+\text { pel }_{i j+1}+\text { pel }_{i+1}\right)-\text { superpel }_{\text {and }\left(\operatorname{div}(l, 3), \frac{\text { width }}{6}\right)+\frac{\text { width }}{6} \operatorname{div}(l, \text { width })}
$$

where $i=3 \operatorname{div}(l$. width $)$ and $j=2 \bmod \left(I . \frac{\text { width }}{2}\right)$. The first term in the superpel index above accounts for the horizontal location of the superpel and the second term accounts for the vertical location of the superpel. The superpel is subtracted from the triad to achicve the alternating current (AC) value of the triad. A triad in the lower row of a line group (where mod(div(l. width $\left.\frac{2}{2}\right)=1$ ) is calculated by:

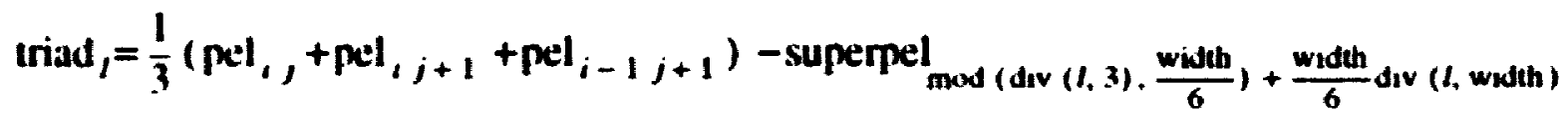

where $i=3 \operatorname{div}(l$. width $)+2$. and $j=2 \bmod \left(l . \frac{\text { width }}{2}\right)$

The AC value of each pel is evaluated by subtracting the sum of the superpel and triad from the original pel. Next is the thresholding of the AC pels. In this part, each pel less in absolute value than a prescribed threshold is considered zero. Run-length coding is then used to decorrelate close pels in the same line group. The output of the run-length coding (RLC) stage is entropy-coded (VLC-coded) using the Huffman scheme. The VLC stage cost depends highly upon the entropy value of the pels. 
The lossy ATM channel is simulated hy a geometrically distributed random function. The function generates the intervals hetween each lost cell and the next ane.

The decode program segment reverses the eneoding scheme. The resulting: millye' differs from the original due $(1)$ the quantization cror in thresholding differential $p^{*}$ ls and to lost cells in the three feature hands.

\subsubsection{Algorithm Implementation}

The first part of the algorithm averages the pels in threc hands of resolution. Ihe sum which effectively reconstructs the original image. A superpel is the average of Ix pels. $\Lambda$ triad is the average of 3 pels; 6 triads constitule a superpel. This can he lliked (1) save calculations by first calculating the triads and then averaging the triads in each superpel to achieve the superpel value. This task can he achieved hy calculating the sum of every group of 3 pels that forms a triad and storing them. Then the sum of the triads that lorm a superpel is calculated and (effectively') divided hy 18 . The triad averages can then he evaluated by (effectively) dividing the triad sums hy three. Next. tinal pol values are achieved by subtracting superpel values from them. Finally. superpels are suhtracted from triad averages to form the final triad values.

For a superpel (I8 pels), the operations (additions. suhtractions, multuplications divisions) and memory accesses (MA) involved in the aforementioned task are:

$\begin{array}{cl}6(2 \mathrm{ADD}+4 \mathrm{MA}) & \text { (triad sum) } \\ +5 \mathrm{ADD}+7 \mathrm{MA}+1 \mathrm{DIV} & \text { (superpel average) } \\ +6(2 \mathrm{MA}+1 \mathrm{DIV}) & \text { (triad average) } \\ +6(3 \mathrm{SUB}+7 \mathrm{MA}) & \text { (inal AC: pels) } \\ +6 \mathrm{SUB}+13 \mathrm{MA} & \text { (tinal AC triads) }\end{array}$

That averages to $2.28 \mathrm{add} / \mathrm{sub}, 5.44 \mathrm{MA}$ and $0.39 \mathrm{div}$ per pel.

The next task is to disassemble the superpels and triads into ATM-lake data cells. This task mainly transfers superpels and triads to a stream huffer, interleaved by cell identification words (overhead of $10 \%$ of the data sie). This involves 15.4 MA per superpel or $0.86 \mathrm{MA}$ per pel.

Pels smaller in absolute value than a specific threshold are suhstituted with aeros. This

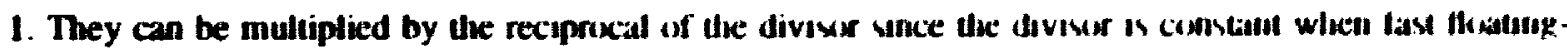

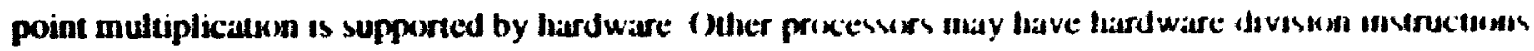


task involves 2 MA and 1-2 comparisons per pel (due to the two destinations of comparison. caused by using an absolute value for the threshold). The resulting data is compressed using run-length coding.

Run-length coding (RLC) is followed hy variable-length Hultiman coding (VLC). To prevent error (or loss) propagation in the cells that follow a lost cell, each cell must be coded individually. Therefore, a VLC length counter is initialized at the heginning of the RLC coding of eyery cell to follow the progress of the equivalent Huffman length of the data encoded in the cell. When a hyte is coded, the VLC counter is incremented by the VIC code length of the hyte. An address field is prepended at the beginning of every cell (1) specify the location of the information content of the cell in the image frame. This method ensures that every cell is loaded with data according to its capacity and makes decoding a cell independent of any other cell. A homogeneous run must be longer than three pels. This compression method achieves a compression percentage of about $20 \%$ for the image simples used in the experiments reported in Chap.er 5. Therefore, each pel requires on average $3 \mathrm{add} /$ sub (the address, the VLC counter, and the RLC counter) $4.8 \mathrm{MA}$ (1 for the source: (1.X. destination; 1. preceding pel; 1, address; and 1, length), and I comparison. This cost is statistically variahle.

Hutfman VLC is applied to the result of the preceding stage. Every byte is replaced by its VLC code without any calculations hecause the necessary arrangement was made in the RLC stage. The result of this stage is a sequence of ATM-like cells ready for the ATM channil stagc. ( In average, an $\$$-bit byte is compressed into 5 bits. This involves an average (1) 5 register shifts and 3.(12 MA per pel. This average comes from 0.8 MA for each of the swurce, corde, and length: and 0.62 MA for the destination. (The factors come from the respective average compression rations.).

In the channel loss simulation routine, for every lost cell, a geometrically distributed random number is generated. Generating the random number mainly involves generating a uniformly distributed random number. calculating a logarithm and 2 divisions. The probability of cell loss is very low (lower than $10^{-6}$ for the low-priority stream) such that the computational cost of this routine can he neglected. The loss probability that was used in the actual simulations was much higher (about 0.02 ) so that generated errors could be detected. The average cost is much less than 1 multiplication per pel.

The decouding stage starts with VLC decoding. Assuming an average of 5 bits per pel. decoding one symbol (pel) using an optimal method requires 5 register shitis and 5.4 MA 
(0.6 for reading the symbol: 0.8 for each shit: 0.8 for w ritilg: it). Practically speak ing. Mis stage requires $4-6$ times the time reyuired by VLC conconding.

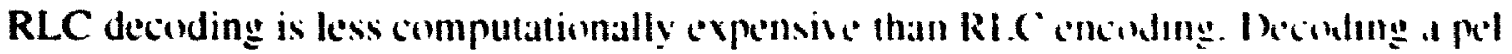
approximately costs 2 MA.

Finally. the image is reconstructed from the three hands. This stage requires 2 additions and 2.4 MA per pel (0.06 lor superpel: (0.33, triad: 1, pel read: 1. pel write).

The operations total is ahout $7.3 \mathrm{add} / \mathrm{suh}, 0.4 \mathrm{div} / \mathrm{mul}, 25.9 \mathrm{M} \mathrm{A} .2 .5$ comparimons and 10 register shifts per picture elentent. Execution overhead includes accessing instructions. calculating array indices, branching. etc. The efliciency of exesution depends an the architectural design and features of the specitic processor used to carry out the algorilhm.

\subsubsection{ATM Adaptation Layer Protocol}

The ATM adaptation layer supports infirmation-transfer probocols nol hased on ATMld" Its purpose is to assemble and disassemble hits, frames and data 11 and from ATM cills in a fashion suitable for the application. It provides and maintains liming relationships of real-time applications, handles cell loss. forward error correction and wher altrihutes mol carried out or preserved by ATM, and provides segmentatoon and reassembly in ATM

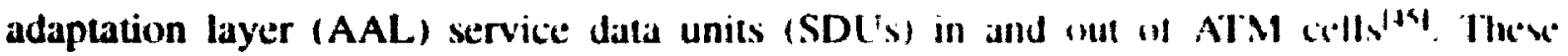
functions include ones which are common to all services and others which valy dependin! on the service in question. To support these classes of service. AAL prolixcols alc reyulred.

In this thesis, the algorithm does not involve the cell header except in assummen Iwn priority levels. The algorithm also leaves 4 hyles of the information paylodid teld to be used by the ATM adaptation layer protocols. The control s:heme used hy the algorithm uses two bytes of every high-priority cell payload for serial identitication (II)) numbering and four bytes of every low priority cell payload for the satme purpore. Ince a specille AAL protocol is decided, the assumption used can the changed accordingly.

\subsubsection{ATM Channel Model}

The ATM channel is represented by a geometrically distrihuted ume sequence between lost cells. The cell loss rate used for the high-priority stream differs from that uxed for the low-priority one. The algorithm uses cell loss rales much higher than the real case in order to enhance the ohservation of typical results of errors with the limiled image data sample used in the experiments. 


\subsection{Banshee Multiprocessor Board}

The Banshec hoard is hased upon Texas Instruments TMS320C30 floating-point digitalsignal processor. It has a static random-access memory (SRAM) and dual-port memory that can he addressed readily hy holh the Banshee processor and the host processor. A multuprocessor interliace (.MPI) dattghter hoard is used to intertace the Banshed hoard to wher Banshees via dual-port memory and common huses. These are explained in the followiag sections.

\subsubsection{The C30 Processor}

The information in this section is hased on TMS320C30 Useris Guidel+6|. The TMS320C 30 is a CMOS 32-hit toating-puint digital-signal processor. It achieves high perlormance hy implementing in hardware what general purpose processors implement in soltware or microcod". achieving a $6(1)-n s$ single-cyele execution time. The processor can perform parallel multiplication and ALU operations on integer or thating-point data in a single cycle. The C.31) possesses a general-purpose register file, program cache, dedicated auxiliary register arithmetic urits, intemal dual-access memories, one direct-memoryaccess (DMA) channel supporting concurrent $V / O$, and a short machine cycle time.

The 6() -ns execution cycle corresponds to 16.7 million instructions per second (MIPS). and the ahility to perform two floating-point operations within a single cycle makes the lloating-point data processing peak 33.3 mega lloating-point operations per second (MFL( OPS). The processor's two address generators with eight auxiliary registers and two atuxiliary arithmetic units make it possihle io address two data words at the same time. The on-chip memory supports this dual-access feature.

The on-chip memory consists of 6 kilowords (Kwords) divided into a 4-Kword dualaccess R(OM hlock and two 1-Kword dual-access random-access memory (RAM) blocks. The program cache is 64 words controllable by software to the cleared, enabled or trozen. The data hus is 32 hits wide and the address hus is 24 hits wide. Although the addressable data clement is a 32-hit word, the processor has eight 40)-bit wide floating-point registers and a supporting multiplicr data hus in addition to the 32-bit integer-data processing capahilitics. An improvement over most previous digital-signal processors is the capability of single-instruction and blick repeats with zero overhead. The processor has conditional instructions for calls, returns and loads. 
The C30 processor enhance's gencral-purpose applications hy having a large address space. a multiprocessor interface. intemally and evernally generalled watit stalles, two external intertace ports, two timers. tao sorial ports, and a multiple interrupt structure. Tio facilitate multiprocessing. the $C 30$ has two external intertace ports and interloched instructions.

\subsubsection{Pipeline Operation}

The C 30 pipeline structure includes five units: Fetch Unit (F). Decode ('nil (D)), Read ('nil (R), Execute Unit (E) and DMA Channel (DMA). A basic instruction has four levels: fetch, decode, read and exceule. The perfect overlap acious when the finer units are each husy with a different instruction. A pipeline conflict occurs when one unit tinishes while the next unit is still husy: in this case. it waits until the next level is ready. Beciase the DMA. which hi's the lowest priority, has its own data and address huses, contlicts with the CPU can he minimized or eliminated hy suitable data structuring.

Pipeline contlicts can he grouped into three main calegories: hranch conflick. which involve most operations that read or rosdify the PC: register conflicts. which involve delays occurring when reading or writing registers used for address generation: and memory conflicts, which occur when the internal units of the processor compele for memory resources. Causes of memory conflicts include multicycle memory access and interlocked losd instructions. Multicycle memory accesses are caused hy the gap hetween the CPU and memory handwidths. The interlocked load may he delayed by another processor's locking memory.

\subsubsection{Provision for Multiprocessing}

Processors in a multiprocessor system miay share glohal memory. In order for the glohal memory to be shared by processors in a coherent manner, arbitration or handshaking is necessary. This requirement of arivitration is the purpose of the interlocked operations. The C30 has five interlocked operations which provide synchronization mechantsms through the use of external signals, guaranteeing the integrity of the communcaatson and resulting in a high-speed operation. The operations are integer and flowting-point load and storc, and interlocked signal. When a processor executes an interlocked loading insiructuon, other processors are denied interlocked memory access until the interlock is cleared thy an interlocked store operation) by the same processor. Interlicked signai operatuons can 
synchronize processors hy using hardware signals to idle until interlocked signal operations are execuled by the other processors.

\subsubsection{The Banshee-Host Interface}

The information in this section is based upon Banshee System Instruction Manual ${ }^{[7]}$. The Banshec Mother Board is a lull-length AT-compatible board.

\subsubsection{Software Interface}

The Banshec board is accompanicd by a shell program, a debugger, a program loader, a $C$ compiler, a C30 assembler and signal-processing supporting libraries. The sheli is an extension of DOS to execute Banshee programs from the DOS prompt. A symbolic dehugger is included to interactively debug programs from the PC screen. A loader is supplied to load Banshee target programs to be executed in the background. SPOX, a realtime signal processing operating system, provides a device-independent $\mathrm{V} O$ and digitalsignal processing (DSP) functions to the system.

\subsubsection{Hardware Interface}

A Banshee hoard can be configured on either of two 1/O base addresses. Each of those base addresses can take up to 16 hoards making a maximum of 32 boards to be hosted on one host. This is made possible by decoding the next more significant 4 bits of the VO address hu: that the host computer does not decode.

The host computer's processor address space interfaces to the Banshee memory through a 16-Khyte (4-Kword) memory window. By disabling and enabling the Banshee memory accessed by the host through this window, any number of Banshee systems can share the same memory window address as long as only one board is active at any one time.

\subsubsection{The Banshee-Host Communication}

Communication and data transfer hetween the host and the Banshee system can be carried sut in several different ways.

The host can directly write to the Banshee memory through the 16-Kbyte memory window of the host. In this method. the Banshee processor must be in a HOLD state. This method is usetul when transferring large blocks of data to justify holding the Banshee processor. 
Through the same menory window, the host call access the dual-port memory while the Banshee processor is active. The dual-port memory is 8 Khyles: therefore, it is useful for smaller blocks of data. especially as it is slower than the Banshec static me'mory.

In the former two methods, a signalling profucol must be used hetwern the two processors since the memory cannot set any llags or activate any interrupts. In thow: lwil methods, the host DMA can be used to do the transfer, as is also the case in the following two methods.

A rather slow way of hlock communication is fo set up a channel hetween the hose DMA and the Bat.shee processor. This way, interrupts can be used lo relieve bulh processors from data transfier hut the Binshee processor reads one word all a lime.

The last method is the program $1 / 0$ ) data exchange, where the host writes lo a 4 -hyle $/$ $O$ register that can be read as a word hy the Banshec processor. Interrupts can he generated on either or both of the processors. This method is usctul for signalling the arrival of bleck data or the start or end of a program task; however, it is very slow for large data transfers.

\subsubsection{The Banshee Multiprocessor Interface}

The Banshee Multi-Processor Interface (MPI) daughterhoard connects multiple Banshec boards in a ring structure providing communications between each processor and its left and right neighbours. This interface provides multiprocessor synchronization, a comnom clock, a common hold and a DT-connection. The DT-connection provides a parallel datia port and an RS-422 buffered serial port for the motherhoard processior.

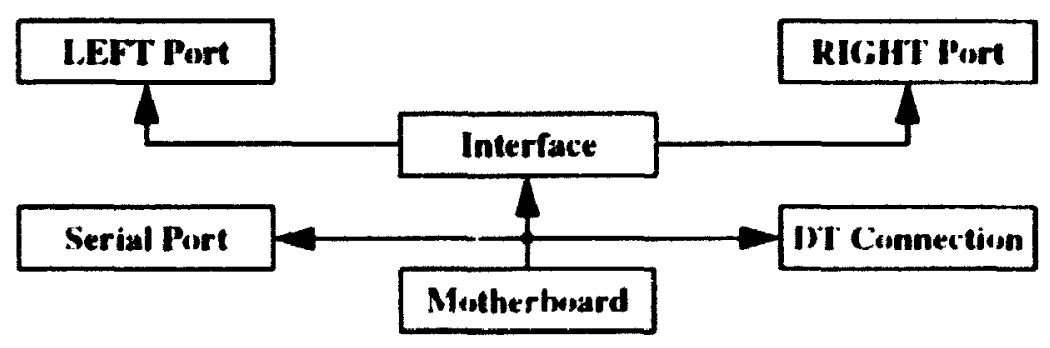

Figure 3-2: MPI Bkeck Diagram

The daughterhoard has a 2-Kword dual-preft memory buffer hetween processors with interprocessor memory allocation flags and interprocessor message status flags with interrupt capability. It also provides a common master clock, common SYNC, and hostcontrolled common processor HOLD for all processors. It provides the host with the status 
of SYNC and fIOLD signals. It has a Multi-Processor Interlace interrupt controller and a status port.

The interface is connected to the expansion hus of the motherboard and provides three ports; two to connect to the RIGHT and LEFT MPI boards. The third port provides an external serial interface through a D-type connector on the back of the motherboard and two 16-hit unidirectional parallel data ports through two 26-pin connectors for the DTconnection. The dual-port mentory on the MPI is mapped into both the memory and $1 / O$ address spaces of the motherboard processor The MPI has an interrupt control port accessible by the host.

The MPI interrupts and external ports can be configured by a Banshee processor write to the control register. Status can be read from the same register. Another control register is available to the host to control and monitor the common hold request, the common hold hus and synchronization signals.

\subsubsection{Interprocessor Communication}

A number of Banshec systems can be configured in a ring using the dual-port memory. Data can he passed from any system to its LEFT or RIGHT neighbour directly through the shared memory. Longer hops can be made around the ring or by the host's bridging the gap.

The dual-port memory requires one wait cycle from the Banshee processor, more if two processors allemp to a ceess the same word simultaneously. It can be accessed as VO or memory. When it is al essed as $\mathrm{V}(\mathrm{C})$ it can set or clear tlags and generate interrupts, but it is one cycle sle we lor read. This memory is a fast communication channel taking two cycles to read ard three cycles to write, so the peak bandwidth is one word per five cycles, which comes to 13.2 megahytes (Mhytes) per second, provided that only one processor at a time accesses the memory to avoid memory data conflicts. There is a mechanism for software access organizatior - flag is used for each LEFT or RIGHT channel to show whether memory is allocatc iree; however, access will not be physically denied if memory is allocated to the other processor. Nonetheless, physical access denial can be implemented using interlocked instructions. 


\section{4 \\ Single Processor Performance}

This chapter first presents performances of several single processor systems in order to establish comparative speeds for this application. The coding aigorithm was implemented with a $\mathrm{C}$ program which was run on a Sun 4/75, a 33-MHz. 386/387-hased PC. a 33-MI1/. 486-based PC and Banshee hoard machines. The 386 and 486 processsors were run in the Real Mode.

The program processed a 144-by-96 8-bit pel frame (depicted in Figure A-1). Table 4-1 and Figure 4-1 only reflect processing times; file loading and data transfier times: between the host and the processing elements are not included.

Tuble 4-1: Coding Abgorithm Performunce on Difterent System.

\begin{tabular}{|l|l|l|c|}
\hline \multicolumn{1}{|c|}{ System } & \multicolumn{1}{|c|}{ Operating System } & \multicolumn{1}{c|}{ Compiler } & Time (s) \\
\hline \hline Sun 4/75 & UNIX & GNU CC V. 2.3.3 & 10.54 \\
\hline 386/387-PC & MS-DOS & Borland C ++ V. 2.1) & 1.50 \\
\hline 486-PC & MS-DOS & Borland C ++ V. 2.0 & 10.811 \\
\hline Banshee & SPOX/AShell/MS-DOS & TI C V. 4.10 & $10.34^{\dagger}$ \\
\hline Banshee & SPOX $^{\ddagger}$ & TI C V. 4.10 & $0.35^{\dagger}$ \\
\hline Banshee & none (Assembly Language $)^{\ddagger}$ & TI Assembler $\because .4 .11)$ & 0.20 \\
\hline
\end{tabular}

$\dagger$. With less compiler optimization. processing tume may reach 0 (s)

$\ddagger$. This mole can be used for muluprocessing.

In the remainder of this chapter, examination is made of the performance of two single processor systems running the algorithm explained earlier (1n Section 3.1.2). The 
computational cost of the routines of the algorithm achieved below pertains to the completely optimized implementation of the algorithm. In high-level language implementations, there is additional overhead on top of the algorithmic computations involved.

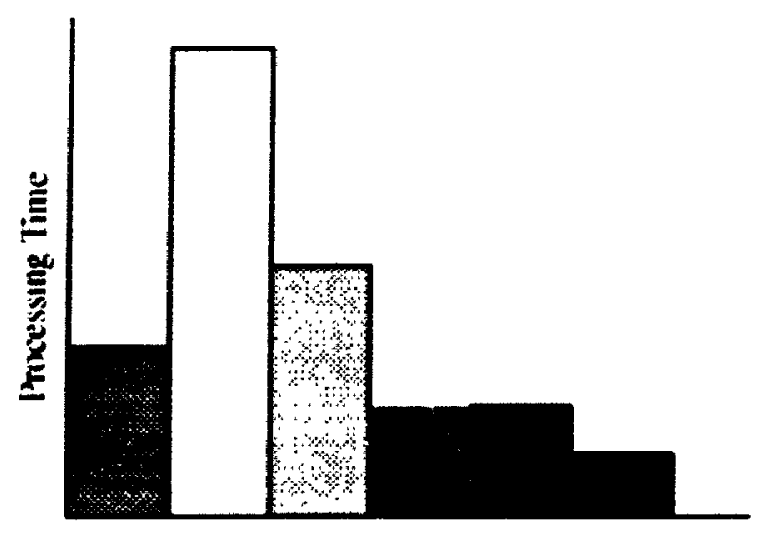

Computer System

Sun 475 $\square$ 386/387-PC $\square$ 486-PC Danshee with Ashell

Banstke wathout Asicll Banslee Assembly (without Ashell)

Fïgure 4-1: Comparative Performance Bar Graph

\subsection{Personal Computer Performance}

In this section. hrict examination is made of running the image coding and decoding algorithm presented in Section $3.1 .2 \mathrm{cn}$ a personal computer based upon Intel 80386 or $8(1) 486$ microprocescis)r.

The Intel 386 processor is a 32-bit microprocessor ${ }^{1+81}$, with 8 32-bit general-purpose registers. although the registers do not work identically. It has two modes of operation: Real Mode and Protected Mode. In the Real Mode, it operates as a very fast 8086 . In this experimental work, it was operated in the Real Mode. In this mode, the maximum contiguous memory segment size is fixed at 64 Kbytes. For data transfer, the shortest time unit is a bus state which is one processor cycle in duration. A complete data transfer requires a bus cycle which is composed of two or more bus states. Simple data transfers range from 2 to 4 cycles, and up to 7 cycles if simple arithmetic is involved.

When dealing with huge blocks of data, a particular architectural point of the processor is disadvantageous, namely. the limited size memory segment. Blocks of data 
larger than 64 Khytes must he partitioned among different segments or into extended or auxiliary memory and he switched hack and forth. When data involved is larger than ot11 Khytes. use of extended or expanded memory or auxiliary memory is required. Extended and expanded memories are managed by software intertaces $(+1) \mid$, which make's it detinitely slower than the processor's main memory. New compliers are available which run in the Protected Mode.

An instruction cache can be of benetit for speeding up a program if the conde is wrillen to use it efficiently by localizing code and using as lew branches as possible. In general. programs can be executed more efficiently hy optimization techniques usually integrated in optimizing compilers. Some of those techniques involve expression simplitication and alias disambiguation ${ }^{1 / 50 \mid}$. Data flow optimization, control flow and lowp optimization and in-line expansion of some code can be of a great effect on the program efficiency. Most often, expanding the program on larger memory can make it execule more efficiently.

The compression algorithm starts by calculating the superpels and triads, which are averages calculated by dividing the sum by an integer. This part is not computationally expensive; it takes about 10\% of the total processing time; Table 4-2 shows the details. There are six triads and one superpel to the calculated for each group of eighteen pels. Calculating the superpels can be optimized by coding them in Assembly language rather than using a general shift-and-subtract division algorithm. Calculating the triads can the sped up by using functional arrays if necessary, which means indexing the quotients hy the nominator values. In some special cases where the denominators are powers of two. divisions map directly into register right shifts. Then the calculalted results are disassembled into ATM cells. This part is lairly last and simple. It can be sped up only hy coding it in Assembly language. The pels are quantized by truncating low values to zero. A look-up table can be easily used to speed up this operation by saving hranches on comparisons.

The run-length coding used in this algorithm is more complicated than normal. Here the RLC coding is done so that the Huffman coding of the result will efficiently fit into ATM cells (see Section 3.1.2). Therefore, as the code is built, the Huffman code length is updated as every code byte is produced. It can be coded in Assembly language (1) achieve

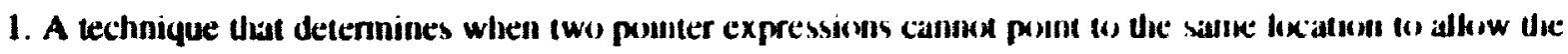
compiler to frecly optimize them. 
beller pertiormance.

Tuhle 4-2: I'enwonal Computer Time Cost of Subtusks

\begin{tabular}{|l|c|}
\hline \multicolumn{1}{|c|}{ Subtask } & Time (s) \\
\hline \hline calculate superpels, triads and pels & 0.2 \\
\hline disassemhle superpels triads to cells & 0.1 \\
\hline quantize pels & $<0.05$ \\
\hline run-length-encode & 0.1 \\
\hline Huffiman-encode & 0.1 \\
\hline introduce channal loss & $<0.05$ \\
\hline unpack cells to hytes & 0.1 \\
\hline Hutiman-deccode & 0.7 \\
\hline run-length-decode & $<0.05$ \\
\hline huild result pels & 0.1 \\
\hline total & 1.5 \\
\hline
\end{tabular}

The resulting run-length code from above is Huffman-coded. The coding is simple: codes are read from a coding array, their lengths are read from another array and the codes are shifted into a regisic: according to the code length parameter. The routine can be optimized by coding it in Assembly language.

The channel simulator routine takes the generated cells, the high-priority data from the disassembler routine above and the low-priority data from the Huffman coding routine and passes it through a geometrically distributed cell-loss function. The cells, pointed to by the random function, are replaced hy zeros. However, any other action of the algorithm can be taken, such as using the data in the spatially or temporally previous line. Each value of the random cell loss function involves one call to each of: a uniform random function; a logarithm function: a floor function; a division anc a multiplication. This random sequence can the generated beforehand and can be read from an array to save time.

Next, the high priority components, the superpels and triads, are disassembled from the cells into arrays. This is a simple routine that mainly involves shifting and masking. It 
can be easily implemented in Assembly language.

The Hutfman code in the low-priority component is deconded. This is the most computationally expensive routine in the program: it consumes approximallely $47 \%$, of the total processing time. The Huffman codes are searched linearly in a decirding lahke, in which the codes are sorted in descending order of trequency. The search can be done in the binary-search method to save about $30 \%$ of the time. However. a hetler search methixd can be designed to take into consideration the relative frequency of the cindes, since the upper half of the code table is considerably more likely to have the desired value than the liwer half. This is usually the case in most table partitions. Since this is a critically expensive part of the code. it is hest to he implemented in Assembly language. especially since it mainly involves searching and then shifting the code out of the conde register. according of its length, from another table, and storing the symbol in its respective lication.

The run-length decoding is computationally very inexpensive. It only involves reading run-length counts from the code array and transfierring data accordingly $(1)$ anowher array. Coding it in Assembly language can make it taster, but produces little improvement.

The last stage is adding the differential superpels, triads and pels together fo generalc the resulting frame, which involves two additions per pel. Three locops are required lir this task. Temporary variables can be used to save recialculation of array indices.

\subsection{Single Banshee Board Performance}

There are some program optimization techniques specific to the C.31) processsor hecauxe of its special architecture. The $\mathrm{C} 30$ has a large register tile that can be used for storing frequently-used pointers and variables to exploit the relative speed of accessing registers. Register variable tracking avoids reloading registers if they are to be reused som. Cistbased register allocation, autoincrement addressing, repeat blocks. parallel and conditional instructions and delayed branches are techniques used by the optimizing compiler. However, the programmer can help the optimizer, and make it more efficient. by avoiding complicated programming styles that decrease the efficiency of compiler optimization.

The C30 has 2 Kwords of fast internal RAM that can he uxed as scratch proxessing areas and variables, providing higher performance than off-chip memory It alsi) has an instruction cache that can be used efficiently by good design of the program (licaliaing 
code and minimizing branches).

Tuhle 4-3: Aunshee System Time Cist of C Program Subtasks

\begin{tabular}{|l|c|c|}
\hline \multicolumn{1}{|c|}{ Subtask } & $\begin{array}{c}\text { Time (s) } \\
\text { (without } \\
\text { optimization) }\end{array}$ & $\begin{array}{c}\text { Time (s) } \\
\text { (with } \\
\text { optimization) }\end{array}$ \\
\hline \hline unpack words into bytes & 0.023 & 0.007 \\
\hline calculate superpels, triads and pels & 0.090 & 0.023 \\
\hline disissemble superpels and triads to cells & 0.011 & 0.006 \\
\hline quantize pels & 0.060 & 0.040 \\
\hline run-length-encode & 0.110 & 0.053 \\
\hline Huffman-encode & 0.075 & 0.025 \\
\hline introduce channel loss & $<0.0005$ & $<0.0005$ \\
\hline unpack cells to bytes & 0.103 & 0.003 \\
\hline Huffman-decode & 0.343 & 0.149 \\
\hline run-length-decode & 0.028 & 0.014 \\
\hline huilding pels & 0.030 & 0.012 \\
\hline packing pels into words & 0.017 & 0.011 \\
\hline total & 0.890 & 0.343 \\
\hline
\end{tabular}

Calculating the superpels and triads accounts for approximately $11 \%$ of the total processing time; details are in Table 4-3. Analysis here is done on the unoptimized version to be compared with the unoptimized Assembly Language version in Table 4-4. Division was implemented by transtorming division (by a constant) into multiplication by the reciprocal of the constant divisor. In processors where fast multiplication is not provided. division can be optimized by coding it in specific Assembly language division routines instead of using less-efficient general shift-and-subtract division algorithms. Calculating the triads can be sped up by using functional arrays (where quotients are indexed via numerator values). The availability of floating-point arithmetic on this processor made it efficient at transforming integers to floating-point values and using unicycle floating-point multiplication to calculate the quotient. The floating-point quotient is then transformed 
back to an integer. The two transfiomations and one multiplication require three exectution cycles-faster than any integer-division routine.

Next. the calculated results are disassembled into ATM cells. This simple task can only te sped up by coding it in Assembly language.

The pels are quantized hy truncating low values to sero. A linek-up tahle can he used to speed up pel quantization hy saving branches on comparisons. This reduce's its cxecution time substantially.

The run-length coding can the programmed in Assembly language, achicving heller performance by minimizing the effect of hranches that consume most of this task time.

The resulting run-length code from the routine ahove is Hutrman-cinded. The cinding routine is simple, hut it involves reading codes and lengths from two arrays and shifting the codes into a code register according to their length. The routine can be uptimised hy conding it in Assembly language.

Each value of the geometric random cell-less function involves one call to each of: a uniform random number generator: a logarithm function; a floor function: a division and a multiplication. This random sequence can be generated heforehand and can be read from an array to save time. Using floating-point operations reduces the processing cost of the logarithm function. All calculations are made in floating-point arithmetic and the linal result is transformed into an integer value.

The high priority components, the superpels and triads, are then disassembled from the cells into arrays. This is a simple routine that mainly involves shifting and masking. It can be easily implemented in Assembly language.

Decoding the Huffman code is the most expensive task. taking athout $40 \%$ of the total processing time. It can be improved by the same methods suggested in Section 4.1.

The run-length decoding only involves reading counts from the array and transfitring data accordingly to another array. Coding it in Assembly language can make it faster, but it is not a time-consuming task.

Building the result frame from the superpels, triads and pels is identical to the case in the previous section. The main computational cost is address arithmetics.

The temporary arrays for keeping superpels, triads, pels, and run-length code while calculating can be allocated in the internal memory since writing to external memory takes double the time of writing to internal memory. 
In the multiprocessing experiments reported in the next chapter, an Assemblylanguage version of the above program was used hecause of its relative ease and accuracy of interaction with the hardware and timing measurement. Because of the overhead of high-level languages mentioned earlier, the assembly-language program is over four times faster than its $C$ counterpart; set Tahle 4.4 tor details. It, l16), can he further optimized, in buth coding and algorithms of individual lasks.

Table 4-4: Aannshee System Time Cost of Assembly-Ianguage Prongram Subtasks

\begin{tabular}{|l|c|}
\hline \multicolumn{1}{|c|}{ Subtask } & Processing Time (ms) \\
\hline unpack words into hytes & 3.8 \\
\hline calculate superpels & 2.2 \\
\hline calculate triads & 8.4 \\
\hline disassemble superpels and triads to cells & 1.5 \\
\hline quantize pels & 12.3 \\
\hline run-lingth-encode & 24.1 \\
\hline Huffman-encode & 15.8 \\
\hline introduce channel loss & 0.1 \\
\hline unpack cells to hytes & 2.4 \\
\hline Hufiman-decode & 110.9 \\
\hline run-length-decode & 5.0 \\
\hline adding superpels to pels & 5.2 \\
\hline adding triads to pels & 4.5 \\
\hline packing pels into words & 3.6 \\
\hline total & 199.8 \\
\hline
\end{tabular}




\section{5 \\ Multiprocessor Performance}

This chapter addresses the processing of the algorithm descrithed in Section 3.1 .2 on twil of the Banshee boards described in Section 3.2. The processurs are comnected in a ring and each is also connected to the host computer as illustrated in Figure 5-1. The hest compuner can address all the memory address space of any of the PEs and each PlE halres a manl box memory with its neighhour ${ }^{[6]}$.

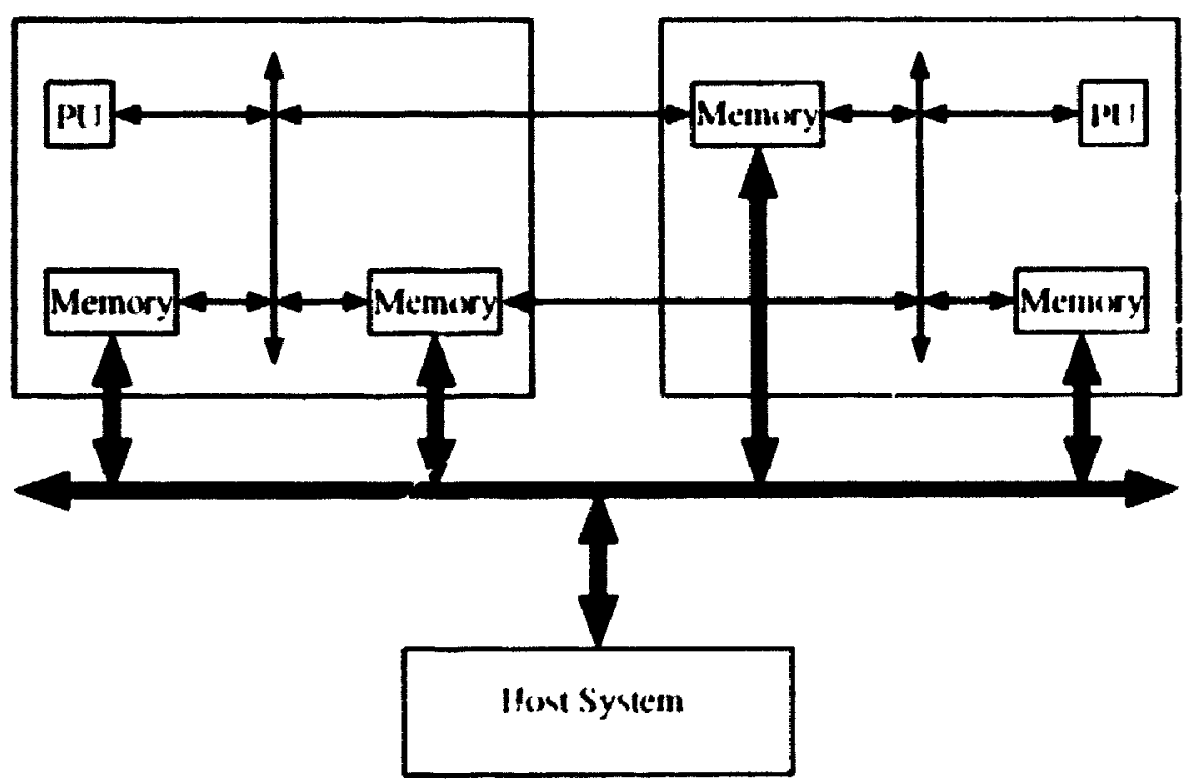

PU: Processing Unu

Figure 5-1: System Architecture

As documented in Table 4-1, the program execution time is (1.20)econds when it is run on a single Banshee system board. The overhead added to this processing ume by the M: 
data transters 10 and trom the frard's local memory makes the total time 0.209s. Ideally using two Banshee system hoards in parallel should pertorm the processing task in half the time requrred hy a sngle hoard. However, achievement of this performance is impeded by the eneflecency and averhead imposed by splitting the processing unfairly between processurs, as well as the time required for interprocessor communication. In elfect. the overhead caused hy loading data to the Banshee memory is constant, therehy reduces the multiprocessing gann. This orerhead hecomes more pronounced as the number of processors increases.

The program timing dissected for a single processor requires $0.080 \mathrm{ks}$ sor the top half of the image, and 1.1197 . for its lower halt. The difference is due to the difference in image complexily helween the two parts of the picture. The program stages, for a complete image. consume $0.06 \times 4$ s for simulating the coding ar.d transmission stage (from source encoding 61) simulating the channel loss), and 0.1317 s for simulating the reception and decoding stage (the reverse process of achieving the result trame). This makes fair load sharing per frame not readily possible. The following sections discuss various methods for load assignment hecause no general solution of the load balance prohlem has been achieved.

\subsection{Star Architecture}

In the star arebicieture, the processing elements operate in a SIMD' mode with the host processor operating as the controller. However, it is not a light SIMD since each PE has its own instruction stream stored in its local memory. Nonetheless, the host processor distrihutes data to the PEs, signals them to start and collects the results. In this mode, the PEs are completely controlled hy the hos processor hecause it provides each of them with 1/6) services and operation control.

In the experiments reported on in this section. each PE excedted the coding algorithm explained in Section 3.1.2. Data is loaded into the PE local memory and then the PE is signalled to start processing. When the PE completes its lask. it signals the host processor to diwnload the results. The processed images resolution is 144-t.y-96 8-bit pels (see Appendix A).

1 In a truc SIMII) swicm, motructons are broadcasted by a controller and are executed by all processors at

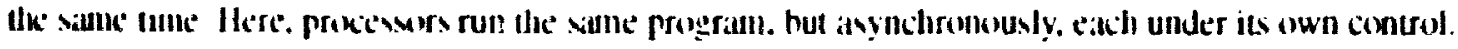


The follow ang sections evaluate spattal and lemporal data destributun sehemes.

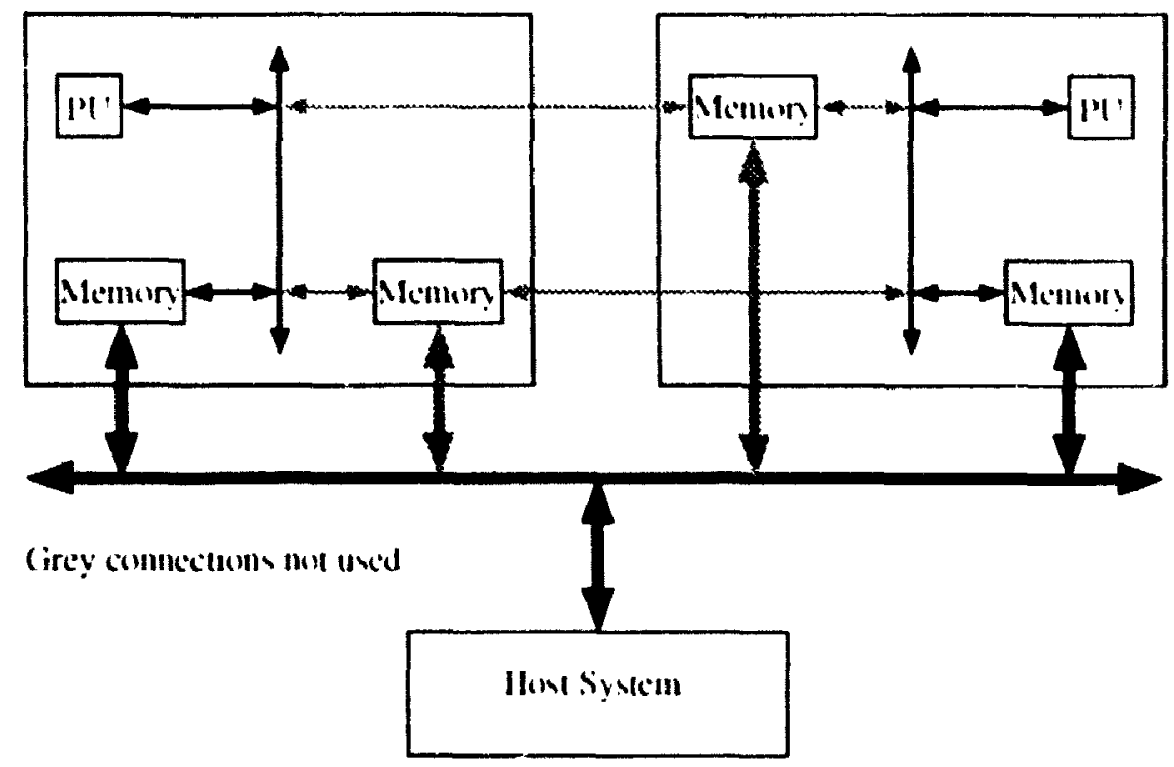

Figure 5-2: Star Configuration

\subsubsection{Spatial Data Blocking}

In this mode, each incoming trame is partitioned into a number of nlocks. The dalla blokeks are then distrihuted to the PEs. The spatial location of a hlock wilhin a frame decides which PE to be assigned (o. Depending on the coding algoruhm, a Pl: maly have ou process blocks of the same spatial areas in each frame, such as in intertrame coding scluelle's. In the experiments conducted, the image frame was split into two blocks.

The absence of data dependencies among hlocks allows images to map nalurally 10 this architecture and permits PEs to process hlocks in parallel with no mterprocessor commul. ation overhead. In this architecture, the overall system pertiormance is hounded by the slowest PE. In the experiments conducted on this contiguration, onle Pl: was ahout

50) ${ }^{1}$ slower than the other hecause of the relative complexsly of lis load share. The necessity of holding the PEs idle while data was transterred in and oul of lleeir focal static memory increased the overall processing time $1010.126 \mathrm{~s}$ (1rom 0.11975). This overlead comprises loading the two data hlocks to the boards and unloading anly the second block

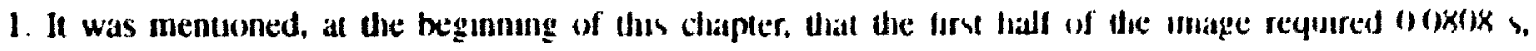
whereas the second half required 01197 s processung unie 
from the hoatd. The total overhead tince amounts to ahout $19.75^{1}$ of the 0.0 (1) 9 -s overhead of the uniprocessor case, which is the expected performance of this configuration.

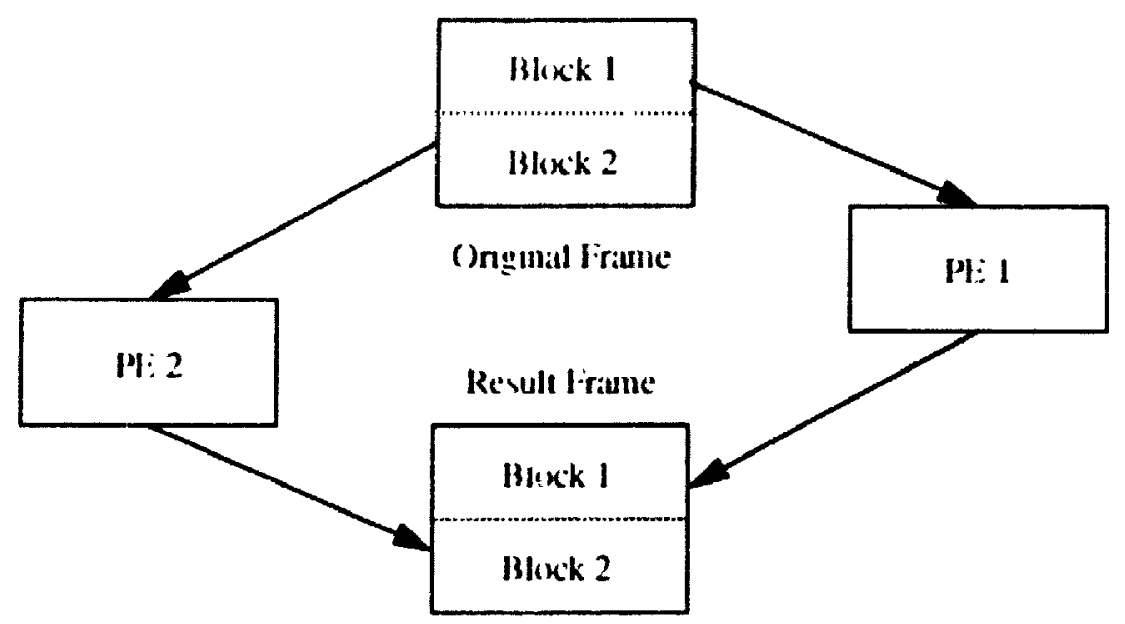

Figure 5-3: Spatial Bleck Distribution Scheme

This contiguration required about $59.8 \%$ of the processing time and about $63.0 \%$ of the lotal curn-around time of the single processor mode.

\subsubsection{Temporal Data Blocking}

In this conliguration. Incegral frames are assigned to PEs. For the intidfame coding schemes, this architecture is often more suitable than the previous one. In this architecture, the processing load is, on the average, shared fiarly hetween the processors because the temporal redundancy maps into similar computational complexities of subsequent frames. This configuration is optimal for intraframe coding schemes.

Due to the fair laad distribution in this case, the processing speed was twice that of the uniprocessor case, requiring $0.10 \mathrm{~s}$ per frame. The data transfer time overhead raised it to 0.107s. Theoretically, it should have heen $0.1045 \mathrm{~s}$, but in this experimental case loading the two frames is overhead. whereas the unloading of only a single frame represents overhead. This makes the overhead time 0.75 of the uniprocessor case, rather than 0.50 of it (as in Section 5.1.1). Datat transfer time was slightly less than that of the previous case hecause half the menory switching time was saves hy transterring a complete frame at

\footnotetext{
I The tirs hlixh was already unloaded since the first processor tinished well thefore the second
} 
once rather than a ha!f-irame hlock.

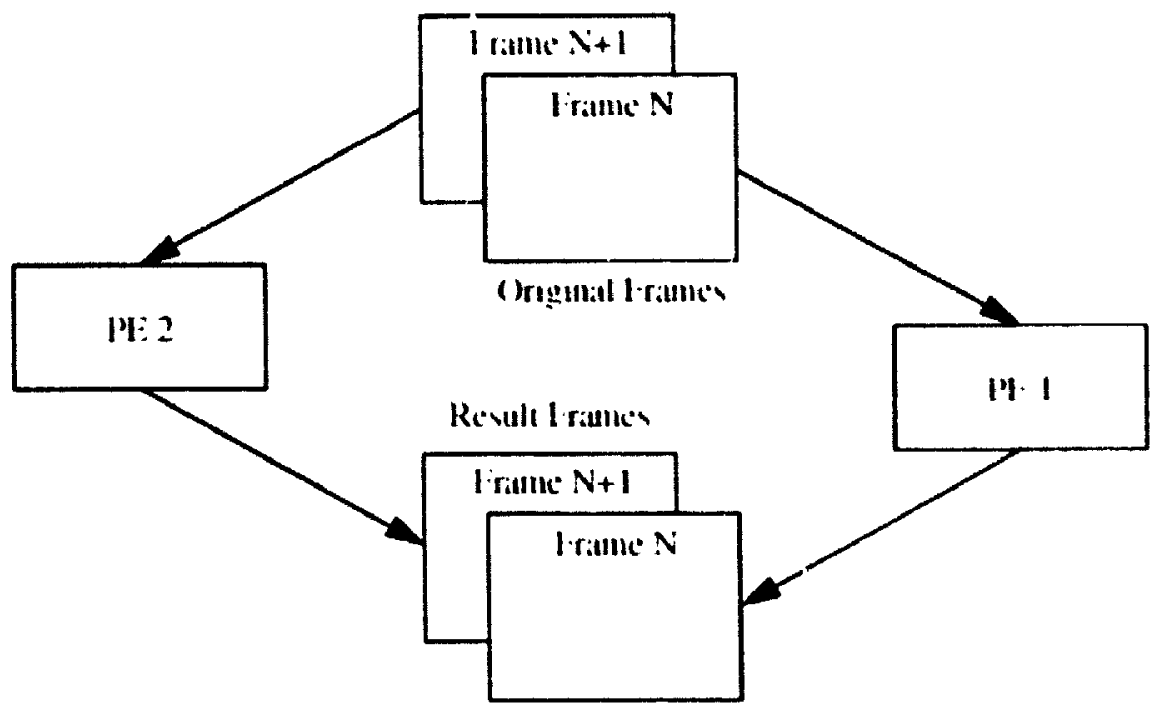

Figure 5-4: Temporal Block Distrihution Sichene

This configuration took $50.1 \%$ of the processing time, and $51.2 \%$ of the foltal turn around time of the uniprocessor mode.

\subsection{Pipelined Architecture}

This architecture operates in the MISD mode. The data stream enters the system at the start of the pipeline. A PE processes the data stream by exectuting its functional part of the program and passing the partial results to the next PE. At the end of the pipeline. the resulting data is collected hy the host processor. Figure 5-5 Illustrate's data llow paths between processors.

This architecture is suitahle for casts where the complete lask divides anto a number on approximately equally complex, simpler suhlasks. In the se cases, each Pl: proglann can be optimized for one subtask. This contiguration allows for hoth temporal and spatial data dependencies. In this configuration. approximately all the data needs to he passed a number of times equal to the number of units in the pipeline. Transfierring data in parallel with processing can conven the pipelining overhead to time delay. In that case, the maximum data transfer rate is the upper bound for system throughput.

The aforementioned algorithm was divided into two parts: the encodeng part and the decoding part. The following sections investigate various methods of interprocessor 
communication (1) reduce the pipeline overhead time.

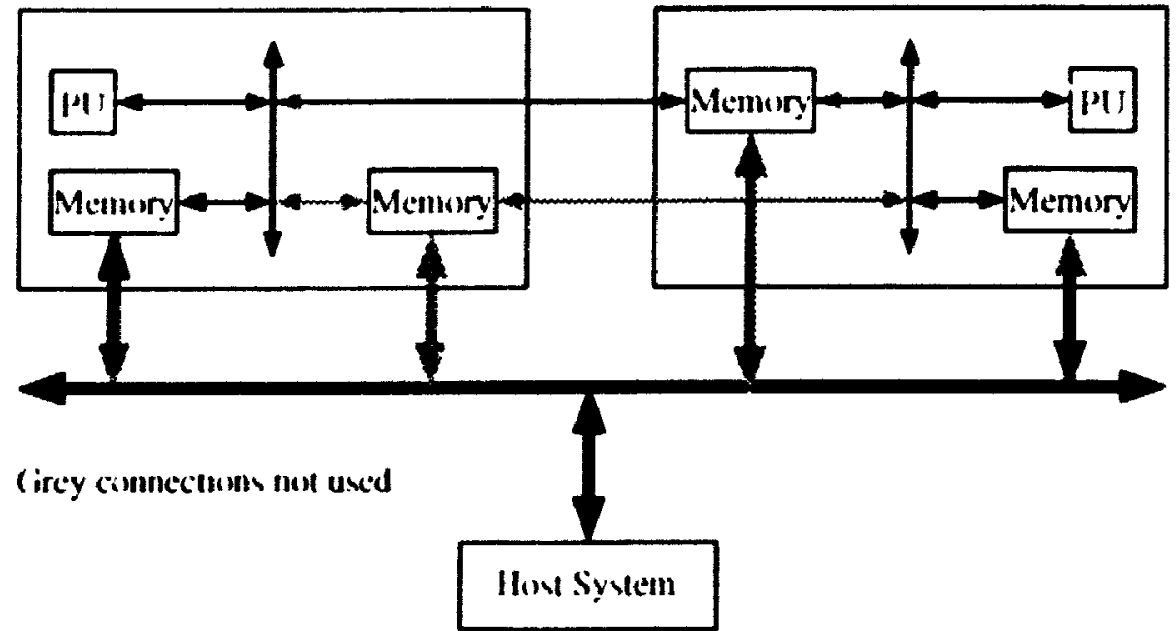

Figure 5-5: Pipeline Configuration

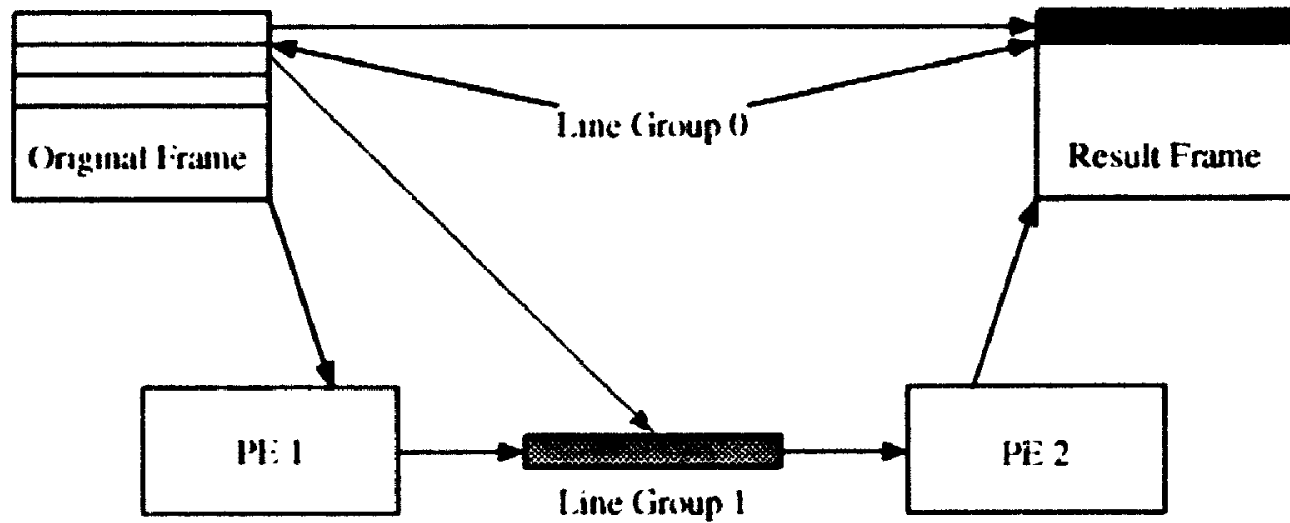

Origunal Intermediate Result

Fingure 5-6: Piping Line Groups

The data size involved in the pipeline is $\mathbf{3 8 6 0}$ (32-bit) words. Each word requires 3 (fo(l-ns) cycles to be written to the $\mathrm{V} / \mathrm{U}$ ) buffer or read from there. Added to that, is 1 cycle to read a word from the processor likal memory and 2 cycles to write it there. This amounts (1) 4 cycles per word to transfer out, or 5 cycles to transfer in. However, using the C30 processor:s husses in parallel cals reduce this to 3 cycles per word in either direction. That amounts $(1) 1390 \mu$ s for piping the complete data frame, reading and writing. The total transfer overhead was measured to he $1.0 \mathrm{~ms}$ for piping out and $1.3 \mathrm{~ms}$ for piping in. The 
net overhead. which is slightly less than 9)( $\mu s$. can he slighly reduced hut cammon he eliminated in any communication scheme. However. the actual transter time may he considerably reduced or eliminated. A more serions prohlem than the communicaltion overhead is idle waiting for buffer access.

\subsubsection{Program-Driven Communication}

The interprocessor communication method used in this calse is direct reading and writing: to shared mailbox memory under program control. A processior wrile's the desired data la the mailbox memory, and the next processor reads that data from there. The lirst processur cannot write the next data hlock until the next prokessor reads the previous one.

This method forces the two prokessors to he synchronized in the sense that a prokessior stays idle until the previous processor tinishes the data bleck it is working on, and if it finishes its task, it cannot pass it along until the next processor finishes proxessing its previous data hlock. This adds waiting overhead on top of the overheiad of data passing. The load distribution ratio was ahout $1: 2^{1}$ : therefore, the lirst processor had 10 always wait for the next processor to read the previous data batch.

This method required (0.1349 s. Thus, it is slower than the parallel spatial data hlikeking method $^{2}$ by $12.6 \%$. It took about $67.4 \%$ of processing time and pipeline delay ${ }^{3}$ as the reference single processor mode.

The above configuration divided the processing load in a 1:2 ratio, with the second processor being the bottleneck. When the load was redistributed hy programming the first processor to perform parts of the Hufiman deconding originally intended for the second processor, a $1: 1^{\dagger}$ load sharing ratio was achieved, with a very slight additional arrangement cost of $1 \%(1 \mathrm{~ms})$ of the total time of each processor. The lotal processing time was reduc:ed to $0.1102 \mathrm{~s}-55 \%$ of the uniprocessor case.

Waiting for buffer access accounts for most of the overhead time. Without waiting for

1. Recall that the first stage of processing takes 0.168ts and the second stage takes () $1317 \mathrm{~s}$

2. This method was selected for comparison due to its flexibulity to lend itsell to mure condeng scliemes

3. The host data transfer time was not included here because il represents a comstant delay independent of use pipeline scheme.

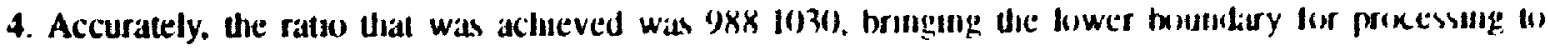
$0.1030 \mathrm{~s}$. 
hutfer access, the suhprograms require $99.9 \mathrm{~ms}$ and $114.1 \mathrm{~ms}$, respectively. Waiting time for huffer access. excluding data transfier time, was $2.1 \mathrm{~ms}$ and $6.2 \mathrm{~ms}$, respectively. Actual data transfer time was $1.16 \mathrm{~ms}$ and $11.93 \mathrm{~ms}$, respectively. Total execution time was $102.0 \mathrm{~s}$ and III.2s, respectively.

Tahle 5-1: Comparisun of CPU and DMA Transfer Schemes ${ }^{+}$

\begin{tabular}{|l|l|l|}
\hline \multicolumn{1}{|c|}{ Aspect } & CPU Transfer & DMA Transfer \\
\hline \hline PEI Idle Waiting & 2139 & 2463 \\
\hline PE 2 ldle Waiting & 6201 & 6042 \\
\hline PE I Total ${ }^{\ddagger}$ Communication & 3198 & 3468 \\
\hline PE 2 Total ${ }^{\ddagger}$ Communication $^{\prime}$ & 7128 & 7419 \\
\hline PE 1 Minimum ${ }^{\ddagger}$ Waiting & 84 & 84 \\
\hline PE2 Minimum ${ }^{\ddagger}$ Waiting & 105 & 105 \\
\hline PE 1 Minimum ${ }^{\ddagger}$ Communication & 984 & 1092 \\
\hline PE 2 Minimum ${ }^{\ddagger}$ Communication & 1014 & 1488 \\
\hline PE I Execution Lower Bound & 99855 & 99966 \\
\hline PE 2 Execution Lower Bound & 104142 & 104616 \\
\hline
\end{tabular}

†. Times are in $\mu s$.

‡. "Tinal" refers to inormal processing times, 'minimum' refers to cases where a pricissin is outputting/inputting dita as fast as the other processor can handle, such that there is no idle time

\subsubsection{Program-Driven DMA Communication}

In this experiment, the direct memory access method is used to pass data instead of the CPU. The CPU stays idle while the DMA transfers data because of the data synchronization problem described above (Section 5.2.1). The DMA controller is optimied for memory and $1 / 0$ data transfers, hut in the case of RISC (reducedinstruction-set computer) processors, there is often no improvement in performance if the C.PU idles while the DMA is working. The DMA requires 3 cycles to transfer a word, which is equal of that which the CPU requires for the source and destination used in the program. In this experiment. there was no noticeable improvement on the results in the 
previous section. Table 5-1 compares the two methods.

Although using DMA in this sense docs not improvec on the previous methed. it provides usciul information lo be used in subseyucnt sections.

Tahle 5-1 shows that. even when PEI's share is less that Pl:2's, smerime's Pl:2 walls idly for PEI to finish a data hatch. Part of this wating is duc to the latency of Pl:I to start piping data out. This is generally the case fior a pipeline system.

\subsubsection{Interrupt-Driven DMA Communication}

In previous pipeline configurations, the second proxiessor, PE2, was the hollleneck of the pipeline due to the relative complexity of its load. Relieving the processors of the communication overhead would not make a very signilicant improvement on perliormance (because it does not modity the processing load assignment). hut it will make solving the more important problem (idle waiting) easier laler (Sections 5.2 .45 .2 .5 ). The first processor's (PEI) communication overhead can the reduced to only initialising the DMA. leaving actual data transter to the DMA. This contiguration increases the idle waiting lime of the first processor from $2.14 \mathrm{~ms}$ to $2.67 \mathrm{~ms}$. hecause it now procieds laster and must wait longer for the second processor. However, it also reduces the overall communication time from $3.20 \mathrm{~ms}$ to $2.75 \mathrm{~ms}$ because the processor does not perform the actual data transfer. The second processor (PE2) is sped up hy ( $0.2 \mathrm{~ms}$ which is the overall speed-up of the pipeline. Making the same moditication (using interrupts (1) drive the DMA) on the receiving end speeds up both processors by also cutting down on the idle walling. It increases the idle waiting of the second processor from $6.11 \mathrm{~ms} 106.2 \mathrm{~ms}$ hut reduces the communication time from $6.9 \mathrm{~ms}$ to $6.3 \mathrm{~ms}$. achieving a total speed-up of $0.33 \mathrm{~ms}$. Modification of both programs reduced the overhead from $10.2 \mathrm{~ms} 109.67 \mathrm{~ms}$, which is an improvement of $5.2 \%$. This corresponds to $54.8 \%$ of the uniprocessor execution time.

The first CPU data transter overhead can be minimized if the processor doces not wait idly at all. This can be done by programming the CPU to initialize the DMA (o start the transfer, resume its processing and leave the rest 10 an interrupt service routinc activated at the end of the DMA transfer. This interrupe notities the next precessorr of the arrival of data and releases the shared data to he read hy the other processor. However, even in this case. the DMA transfers rarely conflict with CPU memory accesses. This memory contenton adds a slight proportional cost to the DMA constant incremental cost. This cost is a cycle for several word transfers. 
Al the receiving end, data arrival activates a data reception interrupt service routine which stans the DMA transier process. At the end of the DMA transfer, another interrupt occurs to release the shared communication hulfer memory and to llag that the data is then inside the processorr's lical memory. However, this contiguration miy cause huffer overrun if hulfered transler is nol supporled. This is addressed in the following section.

\subsubsection{Buffered Interrupt-Driven Communication}

In the previsus experiments, the synchronization hetween processors, to maintain data integrity. calused idle waiting for communication huffer access. A method for independent $I /()$ is required to hreak this synchronization and allow processors to work independently and, therefore, elficiently. Independent $I /()$ can be achieved by implementing a twopointer circular hulfer at the receiving end. In this configuration, the transmitting processor sets the DMA to make the data transfier. When the DMA completes the transfer, it interrupts the processor to release the shared mailbox memory.

At the receiving end, an interrupt service routine is triggered by data arrival. This interrupt routine sets the DMA to transfer the data to the circular buffer in the PE local memory. When the transfer is complete, the DMA interrupts the receiving processor to release the shared memory.

The interrupt part of the program (at the receiving PE) inserts data to the buffer at the end-ot-butier queuc pointer and the sequential part of the program reads data at the heginning-of-hutfier queue pointer. When the heginning of the queue coincides with the end of the queuc. the queue is empty. In the empty queve case. the program idles until an interrupt occurs. In this case (buffer underflow), the program leaves the busses for the DMA and transfer occurs at maximum speed.

The CPU transfer version of this configuration is slower by a time period depending on the transfirred data block size. This is hecause the DMA setup takes a constant lime regardless of the data hlock size, whereas the CPU-access transfer method consumes time in proportion to the size of the data transtierred.

This setup relieves both processors of most of the communication overhead. However. in the casc of huffer undertlow. the program at the receiving end must wait idly. The remaining overhead (which is not eliminaled) is proportional to the frequency of the Iransfers. not to their sizes. There is new overhead introduced at the receiving end by the bulier management software. Data is transferred twice, once from the shared memory to 
the buffer (under interrupt control) and again from the huffer to the data arrays (under sequential program control). This increases the werall werhead hy 0 .6\% and makes it slower than the unhuffered scheme ahove (Section 5.2.3). This prohle'm is addrenced in the next section.

This configuration achieved a prokessing time of 56 , of the single processort case $12 \%$ slower than the ideal.

\subsubsection{Delayed, Buffered, Interrupt-Driven Communication}

Most of the communication overhead incurred in the previous case's wats callocel hy idle waiting due to huffer underllow. Bulfer underllow can he avovided if the transinilling: processor starts a sufficient amount of time bofore the receiving ome. In this case. when processing of the frame at the receiving processor commences. a sullicicolly si/ced part in the data has already been received. The underllow of the hulfier call be gualranteded never lo happen if the processing load is fairly distribuled and this is usually possible sinece parts of the processing can be moved from one processior to the other. especially in the case of computationally cost-constant algorithms. Once the steady state is reached. the system speed becomes the average speed of the slowest processing unit.

If the case of huffer overtlow is likely to happen. another circular hulfer ein ix: implemented at the transmilting end. Then. the transmitling buffer status can the checked each time the shared memory is read. However, huller overtlow or undertlow can he avoided by increasing the size of the receiving hutfer (if possible) and hy distributing the load reasonably among the processors. This also saves the additional management overhead required by implementing another hulfier.

This implementation achieved a processing time slower by $3.7 \%$ than the ideal case of dual processors (103.7 ms), i.e.. $51.8 \%$ of the single processor case.

\subsubsection{Reducing Buffering Overhead}

The overhead involved in the preceding section consists of (wo parts: the IDMA management overhead and the circular hutfer management overhead. DMA managentent overhead is proportional to the number of transfier hatches per trame but almost independent of the data batch sizes. Circular huffer management is proportuonal to the siac of data involved (it also includes a very small component which is propertional to the frequency of transfers). This scheme is the fastest of the pipelining configurations 
exaliained in this chapter.

DMA management cost can be decreased by reducing the number of data batches. which means increasing the hatch size. This configuration requires larger memory to hold data hulfers. Buffer management cost can be minimized hy transferring data directly to the circular huffer without passing thromgh the shared memory stage. This is only possible if the circular huffer can he allexaled in the shared memory. which requires a larger size of dual-port memory. Memory contention does not happen when the two processors access the shared huffer simulancously hecause one processor writes at the end of the buffer and the other reads at the heginning of the hutier.

A limitation of this contiguration is encountered in the case of a full. small or almost full huffer. The hufler transmitting processor waits until the receiving one reads its data and updates the huffer pointer. despite the possibility of its writing data while the other proxessor is reading (writing is slower than or as fast as reading). This can be solved by the reading processor updating the pointer directly before it starts reading. A fair statistical share of the processing load and a sufficient size of the shared memory buffer can achieve optimal pipeline deficiency.

Reading a word from the shared memory and writing it to the local circular buffer memory in parallel takes 3 cycles and transferring it to the data arrays takes 2 additional cycles: hence. every word costs 5 cycles besides the incremental cost of setting up for the Iransfer. However, if the circular huffer is allocated in the shared memory, it takes only 3 cycles per word to transfier data from there to the data arrays, therehy saving 2 cycles per word. For the frame size used in the experiments, that amounts $t 00.4 \mathrm{~ms}$ in addition to the incremental cost saved. This setup also allows for the overlap of shared buffer reading and writing. which makes the peak throughput of the buffer approach 0.33 words per cycle (or abuut 176 Mhps).

These methods can hring the proxessing time down to about $51.2 \%$ of the single proxessur case.

\subsection{Hybrid Architecture}

It is pussihle lu combine proxessurs in a general mode where data is transferred between the processing clements themselves and between the processing elements and the host in hoth dircctions.

This general contiguration requires an increase in the program modularity, additional 
interprocessor communication and protocol complexity. The additional comple vity results in a shorter processing time. Depending on the type of algorithm. stuch a comlyguration may te impossible to implement or he complex heyond heing henelicial or lieasibie:

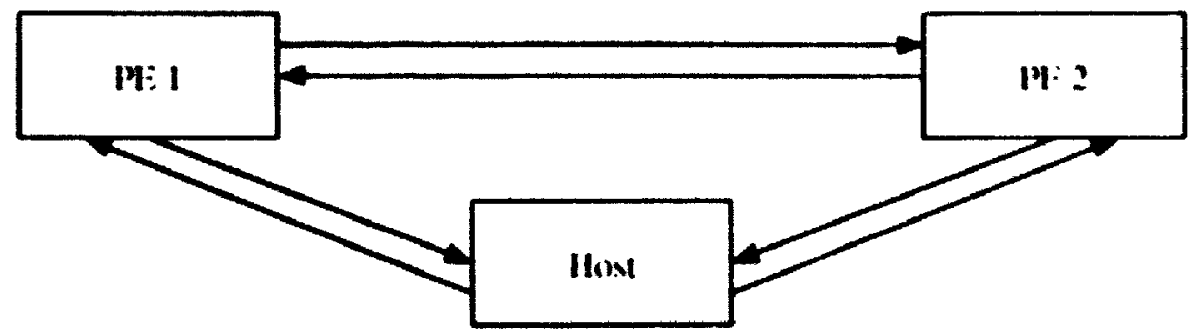

Pigure 5-7: Data Paths in Hỵhrid Architedtures

However, this configuration can the implemented edsily in the casces of low-kevel processing algorithms that do not require a temporal history of data and do not have spattal dependencies. In higher level processing algorithms, transfier of the exciess lobd (o) alluber processor may require transfer of much larger-size temporal and spatial dalla and may cost more time than performing proxessing on the same processior.

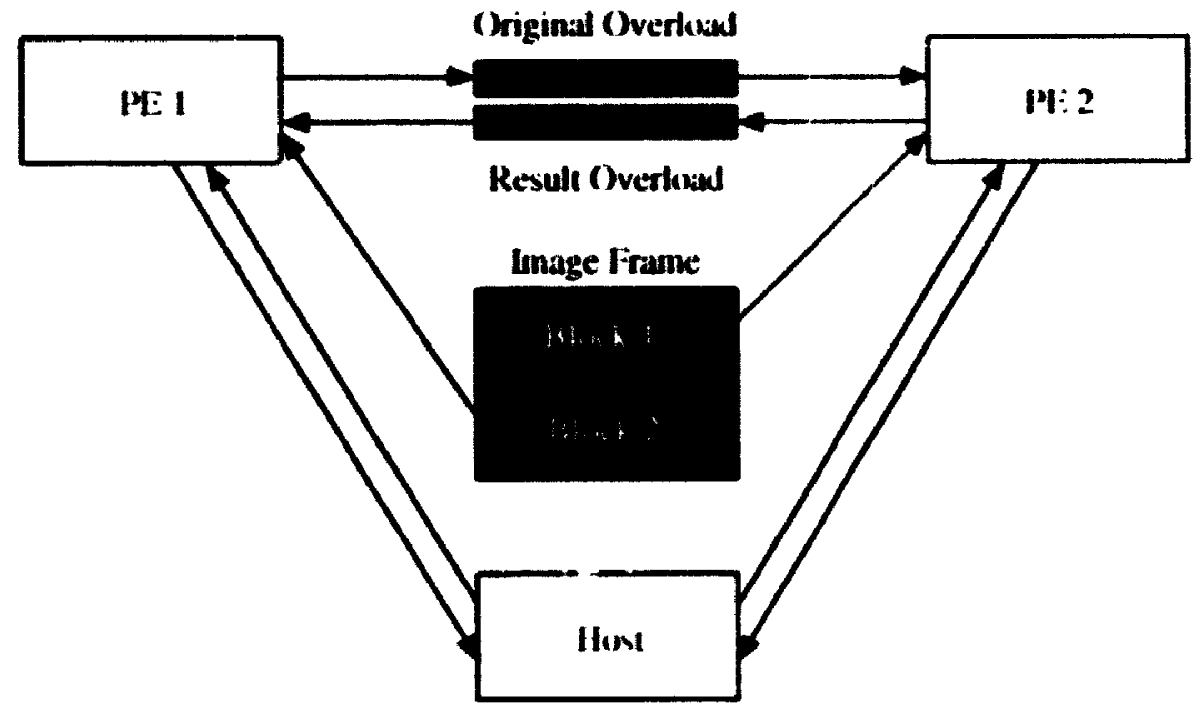

low lintropy $\quad$ Ihgll I:nirupy

Pigure 5-8: Overlowed Sharing

The algorithm investigated in this chapter is low-level. In this casce, al the termination of processing the local data, a processor signals its neighbour. The neighbouring processor checks whether there is sufficient data $(0)$ be shared. If $s)$, it sends the data (1) the (other 
prokessor which makes the processing and returns the data to its original source. Finally, the host collects the data from the processors.

This implementation incurs an additional constant cost of the slow processor to Iransfer the data and receive the results. but this cost is only incurred if the remaining data takes more time (I) prokesss. (On the receiving (faster) end, the processor requires the same lime to reccive and then transmit the data hack; however, it stays idle at least part of the reception time. If the faster prokessor waits idle in any case then it is justifiahle to incur that cost.

Assuming the same algorithm with the distributed ratio of $2: 3$ (4:6). the rcmaining data at the completion time of the first nrocessor will be $20 \%$ of the total data. The remaining 201\% must he shared equally hetween the two processors because the data transmission between processors is so fast that it can be ignored. This part of the algorithm is similar to processing this $10 \%$ part in pipelining except that the second processor perfiorms all the proxessing-double its share of a pipelined $10 \%$ portion-which is equivalent to $20 \%$ of a pipelined frame processing. Since this lo\% load is piped twice the second time it returns (1) its origin), its transmission time is also equivalent to that of a pipelined $20 \%$ load. Hence. the total processing time is $80 \%$ of the star processing time (Section 5.1.2) plus 20\% of the pipeline processing time (Sections 5.2.1-5.2.3, depending on the data transfer method used). The additional overhead to the ideal star case (Section 5.1.2) is 20\% of the pipeline overhead provided that the load ratio variability is less than the overhead ratio (i.c.. this overhead time is greater than the processing time difference between the two processiors including run-time redistribution). Because of the receiving processor's idle watt. this case cannot he partially compared to the huffered communication cases. so the processing time will be atwut $51 \%(0.8 \times 5(0 \%+1) .2 \times 55 \%)$ of the single processor mode. Including the data transfer time hrings it to $52.1 \%$ of the reference case. This configuration is faster than the pipeline configurations discussed in Sections 5.2.1-5.2.5 but its complexity is noticealbly higher.

Other combined architectures require more than two processors. This is investigated in Chapler 6.

\subsection{Summary of Results}

Table 5-2 and the bar graph in Figure 5-9 summarize the results of this chapter, showing the processing time of the different two-processor configurations as a percentage of the 
single processor cases.

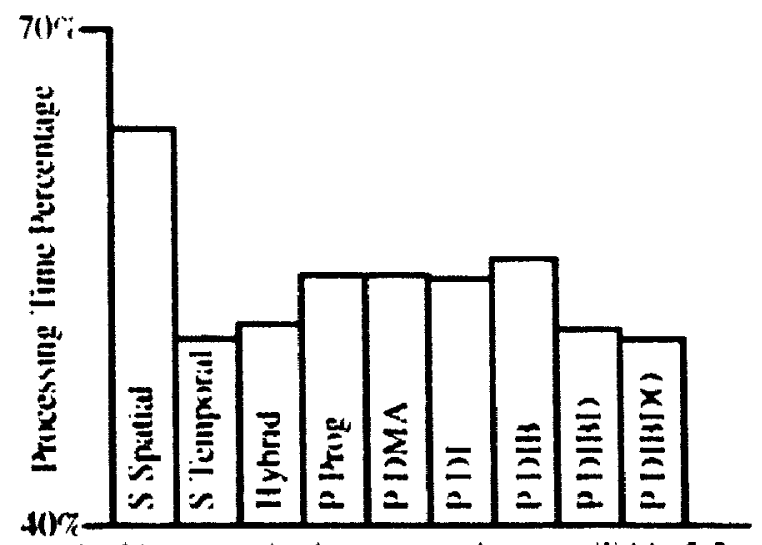

Archilectures in the sitne arder ats in lable 5-2

Pigure 5-9: Hipronesior Comparative Har Ciraph

Table 5-2: Biproxessior Limparative Performance

\begin{tabular}{|l|c|}
\hline \multicolumn{1}{|c|}{ Architecture } & Percentage \\
\hline \hline Star Architecture, Spatial Segnentation & 63.9 \\
\hline Star Architecture. Temporal Segmentition & 51.2 \\
\hline Hybrid Architecture (Overload Sharing) & 52.1 \\
\hline Pipelined Architecture, Program Transfier & 55.11 \\
\hline Pipelined Architecture. DMA Transtier & 55.1 \\
\hline Pipelined. DMA. Interrupts & 54.8 \\
\hline Pipelined, DMA. Interrupts, Butfered & 56.1 \\
\hline Pipelined, DMA. Interrupts, Buttered, Delayed & 51.8 \\
\hline $\begin{array}{l}\text { Pipelined. DMA. Interrupts, Butfered, } \\
\text { Delayed. Overhead Reduction }\end{array}$ & 51.2 \\
\hline
\end{tabular}

$\leftarrow$ Percentages of single processur prikessing unke

The difference in performance between the two star configurations is due to the load imbalance in the spatial segmentation mode. In these conlgguratoons and in the hybrid configuration, the reported time includes data transfer between the host and the prixessung elements because this time depends on the number of processors and because the host capacity afiects the performance peak of the system. In the hybrid architecture, the 
processing lovad a douded evenly helween the processurs, hut there is an overhead addhenal to that in the lemporal slar case hecause of data transler hetween the two PEs. bence the delference in performance.

I'smg IDMA tramster instead of CPL' transier did not improve on the performance of

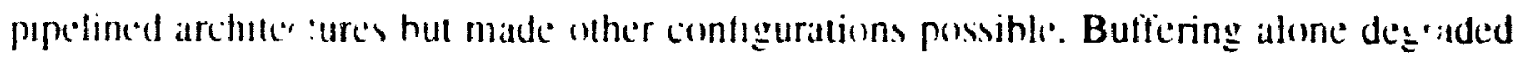
performance hul made isclastion of the PEs posshle. That improved the pertormance. permilting reduction of the hulferme overhead. 


\section{6 \\ Extension of the Architecture}

In Chapter 5, experimental resules on muluprocessing wete pesconted. In the chaplet. the significance of these results is discussed. They are then generalied to cases mulving larger numbers of processing elements. Archilectures afe discuswed which heip) dalla in one single stream, which divide dali in parallel and, which combine hosh.

Figure 6-1 depicts the default archilceture of a video processing system. The sminle'st architecture of the system includes a single processing element. The fixed-rate Inpul stream carrying the raw video data is processed sequentially to produci the lixed-rale output stream that carries the resulting video stream. To increase the viden system throughpul. data can he split into multiple streams among processing elements of processung coleme.llt: can be cascaded to process the same data stream.

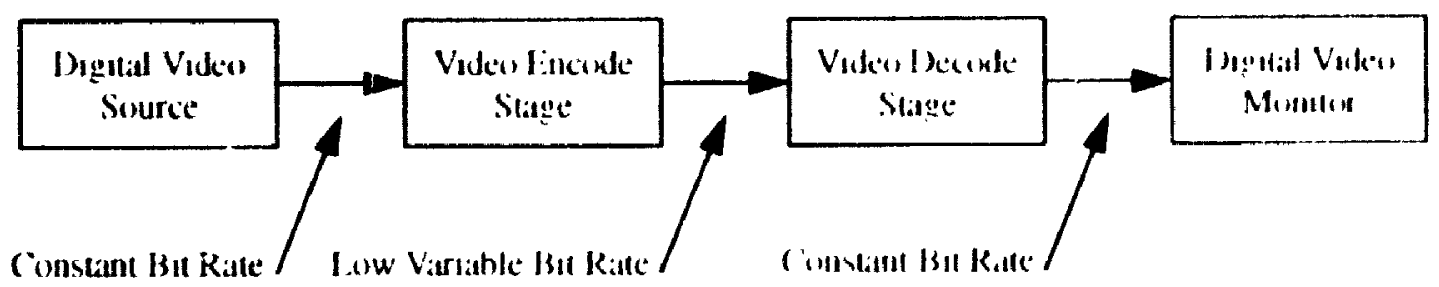

Figure 6-1: Viden I'romessing Setup

\subsection{MISD Systems}

Processing the incoming video data requentially in a single stream deses not regurre at mechanism for disassembling and reassembling dala streams. Pipelune systems have the ability to perform any level of processung an every processung element beadue of the 
availahility of the reyured data in their local memory. However, a pipeline system is required (1) pipe data equivalent (1) the entire original input stream from every processing element to the next. Therefore, the peak performance of the system cannot exceed the pipelime transler handwidth. Lpon reaching the processing peak permitted by the communicattun capacity of the pipeline hetween processors, insertion of additional processors in the system may degrade performance. It is, therelore, heneficial to maximia effective dala transfer across links by the design of functional segmentation. A complete pipcline system operating at its data transfer peak is analogous to a single processor system where pipelining cannot be employed to enhance system performance.

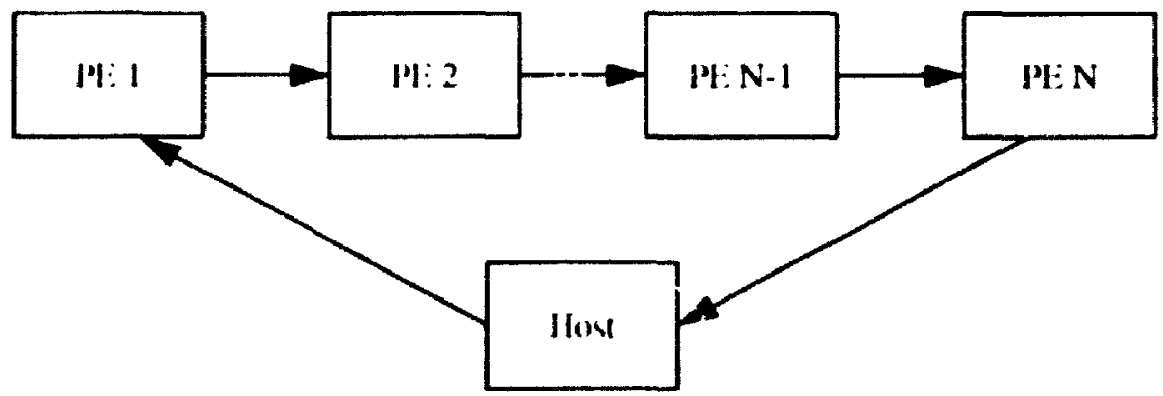

Figure 6-2: (ieneral Pipeline System

\subsubsection{Functional Segmentation}

(Diten, ideal functional partitioning is not achievable due to the computational cost distribution of program functional segments. A functional segment that requires much processing can he lurther segmented. This oflen requires repeating the functional xegmentation of the entire algorithm.

Achieving optimal functional scementation hecomes more complicated as the number of processing elements increases. An alternative method (to the logical functional $x^{2}$ gmentation) is partitioning a given task hetween two or more successive units by making cach unit carry out the task on a portion of the data stream. This technique was used in the experimental pipeline system at the end of Section 5.2.1 and thereafter.

The variability of processing-demand distribution among frames alternates the bottlenecks among processing clements, increasing the difficulty of achieving an optimal functional partituon. This problem was encountered in Section 5.2 .2 and was solved by partioning the processing functions according to their statistical computational cost. This hehaviour of the program reduces system utilization. 


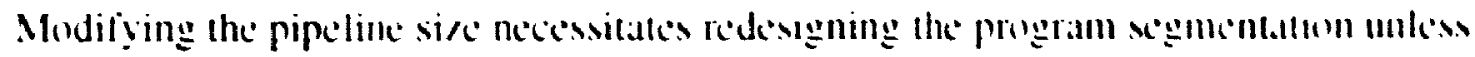
it is done to mect the processing demands of the current partituning.

\subsubsection{Communication Management}

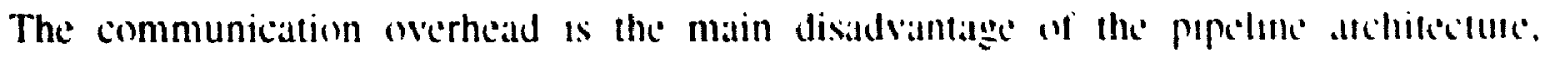

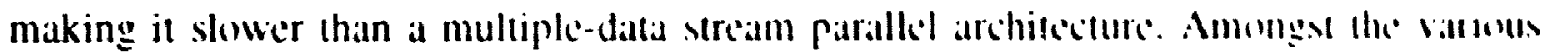
methods of achieving efficient communication, inventegated in Sections 5.2 .5 .25 . $146^{*}$

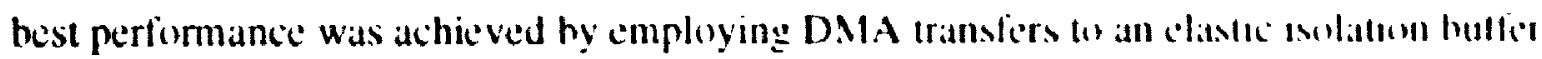
in Section 5.2.5. The communication capacity was reduced by the lact that the shared dual-port memory generales a single wait statc, as well as the hus design, which reyuiled two additional cycles for writing. The use uf no-wait-stale memory (25-ns access tume) and faster buses (single-cycle read/wrike) triples the pipeline handwidth.

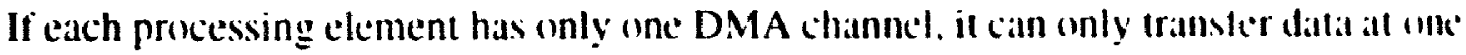
port (input or output) in parallel with processing. This dexes not impose a limit ont the system if DMA channels are used 10 eirher read or write data in all unils. It is. in this caste. better to use DMA channels for inputting data and to leave outputting data for the ('Pl I as it produces results. When the CPU writes a communciaton memory. mo overhead is incurred if no wait states are gencrated hecause the (PI can write data derectly lo lle communication memory instead of storing it in focal memory (as is the ase it the 1)MA were to transfer the results out).

Using larger data blocks for DMA transfers ciccreases the frequency of IDMA hlock transters and. therefore, considerably reduces the (PU timb reyumed fo xervice I)MA initialization and interrupts.

\subsubsection{Performance of MISD Systems}

It was shown, in Section 5.2.5, that the interrupt-driven DMA hlock-Iransfer methol with an elastic isolation buffer was the least costly communication method, enabling a processing element to either save resulting data in the memory of the next processor with no additional cost, or save it where a constant-cost DMA hlock transfer can pertorm the transter. Data arrival interrupts the receiving processing element fo matiate the I)MA transfer into local hutfer memory. In the experiments carried out in Sectoons 5.2 .15 .2 .5 , the approximate computational cost was 51$)(1$ cycles per word per processur, the program segmentation cost (due to splitting logical segments) was about $1 \%$ of the computatumal 
cost, and the communicatlon cost was ahout + cycles per word.

$\operatorname{lMM}_{0}$

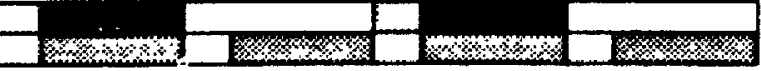

liemeral ciasc

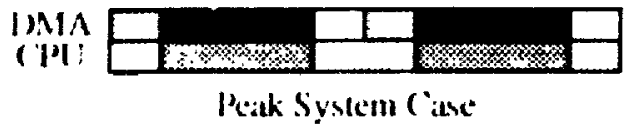

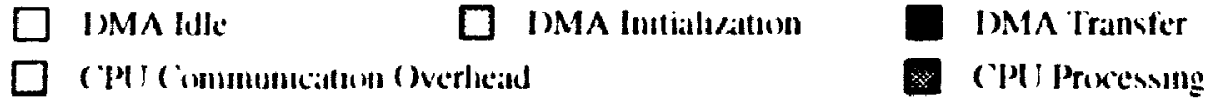

Figure 6-3: IMA and ClU Timing

Ideally, increasing the number of processors would decrease the computational cost per I rame per processor proportionally. The segmentation cost per processor would also he expected to decrease. However, the communication cost per processor is almost independent of the number of processors, hut dependent on the size of data passed across commiunication links, which can he slightly controlled by delineating segments where the least detla neceds to be passed. The optimal de!ineation is very diffic uit to achieve and is also limited in eflect, as it caubes interrupt service routines, for initiating and concluding DMA transfers, to increase gradually as the number of processors increases. Figure 6-3 illustrates the correspondince hetween CPU and DMA activities as the number of processors increases (o) saturation; timing is not to scale. Only DMA idle time and CPU processing lime are decreased and the CPU overhead remains constant (per frame).

An assumption is made that the data source can operate at data rates as high as the pipeline can support. When the DMA initialization time matches the conclusion time of the previous hlock transfer, as in the peak case of Figure 6-3, the system throughput becomes hounded by the $I /()$ capacity of the pipeline. A further increase of the number of processors cannot ameliorate the system performance (unless the segment delineations are moved to optimal positions). Before this condition happens. the speed-up achieved by using $n$ identical processors can be calculated hy

$$
S_{n}=\frac{n t_{p}}{t_{f^{\prime}}+t_{s}+n t_{(0)}}
$$

Where $t_{f}$ is the processing time required hy a single processor. $t_{s}$ is the overhead incurred by e.gmenting the program. and $t_{\nu 0}$ is the processor time spent on $1 / 0$. If all processors 
take the same time to execute then $t_{p^{\prime}}=t_{p}$, wherwise $t_{p^{\prime}}=n t_{p, n+m}$. Whete $t_{f, n m}$ is the

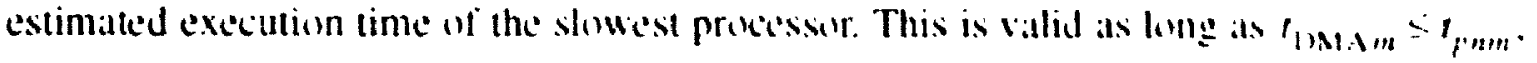

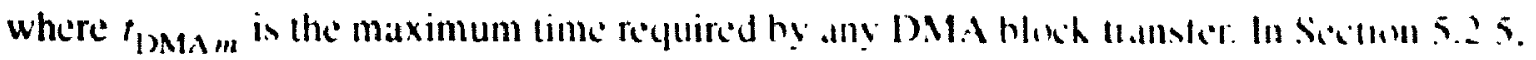
the approximate values of thuse paramelers were $t_{10}=0.5 \mathrm{~ms} . t_{1}=2 \mathrm{~ms}, t_{1}=20.4 .7$ ms. The above speed-up equation is valid since $t_{1 \mathrm{M}, \mathrm{m}}$ is ahout $1 \mathrm{~ms}$. Therefored, specol-up

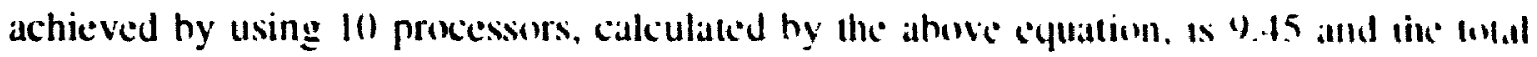
overheasi is $5.5 \%$ (cl. Section 6.2.3).

\subsection{SIMD Systems}

A multiple data-stream contiguration is the optimal archilecture when a litcatns in data disassembling and reassembling is used. It is also the only method to "uhince the performance of a saturated pipeline system (through hybridization).

\subsubsection{Data Segmentation}

Data is segmented among processing acments in a spatial or temporal manuer. Spatial data segmentation schemes are suitable for algorithms that operate on closely licalised data elements. Temporal data segmentation is required hy algorithms that operatte on distributed data elements, especially in high-level viston and image processmg.. In distributing data among processors, spatial data segmentation schemes require higher switching speeds (when using multiplexing devices) hecause each frame is distributed among many processing elements, whereas temporal data segmentation xehentes requirc a frame or more to he assigned to each processor. Therefore, for efficient utilization of a multiprocessor system, there must be a simple ratio hetween the number al hlocks pes frame and the number of processors in the system.

Temporal data segmentation schemes that assign single frames lo processus are ineficient for interframe coding schemes. For this reason, frames must be dostributed fo processors in $n$-frame hatches such that as one processor processes $n$ frames, llee next processor processes the next $n$ frames. Sequences of frames must be stored in the multiprocessor system controller (host) memory or the local memory of individual processing elements. Assuming $N$ processors, this segmentation scheme requires additional storage of $n N$ frames waiting for processing. Distributing thus storage medat 
among processung elements requires every processing element to accommodate $n$ additional frames in its lecal memory. This scheme nonetheless can he employed hy both intraframe and interfiame coding schemes.
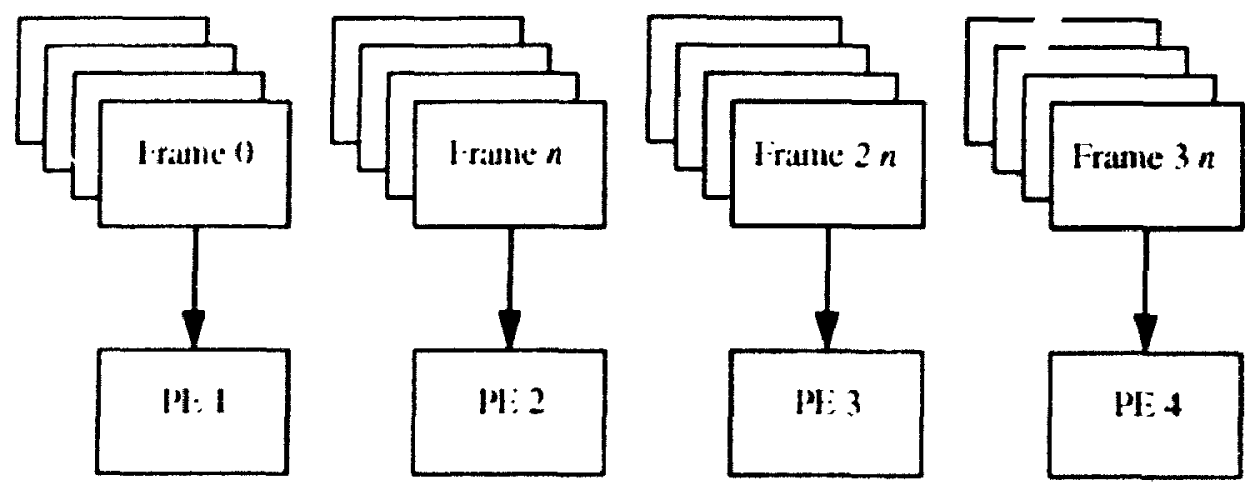

Figure 6-4: Temporal Distribution

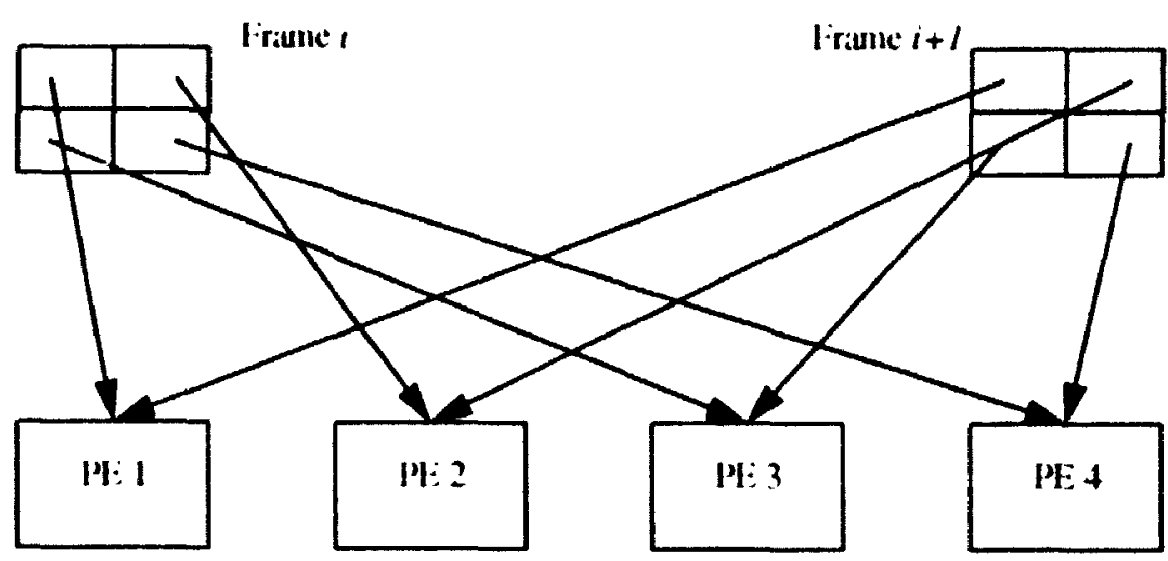

Fipure 6-5: Spatial Distribution

In a spatial data segmentation scheme, the algorithm imposes a limit on the number of blocks a frame can he partitioned into. When the number of processors exceeds the number of hlocks, more than one frame is required to load all processors. However, in intertrame coding schemes, suceessive blocks comesponding to the same spatial area must be prokessed hy the same processor. This requirement introduces temporal gaps in distrihuting frames among processors after the last block of a frame has been assigned. wherwise processors would require past image hlocks, which are in the memory modules of other processing elements. Transferring those hlocks between processors would require signiticant overheded. For large numbers of processors, spatial data segmentation is 
analogous wo lemporal data segmentation for groups of processors. Each time at new frame

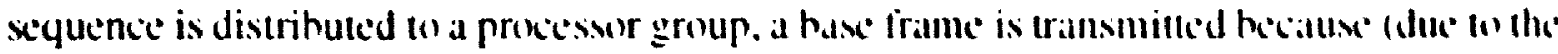
unavalability of the previous frame) a predictive frame cannot he encoded.

\subsubsection{Synchronization and Communication}

A viden data source outputs a single stream of comstant-rate digilal viden datil, and a valen

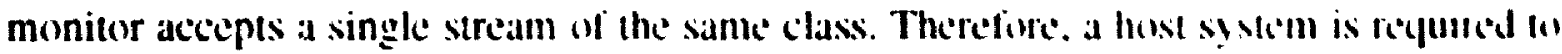
carry out data segmentation and reassembly. Data segmentation and reasiombly devects can the employed by the host or used independently to carry out his task. Synehromiallon of processing elements is required hecause input and output data streams arce synchronous.

Data transfer hetween processing elements and the exlernal enviromment ean be performed via menory access or $V()$ schemes. The selection of the communication methol affects the hardware contiguration of the system. Memory-adecess communication schemes require the host system to provide processing elements with $1 /()$ services. Howerel, because of the limitation of the host $1 /()$ capacity. $1 /()$ communication me multiplexing and demultiplexing devices (1) provide the required $1 /(1)$ services.

The complexity of multiplexing and demultiplexing devices varies according in the data segmentation scheme employed. Segmenting frames into rectangular hlocks rexure: more sophisticated devices. Distrihuting integral trames among processing elements anly requires switching //O channels synchronously al a relativaly low frequency withuut sres. on computation. $/ / O$ data acquisition and dispensation devices recpuire prexessing clements to be tightly synchronized to provide high-speed synchronous data at their outpul ports ill a precise, timely fashion. This is a very strict timing condition which repurres the pasence of two high-speed serial ports in every processing element that can be serviced independently of processing.

It is assumed here that a host system is used for $\mathrm{J} /()$ services. Thes loost system includes necessary high-speed serial data acquisition and dispensation devices instead of distributing those devices among all processing elements. It the $1 / 6$ ) load on the host system is very high, input serial ports may te allached to processing elements to relieve the liost of

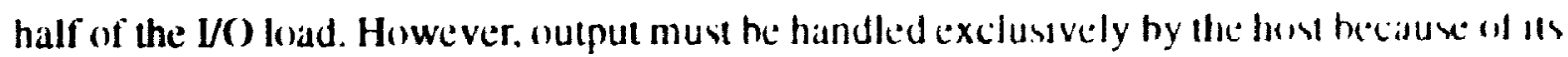
strict timing requirements.

\subsubsection{Performance of SIMD Systems}

Section 5.1.2 established that the hest data segmentation scheme for a multiple data stream 
system is the temporal segmentation method, which essentially provides processors with the same load share. This method is casily scaled 10 any number of processors.

In this architecture, the host $I /()$ overhead limits the speed-up return of processors. Increasing the number of processing elements aceupies the former host s idle time with $V$ () exchanges with processors and external $l /()$ devices, as long as external data rates are increased to ulilize availahle processing power.

This scheme does not have program segmentation overhead hecause the same uniprocessor program is run on all processors. The choice of the $1 / 0$ exchange method hetween the host and processors dices not affect the relative speed-up retum because all processors share the same timing distribution. However, the distribution of idle times innowed by the $1 /()$ scheme affects the alholute system speed and the upper bound of system pertormance.

The availability of data acquisition and dispensation boards on the host system limits the host lask to transferring dati from the acquisition board memory to a processing elencent and then transfierring the resulting data to the data disjensation hoard memory. Using dual-port memory in processing elements and VO devices provides high-efficiency data transfiers.

At the start of loading, $n^{2}-n$ W/O slots are lost. Then idle time is only lost due to statistical deviation of the real execution times from the expected execution time. The eflect of this statistical deviation can he minimied hy employing buffered $1 /$. As long as the idle time of the host is sufficient for the insertion of an additional processor' the system speed-up is lower bounded by $t_{p m} / n$, where $t_{p m}$ is the maximum execution time required hy any processor.

Consider the experiment of Section 5.1.2. The uniprocessor overhead $t_{\text {yo }}$ is $9 \mathrm{~ms}$; the uniprocessor execution time $t_{p}$ is $100 \mathrm{~ms}$. Assuming that $t_{p m}=101 \mathrm{~ms}$, the speed-up factor achieved hy employing 10 processors can he calculated hy

$$
s_{n}=\frac{n_{p}}{t_{p m}}=s_{10}=\frac{10 \times 100}{101}=9.9 \text {, }
$$

I That is lo siy, hon adle tume hetween loadmg the last PLE and unloading the tirst PE is larger than the time

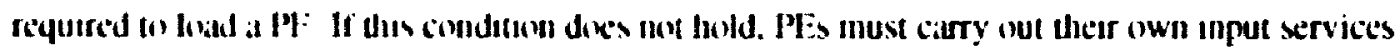




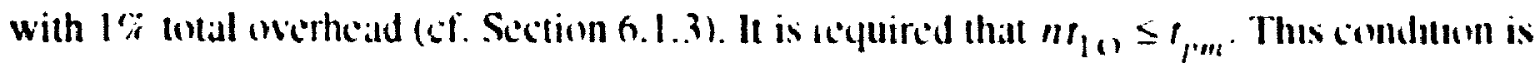
valid up to $n=11$. The houleneck then is the host. unlike that wi the pipeline case whet: the bottleneck was the pipeline link data transfer capacity. For $n>11$.

$$
s_{n=11}=\frac{t^{\prime \prime m}}{t_{1 / 0}}=\frac{101}{4}=11.22 .
$$

\subsection{Hybrid Systems}

Configurations that combine single and multiple data paths can te explonted for viden processing. The architecture of such systems depends largely upon the underlying condeng algorithm. Many such configurations cmploy shared memory or shared hus schemes. Thall requires arbitration and limits scalability. In this section. systems constituted from units that pass data from port to port are considered. Those systems operale in the MIIMI) mikle.

The advantage of hybrid eontigurations is that some operations of video conding lend themselves nicely to SIMD processing and others tit well in MISD wellemes. By using a combination of both archilectures, a pipeline system can be extablished where appropriate functional segments of the algorithm can be distrihuted in parallel in a SIMD mode. (Mile method of designing a hybrid system originates from moditying a pipeline system. Hybrid systems can also be designed using arrow natwork diagrams.

Data is transferred through serial or parallel $1 /()$ ports hecause it cannol to wrillen directly to other processors' memory without implementing hus windows, which is inefficient ${ }^{51 !}$. The system can he configured such that any processing element receives all the data it needs to perform its task from the previous stage to eliminate addilsonal communication overhead.

Synchronization is required to ensure that no processing element is overrun will dala. This can be handled by exchanging ready signals hetween a processor and the previnus processing stage. Each stage of the pipeline is limited in performance hy the slowes processor and the overall system performance is limited by the slowest pipeline stage. If the data rate is relatively high, iwo processing elements at either end of the system can be used exclusively to handle $\mathrm{V}(\mathrm{)}$ between other processing stages and the external environment.

Due to system complexity, expanding a hybrid system requires major changes in system software and hardware. To utilize hardware expansion elficiently, system software 
requires considerable modilications to keep processing loads shared fairly among processurs.

\section{o.3.I Hyhrid System Design}

A hyhrid system can he dessgned using a pipeline prototype. A functional division of the algorithm explained in Section 3.1 .2 can he as follows: (execution times in ms are in parenthesces):

1. Band array calculation (14.4),

2. Quantizalion. RLC and VLC of band 3, including packing into ATM cells (52.2),

3. Disassembling the hands into (wo streams of ATM high priority cells (1.5).

4. Channel simulation (0.1).

5. VIC and RLC decosding of hand 3 (115.9).

6. Building the complete image (15.7)

The timing shows that items 3 and 4 can te combined with item 2 (or 5). Item 2 should be split among threc processors, and item 5 should te split among 7 processors. This results in the following partition:

- Band array calculation (14.4),

- Quantization, RLC. VLC. Disassembling. Channel Simulation (17.9 $\times 3$ ).

- VLC. RLC decoding $(16.6 \times 7)$,

- Building the complete image (15.7).

This requires 12 processors to achieve a processing rate of 55.9 frames per second. The hollleneck is item 2 and the fastest processing is in item 1. Band 3 deses not require disasicembling hecause it is done in the VLC coding stage. Therefore, disassembly can be moved of the tirst (or third) stage resulting in 15.9 at stage one and $17.4 \times 3$ at stage 2 . corresponding 1057.5 frames per second. which in turn corresponds to an efficiency of $96 \%$ (the optimal rate is 60) frames per second) which is hetter than that of the pipeline system ( $9.4 \%$-efficiency for 12 processors). Increasing the number of processors by one (at the butlencek stage) achicves a processing rate of 60.2 and an efficiency of $93 \%$ (very close to that of the pipeline archileclure, despite imposing the additional processor without high computational demand). The performance of this architecture, in general cases, is inferior to that of the temporal distribution star architecture due to the simplicity of its 
design which does not provide for lair processing lobd segmentation and doxes llot reyuire acquisition and dispensation devices. This archelecture has no segmentation cost and is suitable for cases where the processing elements are different such that cerlain segements of the program can to optimally performed hy special purpose devices.

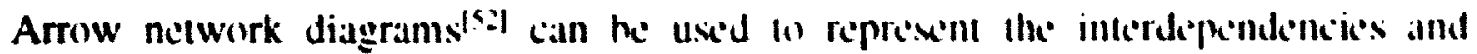
precedence relationships among the tasks of an algorothm. Then, PERT:ClMt (proifect evaluation and review lechnique-critical-path method) can he uned lis selkedule the program. Every task is represenled hy an arrow which starts al the end oll the lasks that must precede it and ends at the heginning of the tasks that depend in it. In ligeure 6.6.a. lasks ABF can he combined in one lask AF with the sum of their individual kenglhs la be the combined task length. Task groups CEG and CDF can also the combined ill the same manner, resulting in Figure 6-6.h.

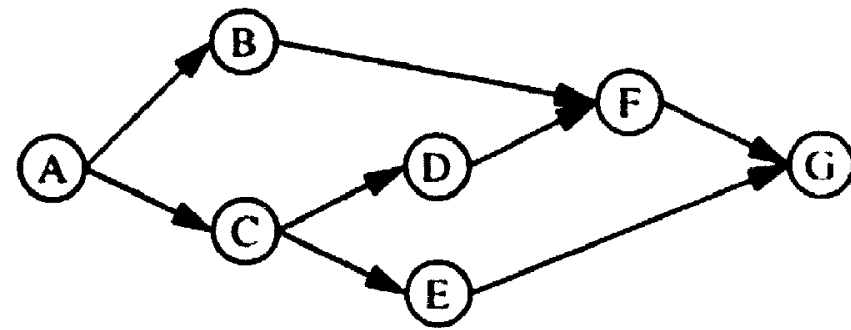

(a)

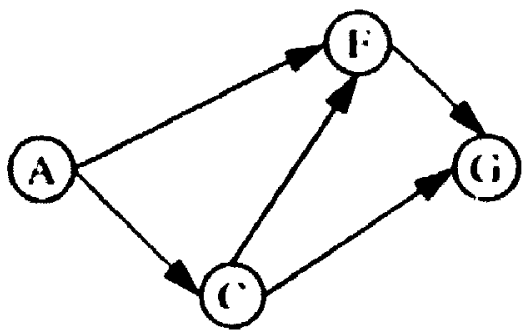

(b)

Fighure 6-6: Ahsurithm Arraw Iiagram

A processor or a number of processors is assigned (o) every arrow (lank ). It nollceable floats are present in noncritical paths, ressurce leveling can he uxed (1) assign processurs lo tasks by relocating processors of noncritical paths to share critical task s wh thal the mumleet of processors is kept minimal at all points in time and the algorithm is fomvlued in the shortest time possible.

This design method is efficient in the cases where tloats are small. This approarh is also useful in determining critical tasks in complicatcd algorithms to estumatc the reyuited resources in a general hybrid system.

\subsubsection{Performance of Hybrid Architectures}

In Section 5.3, it was shown that a hybrid system was superior to the pipelume systems discussed previously. I nis was due (1) the llexihility of run time load amsmbunom. The implementation of this property in a general hybrid system. hy interconnecting processus 
of the same stage. signiflcantly complicales programming and increases hardware complexily and corst.

Becauxe the desired system is a research tool, system configuration should lend itself Io extension and lopological changes. Ensuring that data is transfierred hetween first-degree neighbours diminishes transfer cosss hut. more importantly, requires that lopology be tailored according to data dependencies. Expansion of such a system requires redesigning the copolugy according to the program and data segmentation that contorms to the new number if processours.

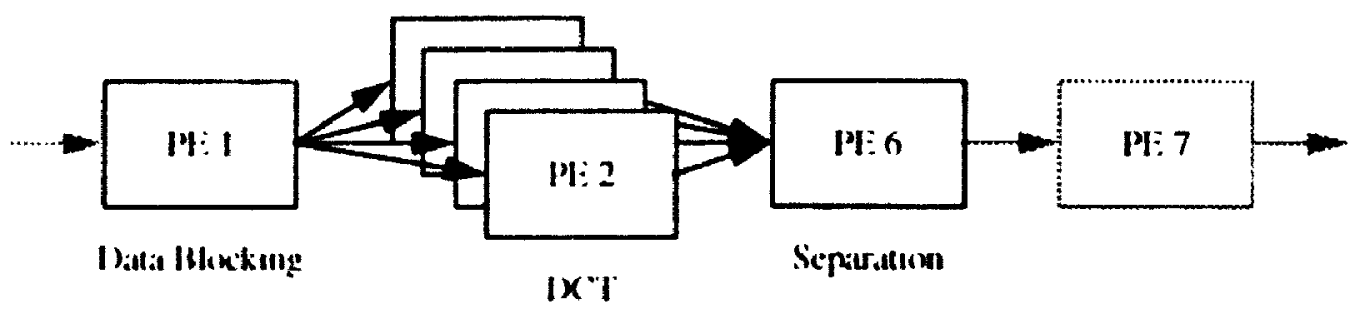

Figure 6-7: Fixample of Hybrid Systems

Consider expranging the sample system, a part of which is depicted in Figure 6-7. Assume that the DCT stage is more computatio:: :ly intensive than its two neighbouring slages., hut the centiguration, displayed in Figure 6.7, is optimal for the available number of prociesors. To estiniale the speed-up achieved hy adding a processor in the DCT stage, the subsystem constituted from the DCT stage and the two neighbouring stages is considered (PE I through PE 6). The additional communication cost incurred by this expansion consists mainly of the solfware initialization of the additional connection added fo cach of PE I and PE 6. If the communication profixcol transmits data blocks intended for the DCT stage on a hlock-hy-hlock hasis, there will be no additional communication cost hecause the change will only involve a moditication of destination addresses. In the case of signiticant overhead, the performance of the preceding stage is reduced (probably creating a new bollleneck). The speed-up gain of expanding the system is the difference between the new sliwest stage throughpul and the former DCT stage throughput.

Assume PE 7 is the system botlleneck and it is desired to share its processing load with a procissor to be inserted at its output port. In this case, the subsystem to be considesed is the longest single processor pipeline that includes PE 7. If rearranging tasks among processors involves dividing the program in a fashion that conflicts with its logical segments. the'n new segmentation overhead is incurred in addition to the additional 1/O 


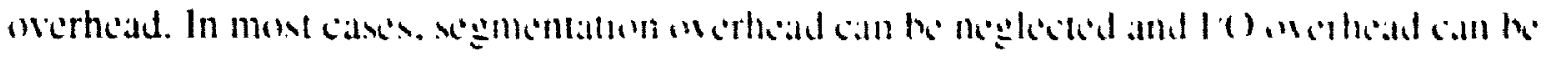

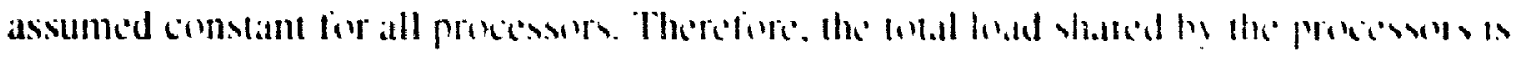

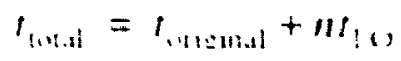

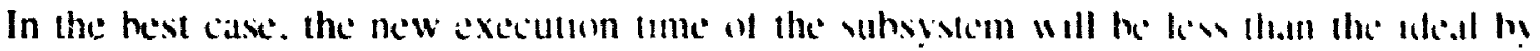
$t_{1 / 0}(n+1)$. otherwine

$$
t_{n+1}=\frac{t_{n+11+1}+(n+1) t_{1, n}}{n+1}
$$

The overall system throughput is limited hy the new bollkeneck st.1:20.

\subsection{Performance Comparison}

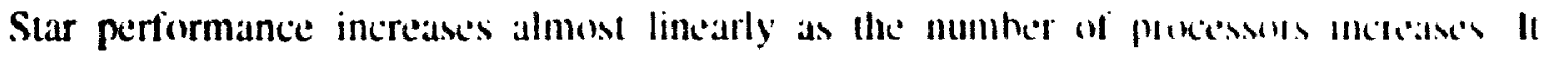
saturates as the host hus hecomes overloaded with data transler hetween the hout and ille

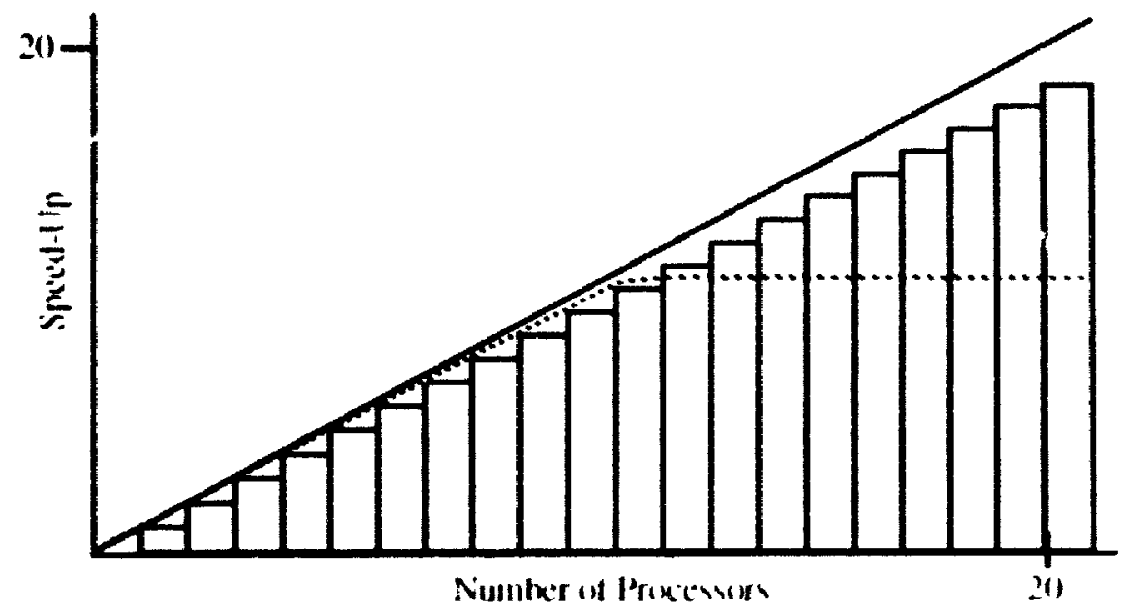

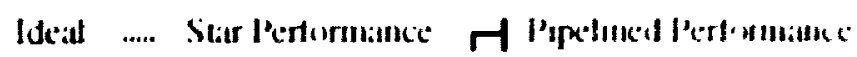

Figure 6-X: Pipelineel and Star L'erfiormance

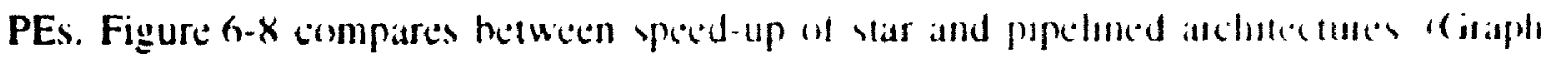
generated from formulac in Sectoons 6.1. 3 and 6.2.3.)

The rate of pipelined architecture speed-up decreases as the number of precessors is increased Processing lasks hecome smaller while the I/( ) overibead siays almost combanl and gradually dominales processor times. The performance peak is also bounded by the communication handwidth of the pipeline. The performance of hybud systems show's mo general tendency, but it sometimes exceds that at the pipelmed anchulecture and 
somitumes is below it, depending comsideratly on the functional distrihution of the algoruhm lavks.

\subsection{Example Design}

The secton investegates the real ume implementation of the algorithm ixplained in Section 3.1.2. using Banshee hoards. It is devired lo design a system that can provide reallime processing of 30 trames per second with a frame size of 288 -by-192 8-hit pels (256grey levels). The process starts with the original trame (similar to that in Figure A-1) and endis with the lesult frame that only differs from the original hy the effects of coding and chamnel crrors (similar o that in 1 gure A-6).

The perlormance of the algow athm in question depends considerably upon the nature of the images heing processed. Worst-gase mages can take more than double the time required by the image of Figure A-1. To account for such computationally intensive umages. a frame slot lume of $20 \mathrm{~ms}$ per frame is selected instead of the average 33-ms frame lime slot (of the 30-frame-per-second rate).

This algurithm. which is desired to be implemented. achieves the performance of 0.2 seconds processing time per 14t-by-96 laame on a single Banshee processor; the processing lime increases proportionally with image slas

To achieve the required red-time performance of 0.12 seconds per $14+4$-hy-96 frame. II times the (effectuve) prikessing power of a Banshee hoard is required. Therefore, the clfective processing power of 40 Banshee processors is required for the real-time processing of the frame in question lassuming the same image complexity for this frame sid.

\subsubsection{System Architecture Design}

'n Sectoon 6.5 above. it was shown that the effective processing power of 40 Banshee processors is reyuired inr real-time processing of $28 x-h y-192256-g r e y$ scale video frames. In Sectons 5.1 .2 and 6.2.3. it was demonstrated that the most efficient data distribution schene divided data between processors in integral trames (achieving linear ellucient peod-up with less than $1 \%$ overhead whthin host 1/O limits). In Section 6.2.2. it was suggested that the host system provide $1 / 0$ xervices to the processing elements.

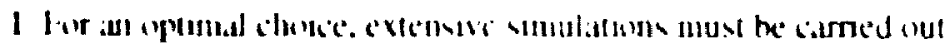


The incomiang data hit ratc a:

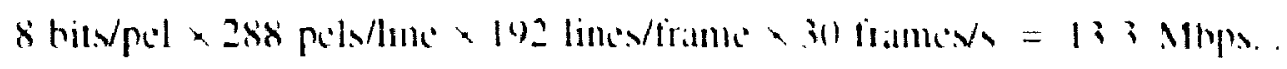

This data rate must he accommodaled at the :nput and outpul ports of the hose

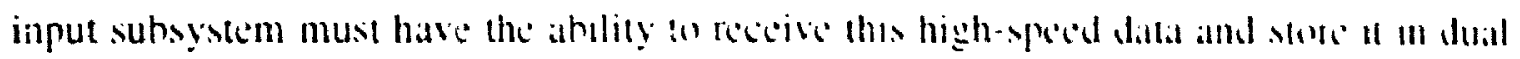
port memory for later retriesal hy the host system. The output subsystem must cattry out the inverse of this operation by cading dual-port memory whlten by the hose and

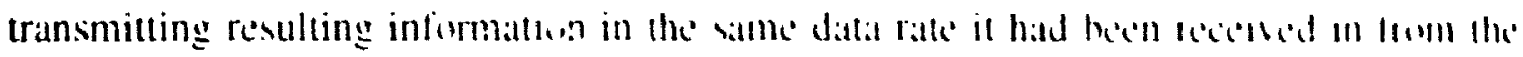
video source.

\subsubsection{Data Acquisitica System Specifications}

Figure 6-10 depicts the hlock diagram of a data acyunitum yosem. The Symchomoms Serial Communications intertace (SSCl) receives serial input data wheh is then reat hy

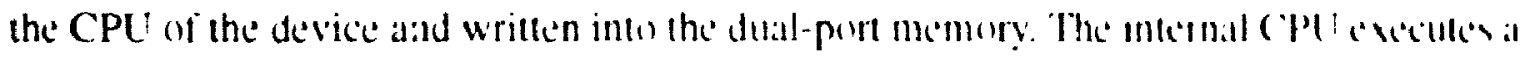

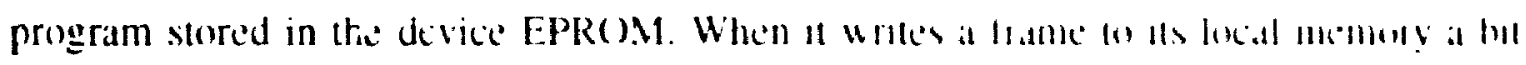
associated with the correspondnge memory hlock in the Fite Frame Memony Re? (FFMR) is set: when the hose reads a frame from memory, lhe concepondmy tlatg in

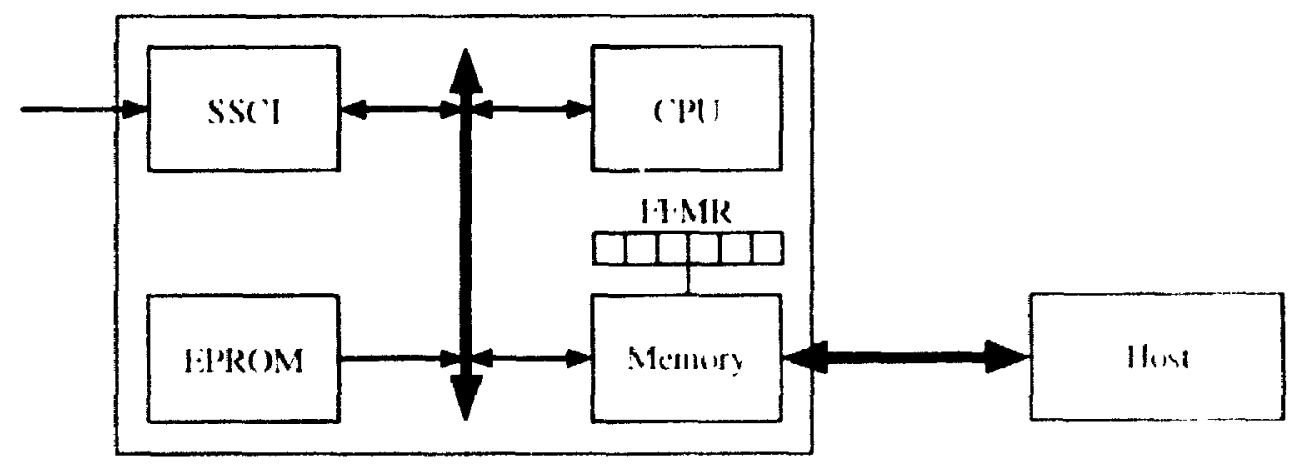

Figure 6-9: Data Aequivition Syentem

FFMR is reset. If the host altempts to read an emply memory hlock, walt slates are

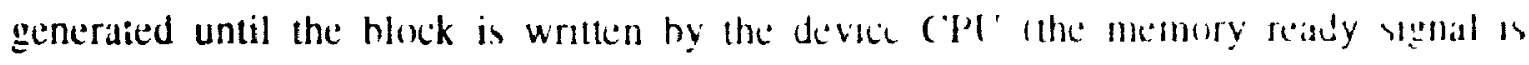
ANDed with the corresponding FFMR llag). Allempung fo wrlte la a lull bleck generalles waiting states for the device CPL and it desta is not read by the hest promptly. the SSC I

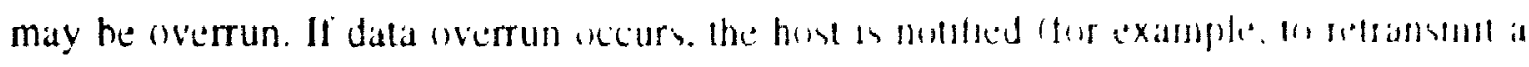
previous trame).

The input device CPL is required (1) write 31 trames per second an lls lical memory 
This ralc 1 equal $16+15 \mathrm{kword}$ per second. Since the CPU is dedicaled to this task, it can acheve that hy executing a tight loop of reading the SSCI and writing the RAM (unless dala overrun aecurs). This $\mathrm{I} / \mathrm{(})$ lask can he handled by a 16-Mhe 386 processor. RAM is reguired lo have any access time helow 120 nanoseconds. The SSCI is required to handle 13. 3 Mhps.

\subsubsection{Data Dispensation System Specifications}

The lows reads viden frames from the input suhsystem and writes them to processing clements in a round rohin fashoun (analogous $(1$ that in Figure 6-4). Each processing element must be read direcily before it is loaded with its next frame. The host must carry this out synchronously with heh accuracy. Synchronization can be achieved by employing an interrupt mechanism between the host and the input system, hut it is heter

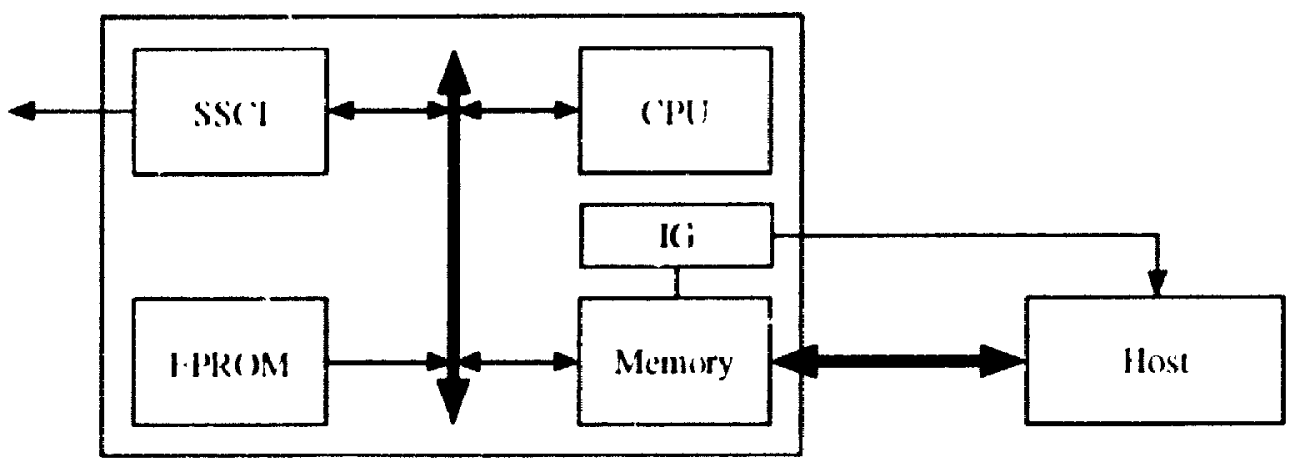

Figure 6-16: Iata Dispensation System

that the system be diven hy an internal timer to avoid interrupt conflicts between the input and output devices. Dut on the criticality of the output system task and the inahility of the host to overcome synchrontzation errors that may happen there, the output system must gencrate interrupts to keep the host in synchronism. An interrupt generator (IG) requests hose service when a frame memory hlock is read. The $1 / 0$ requirements of the output device are the dual of those of the input device: therefore, the specitications of the CPU. SSCI. and RAM1 in both systems are identical.

\section{5.1.3 Host System Specifications}

If is necessary for the host fo carry out the required $1 / 0$ ) transfers for a trame in less than a frame lime she - $33 \mathrm{~ms}$. Board and me mory hank switching overhead requires ahout $3 \mathrm{~ms}$. This leaves 30 ms lor reading a frame twic: once from the input subsystem and the other 
from the processing element memory. and writing it twic: ance to the procesim! clement

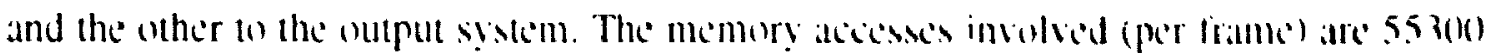

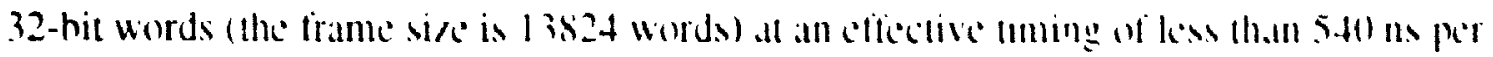

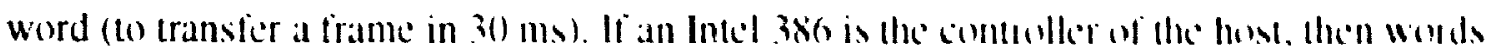

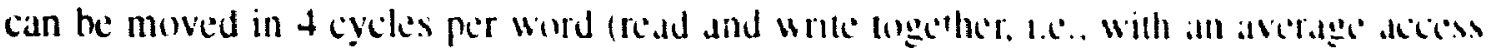
time of 2 eycles per word. using repeat move string word mstruethom. RIP MINSW Therefore, 3.33 Mcycles per second are dedicale.! to data transler (of 30 frames). The processor is mainly required to service 30 interrupts per second. in addition lo leamslemente data (and system peripheral services). Servicing mterrupts is inexpensive hecause most of

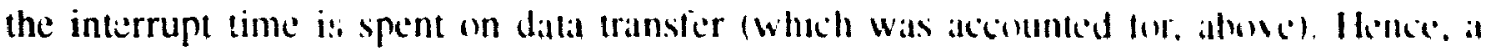

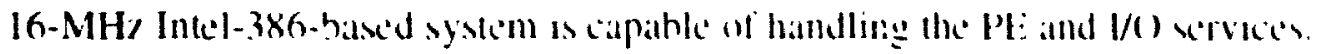

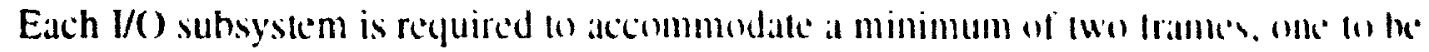

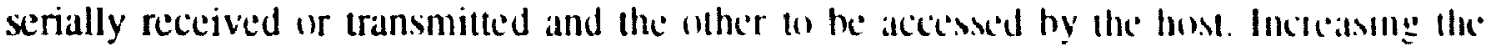
available frame huffer side enables the system to avoid synchroniration corons.

The processing power required by the system can be furnished by 40 (' 30 processors. The efficiency of the temporal distribution scheme uxd hese is very high (>)e\%). The effect of the $1 \%$ overhead is averconte hy the caution that was exefted in selectung the frame time slot to be $20 \mathrm{~ms}$. The processors are contigured in the slat architectute wilh no interconnections required hetween them.

\subsection{Interframe Predictive and Interpolative Coding}

In interframe predictive coding, the previous frame is requared for a processon to encoude predictive and motion-compensaled informaton. To achicve this lask uslige the architecture developed in the preceding section. a processung eleme'nt is recpured en receive the previous frame, in adddition to the Irame to be encoded. Bonth Irames call he read from the input subsystem and wrillen to the processmg cemente Thes douhles the number of memory transfers required from the hose porcessur. However, lace proceswir that has been selected for the host is capable of handling this increase in $\mathrm{I} /($ ) demand. The dala buffer of the input subsystem is reguired of accommosiate an additunal frame. Depending on the coding scheme, this implementatuon may require additumal processme for tine previous frame to be suilahle for use as relerence.

Another data distribution method can keep the $1 /()$ demand from the host processor as it was in the previous section. It the coding scheme uses penode replemshment. Ihis 
destrobution method will not incur any reterence frame overhead (see Figure 6-4). The hose loads each processing element with a group of bames which starts in a frame that will he used for replenishment and ends with the frame hefore the next replenishment frame. Alter the lase processing clement is loaded. the host reads result frames from the tirst processing clenent and loads a frame form input for every frame it passes to output. The idle time of a processing clement while it is loaded with a group of frames is negligihle in comparison wilh the time required to process them. Interpolative coding schemes can be performed in the same manner. This method saves most of the processing overhead required by the relerence Irame. However, it reyuires larger data hulfers in the processing elements.

\subsection{Colour Coding}

Cientrally, the human eye distinguishes about 32 grey levels hut it is capable of distinguishing several hundred discreet color levels ${ }^{\mid 53]}$. The algorithm, described in Section 3.1.2, used a threshold of 5 to quantia pels, resulting in 24 effective grey-levels (| 256/(5-(-5)+1) ). The MPEG standard uses three arrays for coloured viden coding: one lor luminance and two lor the $R$ and $B$ colour information. The three arrays undereo the same coding operations. In this method, coloured images demand three times the processing power required hy monochrome images. It is possible to employ lower resoluteon for the colour components than that of the luminance component without severely affecting picture quality: this is because luminance contrast partially masks suhicetive detection of colour sharpness decrease at transition boundaries between colours $\left.\right|^{\varsigma+1}$ (and hecause of the nature of most images).

Assuming colour resolution of quarter the luminance resolution results in the total of the colour arrays heing equal to half the luminance matrix. One colour array can he appended of the other and the same coding scheme can be rur on the resulting colour matrix. The version of the coding scheme processing colour intormation is scaled down by hall in the width dimension.

The same coding xheme can process the colour matrix if it was equal in dimensions to the luminance matrix. This sclection of colour matrix dimensions makes the luminance and colour matrices interchangeable as far as processing is concerned. It also provides better putture qually: This ratio of chrominance to luminance was used in the HDTV prototype system proposed by Loi and Sunliol.

The: tirst method af colour conding demands $1501 \%$ of the processing power required by 


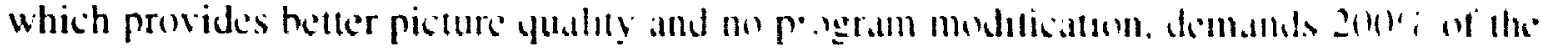
monochrome processing power lo provide the same trame sulpul talk.

\subsection{Special Considerations}

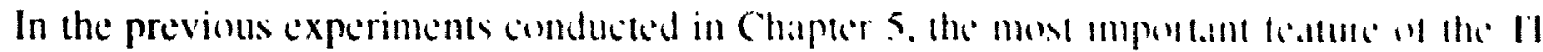

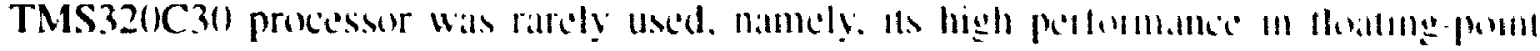

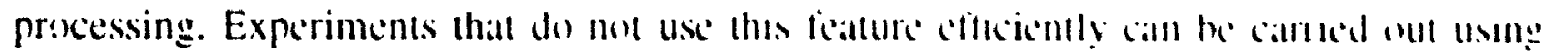
cheaper tixed-point processors. A problem with implementing thox a a

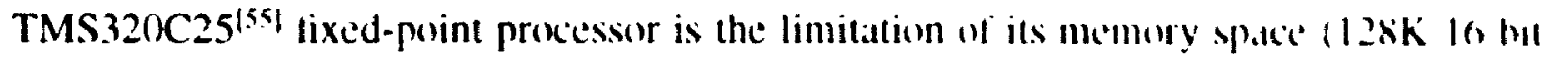
words divided in half hetween data and program memory spaces, in Harvand archelecture. which is another limitation). Limiled stack depth and limiled processor synchomm/almon mechanisms are other obstructions fo conducting the experiments clectenty

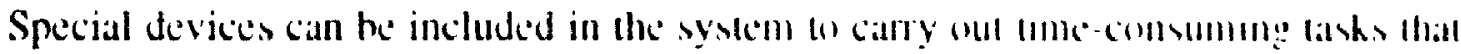
require special-purpone devign to he handled dficionly. In :he experiments canted anl III

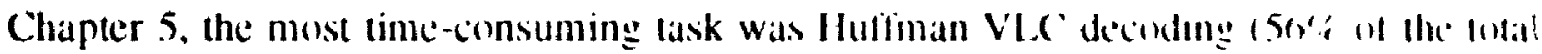
time) hecause it consisted mainly of searching, which requares ltecyu nt branches. unlew content-addressable memory (CAM) is used.

When the tirst codeword is decoded hy matching the first hits of the mput stealln lo llke cedeword table, the corkelength of the word is looked up an a condelength table to be used in

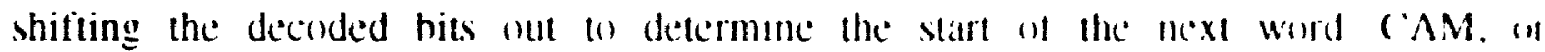
programmable logic array (PLA), can be used for codeword malchung lables, bul a li A faster and cheaper. However, if it is desired to modity code words, then usmg ( $A M$ แ Imon flexible. If it is desired to decode multiple streams that are mulloplexed moro the decoder (such as in decoding the luminance and the two chrominalse compontents, ach ustng a distinct decode tahle), layers of PLAs can he paged in and out acconding (1) the meomm! stream (under software control).

Barrel shitters are used to achieve the highes pertormance. When the oupput at the

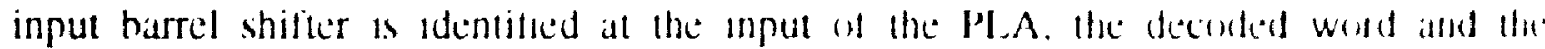

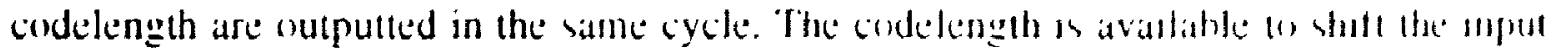
harrel shifter and decode the nex! word in a songle cycle. When the accumulated cordelengeth

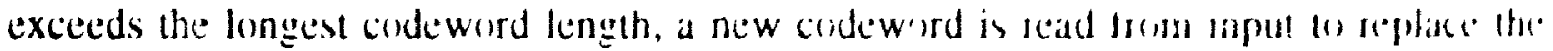


most semfleant word at the input of the hatrel shifter, as the former most steniticant werred stramplerred wh the least signelicant word regester.

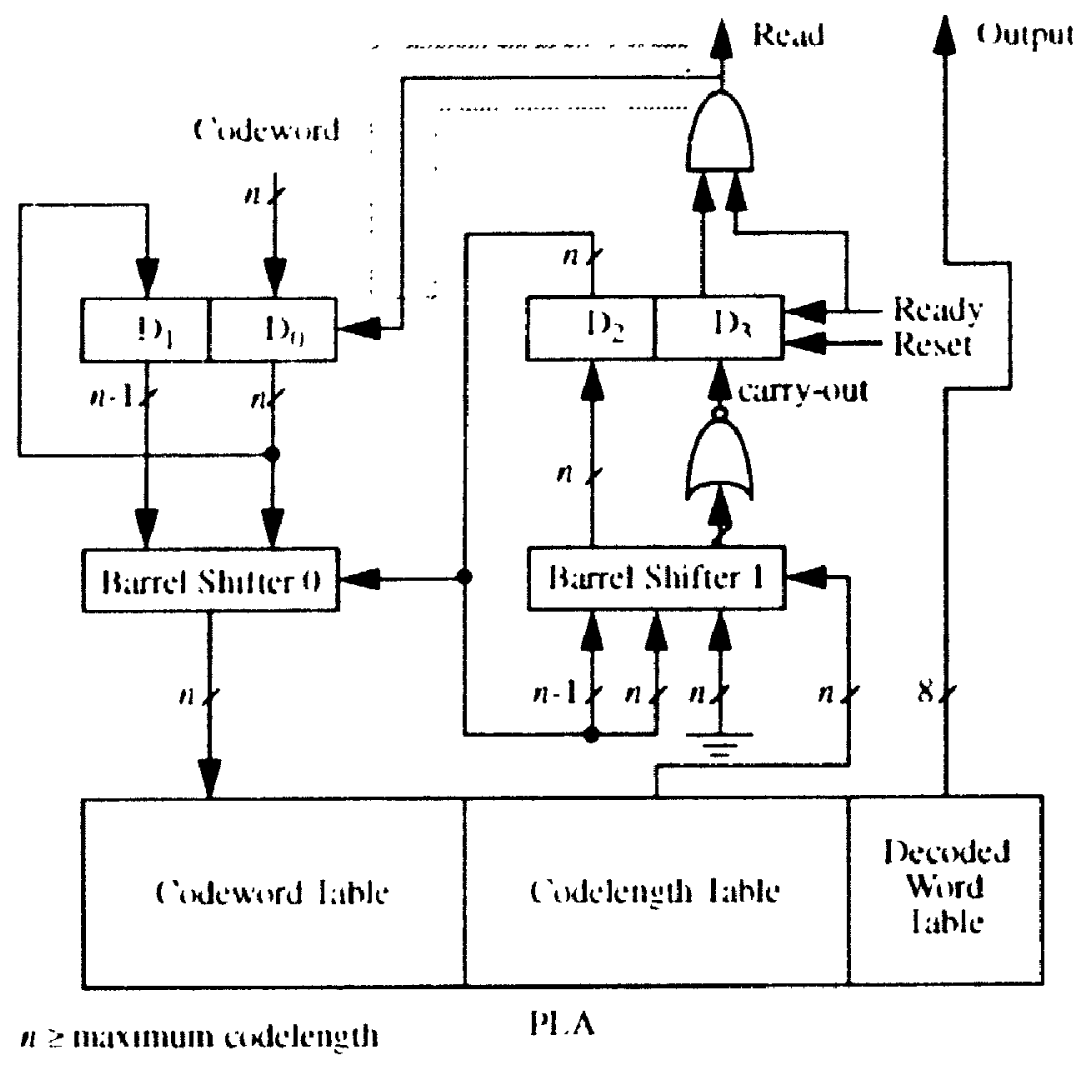

Figure 6-11: VI.C' Decorder

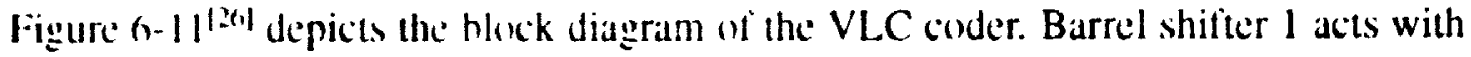
register $\mathrm{D}_{2}$ as a 4 -bit accumulator of codelength (hy rotating a 1 hit round the 16 bit focilluns') fo control harrel shiter () and to generate the read request signal. ${ }^{2}$

In applications where one word per eycle decoding speed is not required, ordinary shifters and adkers can he used to replace harrel shifter 0 and harrel shifter 1, respectively. In that eass, the maximum number af cycles required to decode a word is equal to the matximum codeword lenglh.

Tiv incorporate this decoder in the design presented in Section 6.5.1, it must be moditiced slghtly (besides replacing the harrel shifters). The read line (framed in the figure)

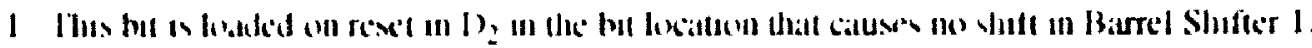

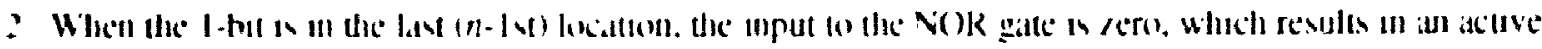

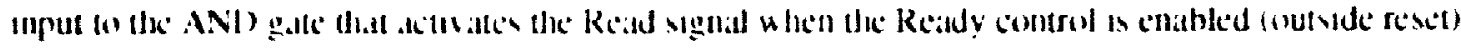




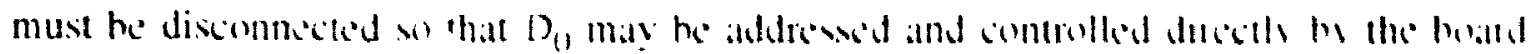

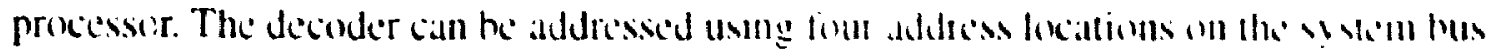

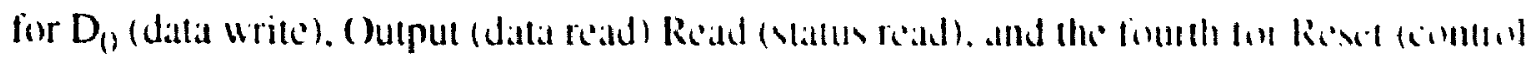

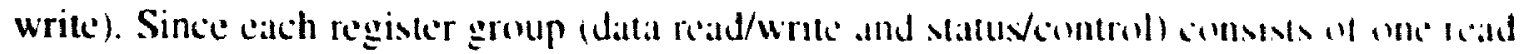

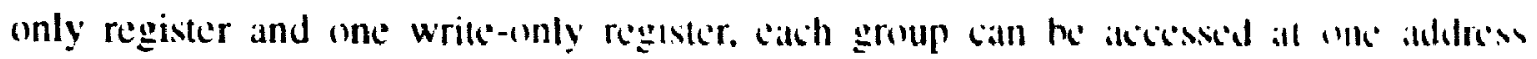
location with the Read/Write control signal ationg as a register select mput.

For research purposes. it is heller lo use CAMl instead of Pl.As lespectally silled top speed is not a requirement). Assuming 20 fol-ns cycles deconding time per symhol. a 2 st hy-192 frame consumes 10.177 seconds, saving $51 \%$ wh the foltal processme lame in the algorithm. The remaining processing demand ledt lor the PI: processors a halved. salveng: 20 processors (replacing them with 20 VLC decoders). Ache'vmg smgle cycle decode lume" saves 4 additional PEs. The cost of 4 PEs muse he compared with the cost of uperaling the

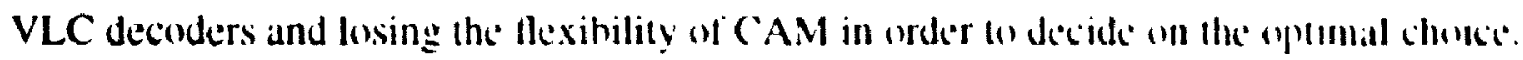

Other parts of the algorithm can he replaced hy hardwate mplememtatmms especially after their feasihility is proven, so that effective analysis of the te'st wh the algenthen can be conducted. It is specially useful to implement more gemeral tasks an the fashum wh that the implementations can he used if design moditications of the system all made.

Other coding schemes may henefit from a multitude ol readily avalahle chups. The DCT transform is a time-consuming lask that is used in many codng algonthms. VI.SI implementations are proposed for this transform ${ }^{\text {inl }}$ and can he used to carry oul sumulat ion of coding algorithms efficiently.

Another instance of using efficient devices to implement timle consummo lask s is ifle use of floating-point processors. Syslems, in which a small proportion of cherallons alle

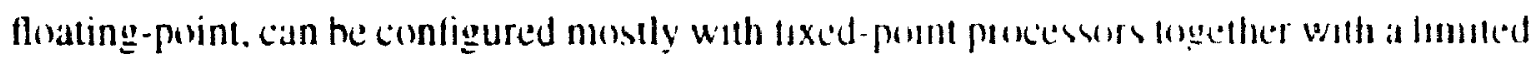
number of llouling-point processurs.

\subsection{Concluding Remarks}

The system architecture proposed in this chapter so not the most ellective arehilecture to cary out every single viden coding algorithm. Tatorng the archotecture for any narmow class of coding algorithms would cause loss of genelally and flexshility as a research lowl

In order 10 simulate algorithms that use a long hostory at trame data, 11 may he necessary to increase the system memory ste. (ciran algenthms would fun most 
efleciently in real applicalions usang CA.M or wher specific devices and architectures. These algonthms can he simulated using the proposed architecture. hut they will not perlorm as fast as they would using their specille implementation architectures. That is why a multiprocessor system is proposed: to compensate for not having the optimum, hut hyghly specialised, hardware archilecture while maintaining the required flexihility. 


\section{7 \\ Conclusions}

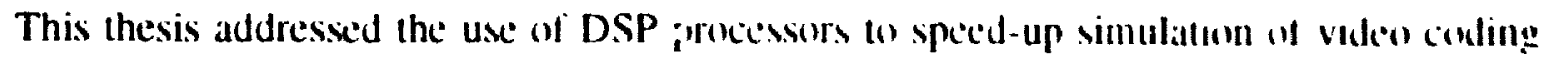
algorithms and ATM channels. Experiments studied the hasic aspects of usme multiprocessing for this class of image and video processme lechmegues.

\subsection{Results and Contribution}

The research showed the promise of using DSP processors to tackle real-1me processor. bound tasks. DSP processors are even more eflecient in this regard than most highperformance, general-purpose processors. Example techniques were proposed to increase the efficiency of processing using single or multiple processors. Digital video processung using multiprecessor architectures proved to he very eflicient and effectively lent ilsell to data segmentation for multiprocessing.

The coding algorithm used exhibited the prohlems that occur in most multiprocessor systems, such as the irregularity of processing demand per frame, the irregularity of processing demands for blocks within the same trame, and the uregularity of processme demand of the stages of the algorithm for the same hlock. Solutions were intemenented w diminish the effects of those problems.

In SIMD systems, the main problem was the load imbalance among processors. The suggested solution was to distrihute data in integral frames, exploitung the intertrame temporal redundancy to distribute the load fairly among proceswors. The scalability requires minimum modification to the hardware and soltware of the system It may he limited by the $1 /($ ) handwidth of the host system. 1 I Ins requires changng or upgradeng the host processors and the $\mathrm{V} /()$ devices. This conflgurateon is found to be mose effecient than pipelining. with a performance close to the ideal and an approximalely linear speed up, due to the lack of interprocessor communicatuon among the processing clements. Where 
mlenpencessur communciation a required among PEs. the techniques developed tor pipelinmg can be used. The difference from the ideal speed-up is due to the incomplete load balance. As the number of processors increases, im halance, on the average, increases hecatuse of the decrease in temporal redundancy upon which the efficiency of the temporal distribution is hased: however. the efficiency (based upon the average frame processing (ime) is lower hounded by that hased upon the most demanding frame.

The main prohlem faced in the MISD systems is the data pipelining overhead time control. Due to this overhead, pipelining systen.s are less responsive to an addition of processurs to the system. As the number of processors increases. the load share per processor decreases hut the $I / C$ overhead essentialiy remains constant, causing $I / O$ to dominalle the processors time. System throughput is limited by the $1 /()$ handwide of the pipeline links. This limit can be extended by segmenting programs across the points where the least dalla is required to he passed to the next processing elements (although the number of PEe may need to he increased for adjusting the nrogram delineation). However, software modilleations are required whenever the system is extended. Thus, various methods of data Iransler atcross pipeline links were evaluated. Larger DMA data block sizes exhibited more ciliciency due (1) the neod for interprocessor data passing being lowered and the $1 / O$ set-up overhead time heing minimized. However, using larger block sizes requires that DMA operation he synchronized with program operation to keep utilizing the communication link for a maximum anount of time. without requiring huge memory space. However, the data transter sel-up may cause a frame period lag between every two neighbouring processing elements. However. pipeline architectures can process data at any level without the need for new communication overhead or special data distribution arrangements.

Different data transfer methods were studied and the efficiency of shared memory data paths was wherved. This study showed the advantage of using DMA and internupt methods in decreasing communication overhead and performing $1 / O$ and processing in parallel. It also c'mphasiad the henetils of huffered $1 / 0$.

Hyhrid archifeclures were considered and shown to be very efficient for small system sices. hut as the system size grows, hardware and software complexity increases exponentially and they hecome difficult to manage and program. Using heterogeneous devices and systems to share the processing load was discussed.

Finally, a typical system was designed that can carry out real time video processing. The design approath was generalized to interframe and colour coding schemes with finite frame history reyuirement as is generally the case. 


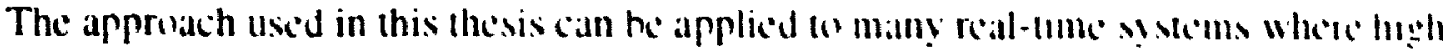
processing power is required. It may also he used an speed-up virtual ime wslems. It interprocessor communication is required, it can be perliomed usme the methods developed for pipelining. even in SIMD systems.

\subsection{Future Work}

The ATM environnent is still under research. especially VBR viden transmissun. Thete is a high level of interaction hetween VBR video coding algomilhms alld the $\mathrm{XlM}$ environment specitications, especially those of the adaptation laycers' which atte als stll under research.

Since the target is in implement inexpensive, flexihle video condec in he used in houscholds and offices, considering the ecomomics of the hatdware implementallun ."I those devices may affect the underlying algorithms and adaptatoon layers. In atly case.

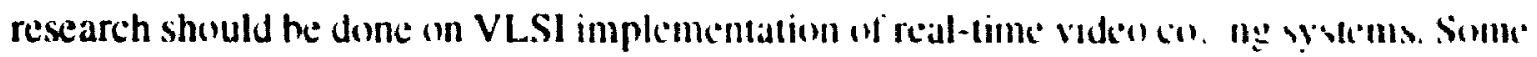

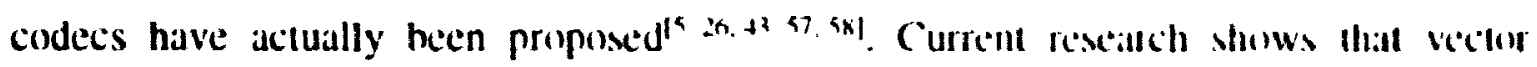
quantization promises a high compression ralio with good pleture quality atel and VI.SI architectures have heen proposed as showing promixe for this scheme e"ll. More rese'alch onl this has to be done to arrive at inexpensive products.

Current research papers usually discuss a particular video coding scheme :and altempl to prove that it provides high quality images and high compression ratios. The future implementations may include multisystem products that automatically allow for changing coding systems such that the hroadcasting industry may use the coding system that sults the specific program heing transmilted. Trying to integratte stch coding systems may allect coding algorithm development, especially as there are sume common routumes between most coding schemes. Also, the user may chose w change the reyunred viden quality, thus requiring the end product to be more flexible.

More complicated multiprocessor DSP archilectures are hecommen cassly implemented by the advent of DSP processors tailored for muluprocessung such. as TI TMS320C40 ${ }^{|54|}$. Such processors not only make the implementaluon of conventumal multiprocessor configurations easier and more eflicient, hut they also provelte for new configurations. Hardware support of concurrent interprocessor communcaston, while processing is going on, changes parameters alleclung the elliciency and pertomance of certain architectures. Therefore, rescarching these architectures may upen up new aspects of multiprocessugg, image processing and signal precessmg. 


\section{A \\ Visual Illustration of the Algorithm}

\section{A. I Frequency Band Division}

This appendix gives visual illustrations of the image coding algorithm that was used throughout the experimental part of this work. The algorithm filters the image into three hands, the sum of which is the complete image.

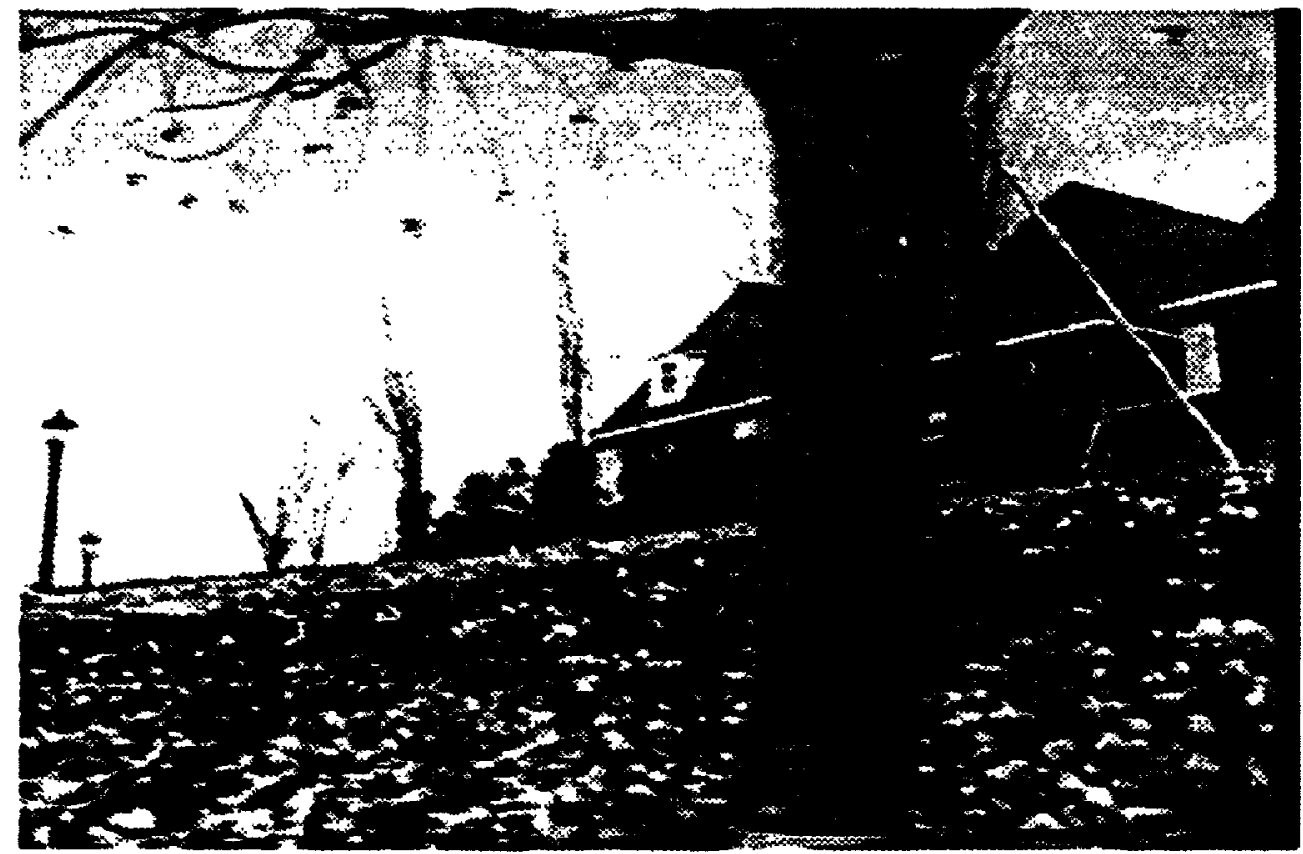

Pigure A-1: Original Pieture

The video film used in the illustrations was taken by a video camera in a car moving to the right. Two frames of the tilm were used to produce the results in this thesis. Other 


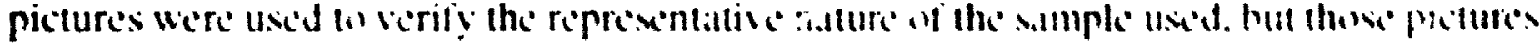

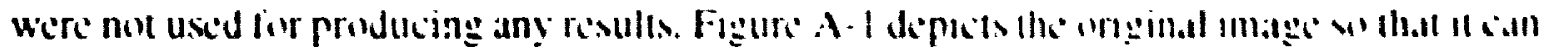

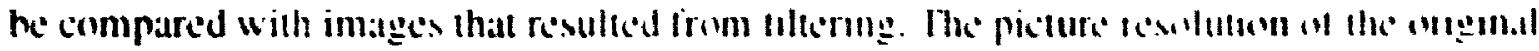
illustrations is 36(1)-hy-240 of $256-k$-vel grey scalce.

\section{A.I.1 Low Frequency Band Component}

The first component of an image consists af the superpels, which are (o-hy-3-pel rectangles. Figure A-2 depicts the result of passing the original mage through a superpel hand filter.

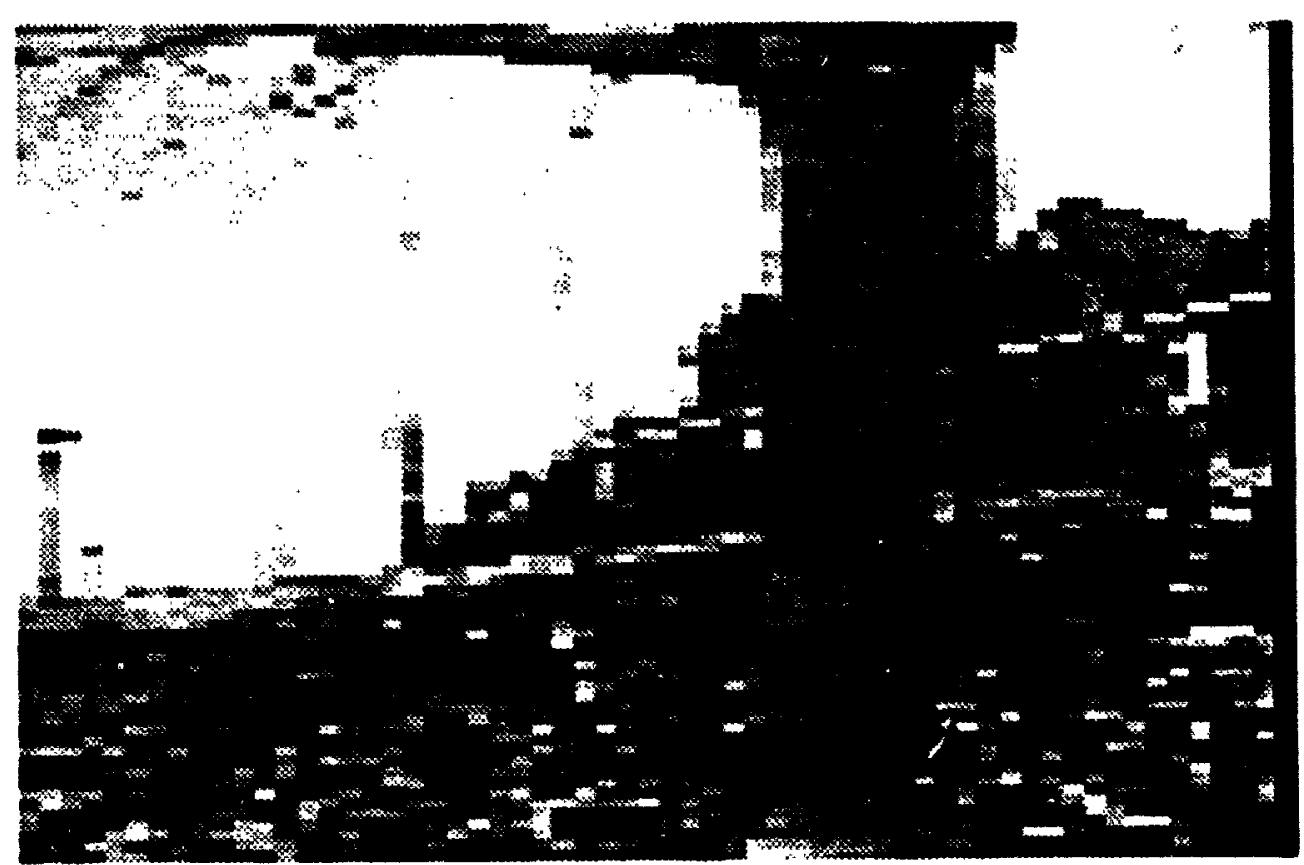

Figure A-2: Picture Superpel Ciomponent

\section{A.1.2 Medium Frequency Band Component}

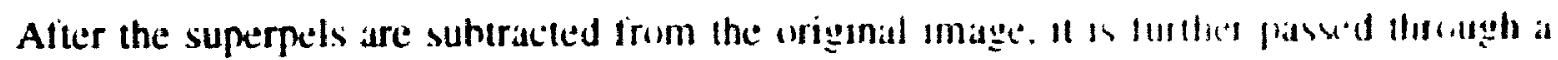

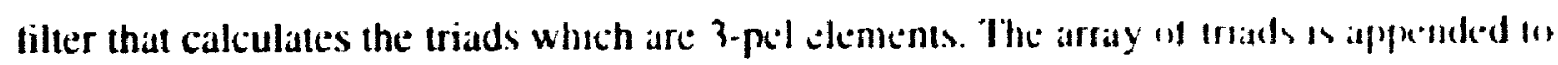
the array of superpels and the compound array is disassembled into AlM cells and is llien transmitted in the high-prionty stream. Fegure A-3 deptets the absolute values wh the triads. Blank areas correspond to rego values and darker areas correspend in areas al higher intensity. (The pels are inverted: the dark is light and the light is dark because the 

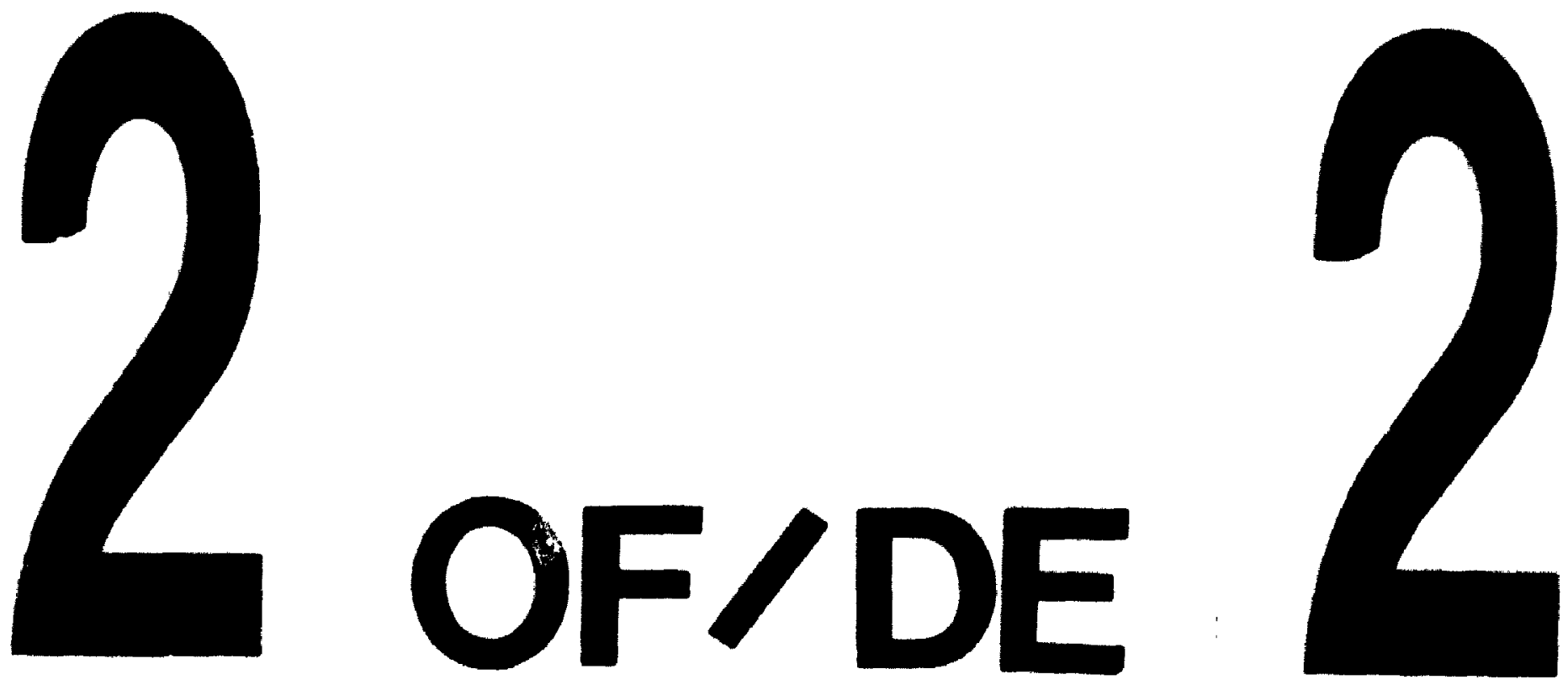

PM-1 3' ' $x 4$ " PHOTOGRAPHIC MiCROCOPY TARGET NBS 1010 ANSI/ISO *2 EOUIVALENT

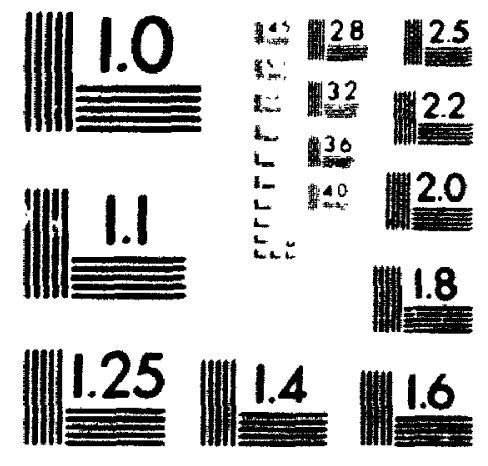


original ones have small values that would gemerate a picture lwo dork lior pels on he disciemed.)

Figure A-3: Picture Triad Companemt

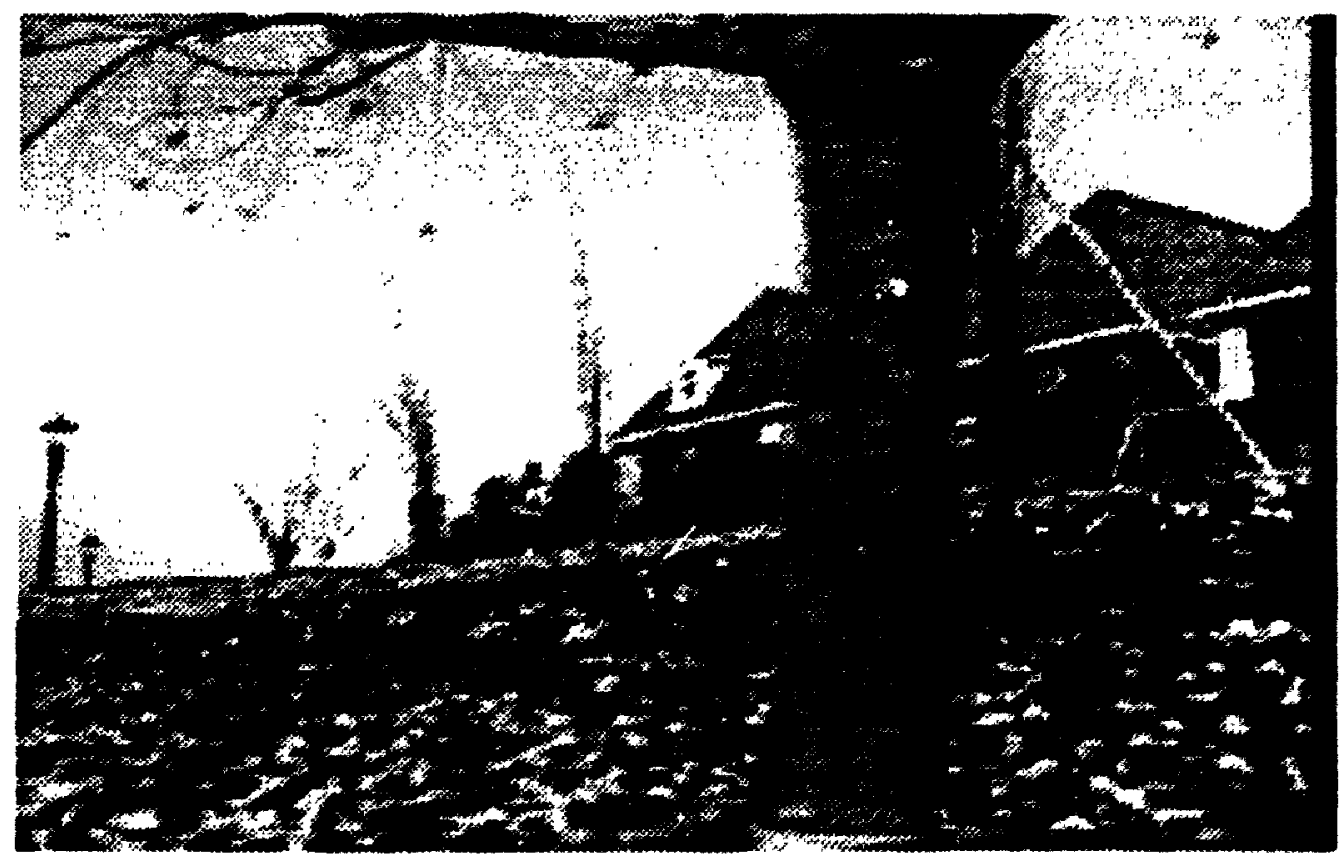

Figure A-4: Picture High-IPriority Component

Figure A-4 dr -icts the pir:ture reconstructed from the superpels and triads (i.e.. from 
IX (riads). The picture is a collection of 3 -pol sets.

\section{A. 1.3 High Frequency Band Component}

Aiter the superpels and triads are suhtracted from the original image, the remaining full resolution information corresponding to the fine details of the picture is encoded and transmitted in the low priority stream. Figure A.5 depicts the finer details of the picture in ahsolute value. (This picture is inverted.) Before transmission, this information is threshold-clipped, run-length-encoded and Hutfman-encoded into ATM cells.

Figure A-5: Picture Difrerential Pel Component

\section{A.2 Data Transmission Cell Loss Effects}

Of the transmission errors, cell loss is the error which affects the picture quality the most. Lust cells of a trame can be replaced by cells from the same coordinates of the previous Irame or by cells calculated according to a cell compensation algorithm. Lost cells in the following illustrations are assumed to be replaced by zero value data.

In the actual algorithm, lost cells were selected by a geometric random distribution function. High-priority and low-priority cells have different adjustable error rates. In the following illustrations, cell loxs errors are generated deterministically for illustration purposes. 


\section{A.2.1 High-Priority Cell Loss Errors}

High-priority cells carry superpel and triad information. Each cell carracs fl) informallion octets (bytes). The tirst cell in a line group carries 40 superpels that represent most of the information in a rectangular ared ot $24(1-b y-3$ pels.

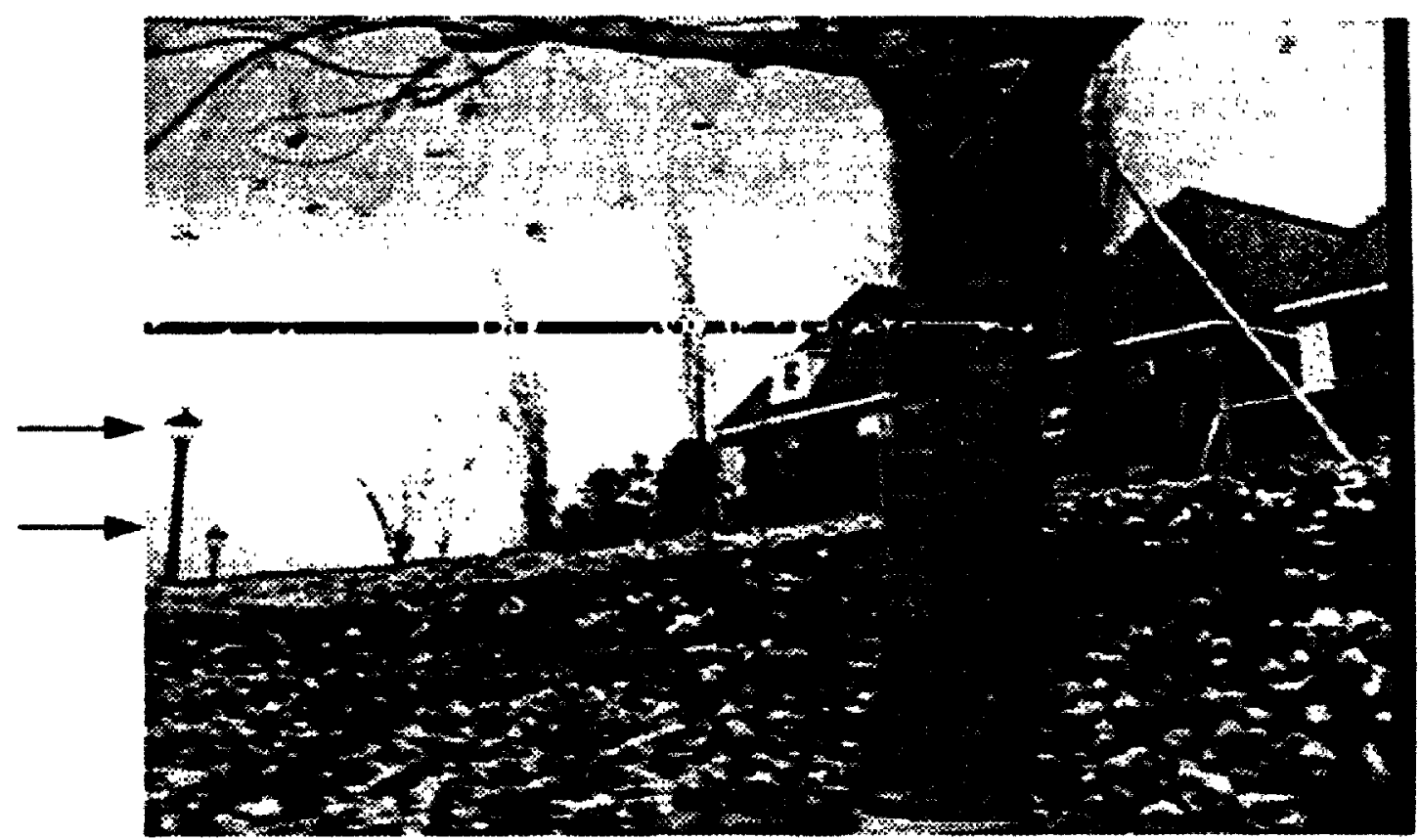

Figure A-6: Picture with Cell I ass Errors:

Figure A-6 shows the picture with four missing cells. The dark line across the picture is caused by losing a cell of superpels. Another high priority cell was lost, hut the information load of that cell belongs to the two raster line's at which the solid arrow points. Because the cell contained triad data, its loss is hardly detectable. Losing many triad cells results in areas of the frame with only the superpel component as in Figure A-2.

\section{A.2.2 Low-Priority Cell Loss Errors}

Cell loss errors in low-priority, fine details are much less detectahle than those in coarser details. The dashed arrow in Figure A-6 points to the line where two low priority cells were lost. The distortion introduced hy the loss of those two calls is unlikely to he detected using monitors of small to medium sizes, especially hecause of the frame's timely updating. Losing larger sequences of low-priority cells makes areas of the frame lowk like in Figure A-4. 


\section{Bibliography}

1!| H. Chin et al., "Statistics of Video Signals for Videophone-Type Pictures," IEEE Journal con Selected Aleas in Commumicarions, vol. 7, June 1989.

[2] F. Kishino et al., "Variable Bit-Rate Coding of Video Signals for ATM Networks," IEEE Joumal on Selected Areas in Communications, vol. 7. June 1989.

[3] Y.-Q. Zhang et al., "Variahle Bit-Rate Video Transmission in the Broadhand ISDN Envirunment," Proceteling of the IEEE, vol. 79. Feb. 1991.

14) K. Rothermel, "Priority Mechanisms in ATM Networks," Globecom '90, 1990.

15| W. Verbit:st and L. Pinnoo, "A Variable Bit Rate Video Codec for Asynchronous Transier Mode Networks." IEEE Journal on Selected Areas in Communications, vol. 7. Junc 1989 .

[6] J. Montciro and M. Gerla and Luigi Fratta. "Statistical Multiplexing in ATM Networks," Performance Elalization, vol. 12. July 1991.

171 G. Gallassi and G. Rigolio and L. Fratta. "Bandwidth Assignment in prioritized ATM Networks." Globecom' '90. 1990).

[8] M. Ghanhari, "Packet Video," in Image Processing (D. Pearson, ed.), McGraw-Hill Book Company; London, England: 1991.

$|M|$ W. Verhiest. L. Pinnow and B. Voeten. "The Impact of the ATM on Video Coding," IEEE Journal on Selected A reas in Communications, vol. 6. Dec. 1988.

[1(1) D. Lee, S. Li and K. Tzou. "Analysis of Video Packet Loss Control in ATM Netwirks." Globecosm '90. 1990).

(11) Caxton C. Foster and Thea Iherall, Compurer Architecture. Van Norstrand Reinhold Company, New York: 1984.

[12] Z. Hussain. Digifal Image Processing. Ellis Horwood Limited. New York: 1991.

113] Graham R. Brookes and Andrew J Stewart, Introduction to occam 2 on the Tramspute': Macmillan Education Lid.; London, England: 1989.

[14] D. Mitchel. J. Thompson. G. Manson and G. Brookes. Inside The Transputer, Blackwall Scientific Publications; Oxford. England: 1990. 


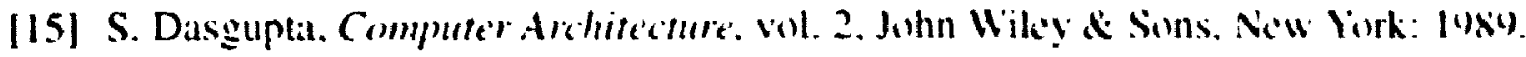

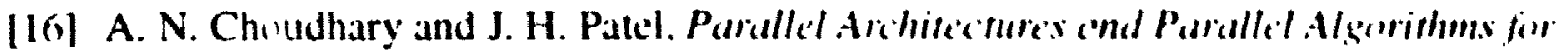
Integrc ed Vision Sistems. Kluwer Academic Publishers: Buston. Mass.: 10(9).

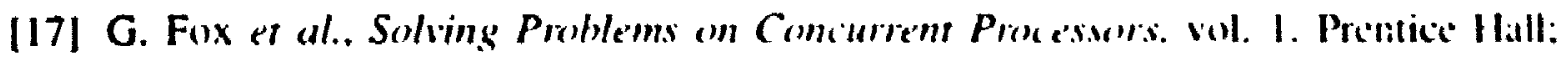
Englewood Clifis, N.J.: 1988.

$118]$ Q. F. Stout. "An Algorithmic Comparison of Meshe's and Pyramids," in Evaluarion of Mulricompurers for Imasge Proressings (L.. Lhe ef al., eds.) pp. 107-121. Acatemic Press, Inc.; Boston. Mass.: 1986.

[19] D. A. Patterson and J. L. Hennessy, Compuster Archite'thort: A Qunamitative' Approach. Morgan Kaulmann Puhlishers. Inc.: San Mateo. California: 1990.

[20] S. Panchanathan and M. Goldherg. "A Systolic Array Architceture for limage" Coding Using Vector Quantiration," IEEE Tramsactions an Circuits and Sivstuss fur Video Technolog!: vol. 1. Junc 1991.

[21] Y. Takagi, S. Hino and T. Takahashi. "Priority Assignment Control of ATM Line" Buffers with Multiple QOS Clasies," IEEE Jomonal on Selected Areas in Communications, vol. 9, Sept. 1991.

122] H. Kroner et al. "Priority Management in ATM Switching Nodes," IFEE Jmumal on Selected Areas in Communications, vol. 9. Apr. 1991.

[23] J.-Y. Le Boudec, “An Elficient Solution Method for Markov Models of ATM Links with Loss Priorities," IEEE Journal on Selected Areas in Communications, vol. 9. Apr. 1991.

[24] M. Nomura, T. Fuji and N. Ohta. "Basic Characteristics of Variahle Rate Viden Coding in ATM Environment," IEEE Journal on Selected Areas in Communications, vol. 7, June 1989.

[25] D. A. Huffiman, "A Method for the Construction of Minimum Redundancy Cides," Proc. IRE, vol 40. No. 9. 1952.

[26] S.-M. Lei and M.-T. Sun. "An Entropy Coding System for Digital IIDTV Applications," IEEE Transactions on Circuits and Systems for Video Technology. vol. 1, Mar. 1991.

[27] A. Lempel and J. Ziv, "Compression of Two-Dimensional Data." IEEE Transactioms on Information Theory, vol. IT-32, Jan. 1986.

[28] J. Ziv and A. Lempel, "Compression of Individual Sequences via Variable-Rate Coding." IEEE Transactions on Information Theary. vol. IT-24, Sept. 1978. 
$|29|$ T. A. Welch, "A Technique for High-Performance Data Compression," IEEE Compurer, vol. 17, June 1984.

[30) A. Gersho and R. M. Gray, Vector Quantizurion and Signal Compression. Kluwer Academic Puhlishers; Boston, Mass.: 1992.

[31] I. H. Willen, R. M. Neal and J. G. Cleary. "Arithmetic Coding for Data Compression," Commenication.: of the ACM. vol. 30, June 1987.

|32| H. Yasuda, "Key of the Future Ac:ivities of IS( )/IEC JTC 1/SC 29," tech. rep.. ISO/ IEC. 1992.

133| E. L. Hall, Computer Image Processing and Recognition. Computer Science and Applied Mathematics, Academic Press. Inc., Toronto: 1979.

134| M. Barnsley and A. Sloan. "A hetter Way to Compress Image," Byte, Jan. 1988.

135| M. Bonomi, "Multimedia and CD-ROM: An Overview of JPEG, MPEG and the Future." CD-ROM Prafessiomal, Nov. 1991.

[36] R. K. Jurgen. "Digital Video," IEEE Spectrum. Mar. 1992.

|37| ISO/IEC. "IVS Baseline," tech. rep., June 1992.

[38] M. M. Anderson, "Preliminary Text for MPEG Video Coding Standard," tech. rep., International Organisation for Standardisation, 1990.

[39] M. Wada. "Selective Recovery of Video Packet Loss Using Error Concealment," IEEE Journal on Selected Areas in Communications, vol. 7, June 1989.

[40] T. Takaste et al., "Variahle Bit Rate HDTV Communication in ATM Networks," Globecomn '90, 1990.

[41] D. G. Morrison, "Variable Bit Rate Video Coding for Asynchronous Transfer Mode Networks," Br Telecom Technol Journal, vol. 8, July 1990.

142] J. Darragh and R. Baker, "Fixed Distortion Subband Coding of Images for PacketSwitched Networks," IEEE Jontnal on Selected Areas in Communications, vol. 7. June 1989.

[43] T. Kinoshita and T. Nakahashi, "Experimental HDTV Codec with ATM Cell Loss Compensation for B-ISDN," Electronic's Letters, vol. 27. Sept. 1991.

|H+| W. Stallings. ISDN and Broudband ISDN. Macmillan Publishing Company, New York: 1992.

[45] G. 1. Stassinopoulos and 1. S. Venieris, "ATM Adaptation Layer for Signalling." Computer Networks and ISDN Systems, vol. 23. pp. 287-304, 1992. 
[46] Texas Instruments; Dallas. Texas: TMSszociol'seri Guide: I(w).

14ij Allanta Signal Processors. Inc:: Allanta. Gerorgia: Bamshe'e Sistem Imerruction Mamual, release 1.3 ed.. 19y().

[48) Intel Corporation: Santa Clara, Califomia; Micopmosessors amd Peripheral Handbook. 1989.

[49] Van Wolverton, Rumning MS-DOS, Microsiblt Press; Redmond, Washington: |99|.

[50] Texas Instruments: Dallas. Texas: TMS.20130 Oprimizins C Compriler Referente Guide. 1990 .

[51] Y. Paker, Multi-microprocessonr Systems. Acaldemic Press: london. England: 1983.

[52] H. A. Taha, Operations Researh. Macmillan Publishing Company. Now York: 1987.

[53] W. B. Green, Digital Image Processing. Van Nostrand Reinho!d, Toronto: 19x9.

[54] A. N. Netravali and B. G. Haskull. Digital Pictures: Represcentation and Compression, Plenum Press, New York: 198x.

[55] Texas Instruments; Dallas, Texas: Second-Generanion TMS.320 Use's Ginide. 1984.

[56] J. Jeong and W. Alexander. "A Real-Time Implementation of the Fifleient 2-D Discrete Cosine Transtorm," in IEEE Proceeding of Southeastcon '91, vol. 2, 1991.

[57] M. Barhero, S. Cucchi and M. Stroppiana, “A Bit-Rate Reduction System lor HDTV Transmission," IEEE Transactions on Circuits and Systems for Video Technology: vol. 1, Mar. 1991.

[58] H. Hang et al., "Digital HDTV Compression Using Parallel Motion-Compensated Transform Coders," IEEE Transactions on Circuirs and Sistems for Video Technolog!: vol. 1, June 1991.

[59] Ray Simar, Jr. et al. -Floating-Point Processors Join Forces in Parallel Processing Architectures," IEEE Micro, Aug. 1992.

[60] P. Sen et al.. "Models for Packet Switching of Variable-Bit-Rate Video Sources," IEEE Journal on Selected Areas of Communications, vol. 7. June 1989.

[61] K. Dezhgosha, M. Jamali and S. Kwatra. "A VLSI Architecture for Real-Time Image Coding Using a Vector Quantization Based Algorithm," IEEE Transactions on Signal Processing. vol. 40, Jan. 1992. 

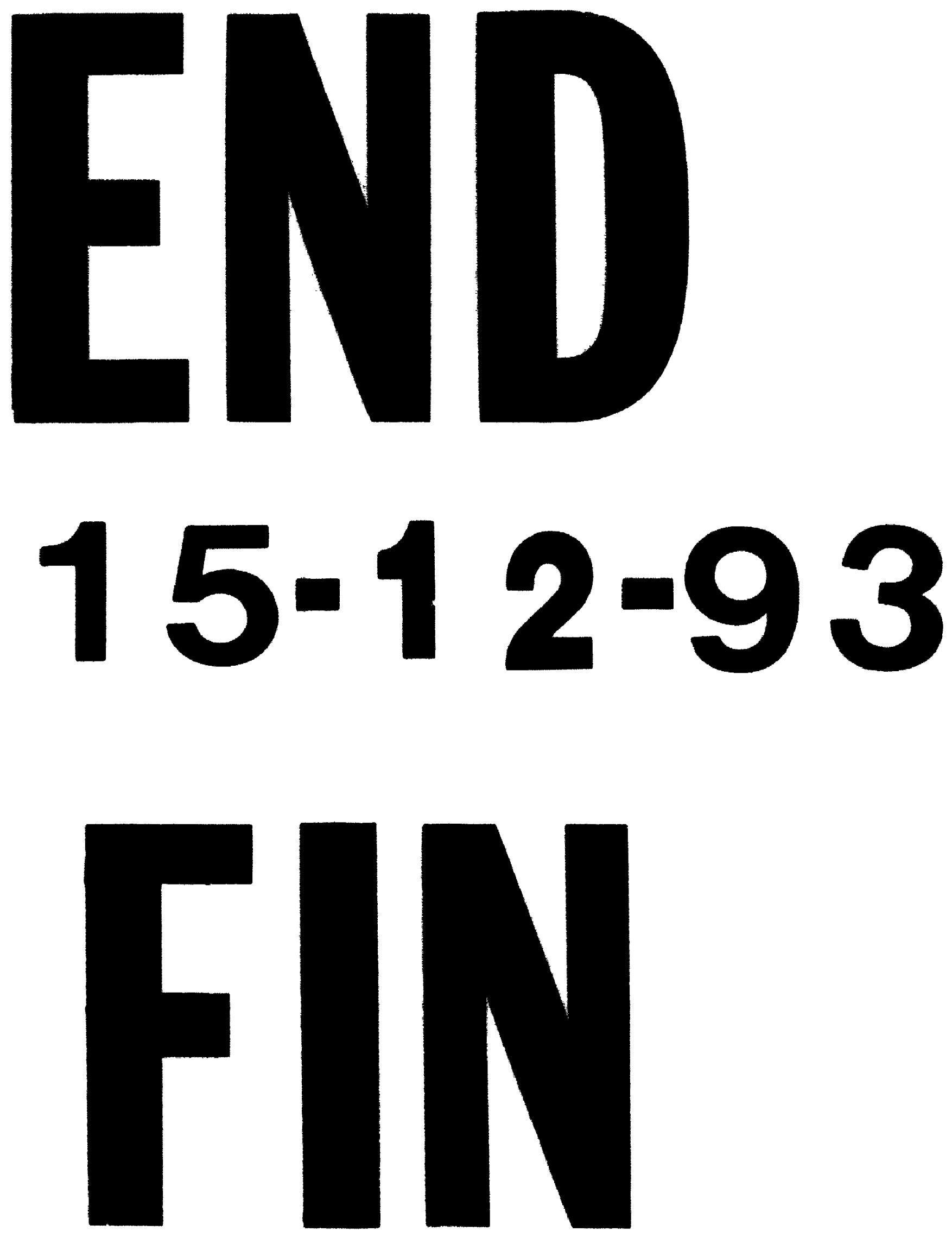